Elsevier required licence: (C) 2019. This manuscript version is made available under the CC-BYNC-ND 4.0 license http://creativecommons.org/licenses/by-nc-nd/4.0/

The definitive publisher version is available online at https://doi.org/10.1016/j.jebo.2018.12.013 


\title{
Fee Structure and Mutual Fund Choice:
}

\section{An Experiment*}

\author{
Mikhail Anufriev ${ }^{\mathrm{a}, \dagger} \quad$ Te Bao ${ }^{\mathrm{b}, \ddagger} \quad$ Angela Sutan $^{\mathrm{c}, \S} \quad$ Jan Tuinstra ${ }^{\mathrm{d}, \boldsymbol{\uparrow}}$
}

December 18, 2018

\author{
a University of Technology Sydney, Business School, Economics Discipline Group \\ b Division of Economics, Nanyang Technological University, Singapore \\ c Burgundy School of Business, University Bourgogne Franche-Comté CEREN, Dijon, France \\ d CeNDEF, Amsterdam School of Economics, University of Amsterdam
}

\begin{abstract}
We present a laboratory experiment designed to investigate the effect of the fee structure on mutual fund choice. We find that subjects tend to ignore periodic and small operating expenses fees and base their decisions on gross, instead of net, returns. A fee in the form of a, much larger, front-end load leads to lock-in into one of the funds. It is used by some subjects as a commitment device, but exacerbates the decision errors of other subjects. Although past returns do not convey information about future returns, return chasing helps explain subjects' behavior.
\end{abstract}

${ }^{*}$ We thank Peter Bossaerts, John Duffy, David Goldbaum, Cars Hommes, Alan Kirman, Marco van der Leij, Francois Koulischer, Malwina Mejer, Andreas Ortmann, Joep Sonnemans, John Wooders and Nan Yang for stimulating discussions, and Frank Lentz and Mihai Oprea for technical assistance with the software. The paper benefited from many useful comments of the two anonymous referees, the Editor, as well as participants of the 18th CEF Conference in Prague, the 2013 Experimental Finance conference in Tilburg, the 2013 Asian Meeting of the Econometric Society, Singapore, the 2015 ESA meeting, Sydney, the 2018 Nanyang Technological University Behavioral and Experimental Workshop, Singapore, and seminars at the Tsinghua University, Université libre de Bruxelles, the University of Amsterdam and the University of New South Wales. We are grateful to the financial support from the EU 7th framework collaborative project "POLHIA" Grant No. 225048 and the Research Priority Area Behavioral Economics of the University of Amsterdam. Mikhail Anufriev and Jan Tuinstra acknowledge financial support from the Australian Research Council through Discovery Project DP140103501. Te Bao acknowledges the financial support from the Startup Grant of NTU (M4018740), Tier 1 Grant from MOE of Singapore (RG68/16) and National Natural Science Foundation of China (71803201, 71721001, 71773013 and 71873149). Angela Sutan acknowledges financial support for experiments from the PARI grant scheme from Bourgogne Franche Comté Region. Jan Tuinstra acknowledges financial support from the ORA project "BEAM" (NWO 464-15-143) which is partly financed by the Netherlands Organization for Scientific Research (NWO).

${ }^{\dagger}$ E-mail: Mikhail.Anufriev@uts.edu.au

†E-mail: Baote@ntu.edu.sg

$\S$ E-mail: Angela.Sutan@bsb-education.com

IE-mail: J.Tuinstra@uva.nl 
Keywords: Mutual fund choice, fee structure, experimental economics, return chasing, learning. JEL Classification: C91, G11, G41. 


\section{Introduction}

Mutual funds are important investment vehicles. ${ }^{1}$ In order to evaluate the performance of financial markets it is crucial to understand how investors choose between these funds. An important puzzle in mutual fund choice is the large and persistent spread in fees between different funds, which apparently is not eliminated by competition between these funds. Elton et al. (2004) and Hortaçsu and Syverson (2004), for example, show that substantial price dispersion between essentially homogeneous S\&P500 index funds exists, with a large amount of cash flowing into funds with excessively high fees. Elton et al. (2004) explain this dispersion in fees by the presence of uninformed consumers together with the absence of arbitrage possibilities for index funds, whereas Hortaçsu and Syverson (2004) suggest it is caused by a combination of non-portfolio fund differentiation and search costs. In a recent study Cooper et al. (2018) show that fee dispersion extends to the entire US equity industry and has grown over time which they attribute in part to an increase of novice investors into the industry - leading to substantial welfare losses. ${ }^{2}$ In fact, Carhart (1997) and Gil-Bazo and Ruiz-Verdú (2009) find that the fees charged by funds are negatively related to fund returns (net of fees). Gil-Bazo and Ruiz-Verdú (2009) explain this by strategic fee-setting of the funds, where funds with low returns target performance-insensitive investors and demand high fees. ${ }^{3}$

Apart from the variation in the size of the fees, there also exist differences in the structure of the fees that may have an impact on how investors select mutual funds. Two types of fees that are commonly used are front-end loads (back-end loads) which are fixed commissions that have to be paid when an investor enters (exits) the fund, and operating expenses fees or management fees that represent the costs for operating the fund and that, as opposed to the front-end and back-end loads, need to be paid by the investor periodically. Barber et al. (2005) find that the flow of money into mutual funds is negatively correlated with the front-end load, but not correlated with the operating expenses fee. They argue that people pay more attention to the front-end load because it is more salient and transparent. Khorana and Servaes (2012), however, find that fund families that charge a (front-end) load have larger market shares than funds charging operating expenses, which they explain by the fact that loads - often used for marketing and distribution purposes - reduce search costs, and make it more difficult to leave the fund. Related to this, Chordia (1996) constructs a model that shows that funds may use

\footnotetext{
${ }^{1}$ According to Investment Company Institute (2018) the value of assets invested in mutual funds in the US was about 22.1 trillion US dollars in 2017, which is more than US GDP in 2017. Moreover, mutual funds are particularly important for household finance. In 2017 a total of $45.4 \%$ of US households owned funds, and the median value of mutual fund assets owned per household was 120,000 US dollars.

${ }^{2}$ Khorana et al. (2009) provide a comprehensive investigation on mutual fund fees and find a large dispersion of fees between different countries, which is difficult to explain by the difference in returns to the investors.

${ }^{3}$ Also see Gil-Bazo and Ruiz-Verdú (2008), who develop a model with asymmetric information and sophisticated as well as unsophisticated investors. In their model low-quality funds cater to unsophisticated investors and charge excessive fees.
} 
front-end and back-end loads to 'lock investors in' by discouraging them from changing funds.

In this paper we present a laboratory experiment aimed at shedding more light on the role that fees play in mutual fund choice. In each period of our individual decision making experiment, subjects choose between investing their wealth in one of two experimental funds ( $A$ and $B$ ), and they have to do this for three blocks of fifteen periods each. The subjects know the return generating processes and fees of the funds, observe past returns of both funds, and are explicitly informed that past realized returns do not affect future returns. We construct eight treatments, where the main difference between the treatments is the fee structure. In particular, in treatments $\mathbf{N}$ and $\mathbf{N}^{\mathbf{R e}}$ neither of the funds charges a fee, in treatments $\mathbf{O}_{\mathbf{B}}$ and $\mathbf{O}_{\mathbf{B}}^{\mathbf{R e}}\left(\mathbf{O}_{\mathbf{A}}\right)$ fund $B$ (fund $A$ ) charges a small operating expenses fee, and in treatments $\mathbf{F}_{\mathbf{B}}$ and $\mathbf{F}_{\mathbf{B}}^{\mathbf{R e}}\left(\mathbf{F}_{\mathbf{A}}\right)$ fund $B$ (fund $A$ ) charges a front-end load. Our experiment is designed in such a way that, although the decision problem is framed differently - with the front-end loads much more salient than the operating expenses fees - subjects essentially face the same choice in each treatment. That is, the expected return (net of fees) of investing in fund $B$ is the same in each treatment, and higher than that of investing in fund $A$ (where it is also the same for each treatment). If subjects take fees into account correctly, their investment behavior should be independent of the treatment. To control for a possible effect of the realized returns on the investment decision, we use the same realizations of returns in all treatments. Moreover, in the 'reverse order' treatments $\left(\mathbf{N}^{\mathbf{R e}}, \mathbf{O}_{\mathbf{B}}^{\mathbf{R e}}\right.$ and $\left.\mathbf{F}_{\mathbf{B}}^{\mathbf{R e}}\right)$ we swap the realized returns of the first two blocks to control for the effect of experience. ${ }^{4}$

The advantage of our laboratory experiment is that we have full control over the gross returns of the mutual funds, and over the fees they charge. Since subjects are informed about the return generating process and fees for each available fund, any effect that the fees have on subjects' decisions cannot be attributed to asymmetric information, uninformed subjects, or search costs. Moreover, there is no non-portfolio differentiation between the funds. The experiment therefore allows us to investigate to what extent subjects take fees into account when the decision environment is transparent, and whether front-end loads lead subjects to be locked into one of the funds.

We report three major findings. First, when we increase gross returns for fund $B$ and introduce a small operating expenses fee, such that net returns for fund $B$ are unaffected, aggregate investment in fund $B$ goes up slightly, although the effect is not statistically significant. How-

\footnotetext{
${ }^{4}$ Note that we implement a between-subjects design for our experiment, where at most one of the funds presented to a subject charges a fee. Alternatively, we could have chosen a within-subjects design by, for example, presenting each subject with a number of different funds that have the same expected gross returns, but fees of different size, to see whether subjects manage to minimize fees. Such a design would be similar to the one used in Choi et al. (2010). However, they present prospectuses of existing S\&P 500 index funds to their subjects. Our hypothetical funds are much more stylized, and only characterized by their expected gross returns and the fee they charge. When designing our experiment we expected that a within-subjects design with these stylized funds would make the task for subjects too easy, and therefore chose a between-subjects design.
} 
ever, introducing an operating expenses fee for fund $A$ (together with increasing gross returns for fund $A$ by exactly the same amount) does have a substantial, and significant, positive effect on aggregate investment in fund $A$. It suggests that even in the very transparent decision environment of our experiment, subjects have a tendency to ignore the operating expenses fee and make investment decisions on the basis of gross, instead of net, returns.

Second, we find substantial differences between subjects' investment behavior in the frontend load treatments vis-a-vis the operating expenses treatments. Most, but not all, subjects understand they should not pay the front-end load more than once. These subjects typically get locked into the fund that charges a front-end load. Remarkably, this is also the case when that fund has the lowest expected net returns. On the other hand, a front-end load for the inferior fund leads more subjects to stay away from that fund. This may be because the salience of the fee forces these subjects to exert more cognitive effort. Overall, the variation in earnings is much higher and average earnings are lower in the front-end load treatments. This is mainly due to the subjects that pay the front-end load more than once and therefore end up with very low payoffs.

Third, even if subjects are explicitly informed that past returns do not convey any information about future returns, their behavior can, to a certain extent, be explained by return chasing. That is, the subjects are more likely to choose a fund that had the highest gross return in the previous period. Furthermore, we find evidence that subjects learn to make better decisions as they gain experience with the decision environment.

To the best of our knowledge, only limited experimental research on the relation between fee structure and fund choice has been done. An early contribution is Wilcox (2003), who presents active mutual fund investors with the choice between different (hypothetical) mutual funds characterized by, among others, names of actual mutual funds, loads, operating expenses fees, and 1- and 10-year past returns. Wilcox (2003) shows that investors pay too much attention to past performance and to the front-end load, and too little to the operating expenses fee. Surprisingly, this bias in decision making increases with the wealth and education level of the investor, and with the investor's results on a financial literacy quiz. Choi et al. (2010) design a field experiment where subjects hypothetically allocate $\$ 10,000$ between four existing S\&P500 index funds, on the basis of the prospectuses of these funds, which also contain information about fees and past return rates. The index funds are chosen such that the ones with the higher fees have the higher annualized historical returns, which is due to differences in the launching dates of the funds. Although people should ignore the past return information, and allocate all their money to the fund with the lowest fee, many of them fail to do so and rely more on the annualized past returns of the funds. Ehm et al. (2014) employ a large scale survey to investigate how people choose between two hypothetical funds that only differ in the fee 
structure: one fund charges a performance fee (meaning that the fund charges a fraction of the gains, instead of a fraction of the total asset value) whereas the other charges an operating expenses fee. They find that people have a higher propensity to choose funds that charge a performance fee, and thereby do not minimize fees, and explain this by loss aversion.

Our experimental design differs in several important aspects from these three earlier studies. First, in our experiment subjects have to make sequential decisions about the same funds, allowing us to study the emergence of 'lock-in' effects in the presence of a front-end load. Second, there are differences in monetary incentives. Subjects in Wilcox (2003) and Ehm et al. (2014) are not monetary incentivized, whereas in Choi et al. (2010) the incentives are more substantial than in our experiment. Finally, most subjects in the other experiments have at least some individual experience with investing in the stock market, whereas our subjects are university students, which typically do not have that experience.

Our results are also related to the empirical and experimental literature on how past performance, although not conveying additional information, affects investors' choices. Sirri and Tufano (1998), Choi et al. (2009) and Asparouhova et al. (2015) show that past fund performance is an important determinant of mutual fund investors' choices. ${ }^{5}$ Furthermore, when represented with a random time series, experimental subjects have a tendency to either overestimate the probability that a random streak of successes will end (the gambler's fallacy) or to underestimate that probability (the hot hand effect), see, e.g., Bloomfield and Hales (2002); Asparouhova et al. (2009); Offerman and Sonnemans (2004); Yuan et al. (2014); Stöckl et al. (2015); Powdthavee and Riyanto (2015).

The remainder of the paper is organized as follows. Section 2 describes our experimental design. We formulate testable hypotheses in Section 3, and discuss the experimental results in Section 4. Section 5 concludes. Appendix A contains the experimental instructions. In Appendix B we collect test statistics and other additional information. The Online Appendices contain the control questions and additional figures.

\footnotetext{
${ }^{5}$ There is a debate about whether there is persistence in the performance of mutual funds, for example because the fund manager is capable of consistently selecting high performing stocks. The general view is that such a persistency does not exist and that, after controlling for risk and trading costs, the typical manager is unable to consistently generate excess returns (see Carhart, 1997). In addition, Jain and Wu (2000) find that funds that advertise higher past returns attract more money, but do not perform significantly better than other funds in the periods following the advertisement. Hendricks et al. (1993) and Zheng (1999) find that there may be a hot hand effect in fund performance in the short run, but that in the long run there is no significant difference between funds that performed well in the recent past and other funds.
} 


\section{Experimental Design}

The experiment took place on December 8 and 9, 2011 and on November 14-17, 2017 at LESSAC, the experimental laboratory of the Burgundy School of Business in Dijon (France). In total 381 subjects participated in eight treatments. ${ }^{6}$ All subjects are first year master students at the Burgundy School of Business, with no prior experience with laboratory experiments on a related topic. These students had two years of training in economics, statistics and mathematics before passing the exam to enter the school, and they took many other courses in business economics after entering the school. ${ }^{7}$ Subjects could choose to have instructions in English or in French. The duration of a typical session was 90 minutes.

\subsection{Subjects' Task}

The experiment is an individual choice experiment, divided in three blocks of 15 periods each. ${ }^{8}$ At the beginning of each block the subject is given an initial wealth of $M_{0}=1000$ points. In each period $t$ of that block the subject has to decide where to invest its accumulated wealth $M_{t}$ : either he/she invests all his/her wealth in fund $A$, or in fund $B$, or does not invest at all. The wealth in the subsequent period of that block, $M_{t+1}$, is determined by the exogenously given stochastic return of the chosen fund (with $M_{t+1}=M_{t}$ if the subject decided not to invest his/her wealth in either fund $A$ or fund $B$ ). The starting wealth is reset to $M_{0}=1000$ at the beginning of each block. The difference between the blocks lies in the realizations of the stochastic processes generating the returns of two funds, as will be explained in Section 2.4.

As in other contributions in the field (for instance, Wilcox, 2003 and Ehm et al., 2014), we do not allow subjects to divide their wealth between the different funds. If diversification is possible, a subject's optimal investment strategy will depend on his/her risk attitude, and the subject's decision problem becomes much more complicated. ${ }^{9}$ If subjects cannot diversify,

\footnotetext{
${ }^{6}$ The treatments are discussed in detail in Section 2.3. The last column of Table 1 shows the number of subjects for each treatment. The difference in the number of subjects per treatment is due to variations in the show-up rate.

${ }^{7}$ The students tend to be quite good. From a population of about 4,000 students that participate in an entrance exam, the Burgundy School of Business has the right to select about 450, with grades between 14/20 and $17 / 20$. Students with a grade higher than $17 / 20$ go to HEC Paris, for instance.

${ }^{8}$ After running the first sessions of the experiment in December 2011, we discovered an unfortunate error in the experimental software. In particular, the returns for fund $A$ in the third block were not consistent with the prices. Since subjects could see both (see Figure 2 below) some of them may have become confused by the discrepancies, although it seems that no subject identified the inconsistencies (indeed, the differences are small and difficult to spot without additional calculations). Nevertheless, we decided not to use the data from the third block from the 2011 sessions and confine the analysis to the first two blocks only. (Note that the programming mistake cannot have had an impact on subjects' behavior in these first two blocks.) The error in the experimental software was corrected for the sessions that we ran in 2017.

${ }^{9} \mathrm{~A}$ substantial fraction of subjects might respond by dividing their wealth more or less evenly between the two funds (see, e.g., Choi et al., 2010, where such a strategy, which is clearly suboptimal in their design, is also
} 
their decision problem is simpler, with a unique and unambiguous optimal investment strategy (always invest in fund $B$, see below), which is independent of the subjects' risk attitude. This makes it much more straightforward to interpret the experimental results. ${ }^{10}$

At the end of the experiment the subjects are paid according to their final wealth from one of the three blocks, where each block has the same probability of being chosen. ${ }^{11}$ Appendix A provides the experimental instructions. Before the subjects start the experiment, they answer several control questions on paper to make sure that they understand the experiment. We start the experiment only when all subjects have answered all control questions correctly. The control questions and correct answers can be found in Online Appendix C.1. At the end of each experimental session run in 2017 we asked subjects to take the Cognitive Reflection Test (CRT), as described in Frederick (2005). The results will be discussed briefly in Section 4.3.

\subsection{Mutual Funds: Returns and Fees}

Consider the (open-end) mutual fund $X$ with a price per share of $P_{X, t}$ at time $t$. This price evolves according to $P_{X, t}=\left(1+g_{X}+\epsilon_{X, t}\right) P_{X, t-1}$, where $g_{X}>0$ is a positive growth constant and $\left\{\epsilon_{X, t}\right\}$ is a white noise process, where $\epsilon_{X, t}$ can take on only two values: $\varepsilon>0$ or $-\varepsilon$, with equal probability. The (gross) return of fund $X$ is then given by

$$
R_{X, t}=\frac{P_{X, t}}{P_{X, t-1}}=1+g_{X}+\epsilon_{X, t}=\left\{\begin{array}{cc}
1+g_{X}+\varepsilon & \text { with probability } \frac{1}{2} \\
1+g_{X}-\varepsilon & \text { with probability } \frac{1}{2}
\end{array} .\right.
$$

Because $\epsilon_{X, t}$ equals zero in expectation, the expected one-period return at the beginning of period $t$ (that is, before $P_{X, t}$ is known) is given by $\mathrm{E}_{t}\left[R_{X, t}\right]=1+g_{X}$. More generally - and for now abstracting from any fees to be paid - the $\tau$-period expected return at time $t$ of investing one unit of money is given by

$$
\mathrm{E}_{t}\left[R_{X, t}^{(\tau)}\right]=\mathrm{E}_{t}\left[\frac{P_{X, t-1+\tau}}{P_{X, t-1}}\right]=\sum_{s=0}^{\tau}\left(\begin{array}{l}
\tau \\
s
\end{array}\right) \frac{1}{2^{\tau}}\left(1+g_{X}+\varepsilon\right)^{s}\left(1+g_{X}-\varepsilon\right)^{\tau-s}=\left(1+g_{X}\right)^{\tau}
$$

For the experimental design we consider two funds, $X=A, B$, with growth constants $g_{A}$ and $g_{B}$, respectively. The random components $\epsilon_{A, t}$ and $\epsilon_{B, t}$ are independent but identically distributed

used by some subjects). Also note that, when diversification is possible, it becomes more difficult for subjects to compute actual fees, in particular in the front-end load treatments.

${ }^{10}$ In fact, Brocas et al. (2015) use an experimental design quite similar to ours (their subjects make 10 sequential investment decisions between two funds, for 15 different blocks, but in their case subjects are allowed to diversify) to measure risk attitudes of their subjects, by fitting investment choices to a HARA (Hyperbolic Absolute Risk Aversion) utility function.

${ }^{11}$ The experimenter throws a dice separately for each subject. The subject is then paid according to his/her final wealth in the first (second, third) block if the dice shows 1 or 2 (3 or 4,5 or 6 ). 
(in particular, the absolute size of the random components is equal to $\varepsilon$ for both funds). We impose that $\varepsilon<g_{A}$ and $\varepsilon<g_{B}$, which means that, independent of the realizations of $\epsilon_{A, t}$ and $\epsilon_{B, t}$, the prices of shares of both funds are monotonically increasing over time.

In our baseline treatments $\mathbf{N}$ and $\mathbf{N}^{\mathbf{R e}}$, where no fees are charged, we also impose that $g_{A}<g_{B}$. It implies that expected $\tau$-period returns for fund $B$ are higher than for fund $A$ (for any $\tau \geq 1$ ). The optimal decision in which fund to invest in general follows from an evaluation of the return and risk profiles of the two funds (see Brocas et al., 2015, for the derivation of the optimal investment strategy when preferences are represented by the very general Hyperbolic Absolute Risk Aversion utility function). However, given the assumptions we make on $\epsilon_{A, t}$ and $\epsilon_{B, t}$, the realized return is strictly positive and the variance in returns is exactly the same for both funds. Hence, independent of risk preferences, the rational investor will choose the fund with the highest expected return, which in this case is fund $B$. By requiring that $g_{A}+\varepsilon>g_{B}-\varepsilon$, there is a positive probability that the realized return of fund $A$ is higher than that of fund $B$. However, since past realized returns do not convey any additional information about future returns this does not affect the optimal investment strategy. Note that boundedly rational investors who do respond to past realized returns might now and then switch to fund $A$.

We consider two types of fees. The first type is an operating expenses fee (sometimes called a management fee). It is a periodic payment that represents the costs for running the fund and providing service to its shareholders. It corresponds to a fraction $\gamma_{X}$ of the investment to be paid each period as a fee. Thus, the operating expenses fee in period $t$ is $\gamma_{X} P_{X, t-1}$ per share. The (one-period) return for fund $X$, net of this fee, then becomes $R_{\mathbf{O}, X, t}=1+g_{X}-\gamma_{X}+\epsilon_{X, t}=1+g_{X}^{\prime}+\epsilon_{X, t}$, with $g_{X}^{\prime}=g_{X}-\gamma_{X}$. The expected $\tau$-period return is

$$
\mathrm{E}_{t}\left[R_{\mathbf{O}, X, t}^{(\tau)}\right]=\left(1+g_{X}-\gamma_{X}\right)^{\tau}
$$

The operating expenses are paid for fund $B$ in treatments $\mathbf{O}_{\mathbf{B}}$ and $\mathbf{O}_{\mathbf{B}}^{\mathbf{R e}}$, and for fund $A$ in treatment $\mathbf{O}_{\mathbf{A}}$. The expenses are chosen in such way that the net returns of the funds are the same as in treatment $\mathbf{N}$.

The second type of fee is a purchase commission, or a so-called front-end load. The investor pays a fixed percentage $F_{X}$ of his/her investment $M_{t}$ as a commission when investing in fund $X$. With the remainder of his/her investment, $\left(1-F_{X}\right) M_{t}$, shares of the mutual fund are purchased. The front-end load only has to be paid upon purchasing the shares. However, if the investor sells his/her shares of the front-end load fund, but at a later time wants to buy shares of this mutual fund again, he/she also has to pay the front-end load again. ${ }^{12}$ The expected

\footnotetext{
${ }^{12}$ For some mutual funds, front-end loads are reduced if the investment in the fund is above a certain threshold, but we will not consider that in our experiment. Similarly, back-end loads (also known as deferred sales charges) may decrease when the length of the investment in the fund increases.
} 


\begin{tabular}{c||c|c|c|c||c|c|c|c||c}
\hline \hline \multicolumn{1}{c||}{} & \multicolumn{4}{c||}{ Fund $A$} & \multicolumn{4}{c||}{ Fund $B$} & Number of \\
\cline { 2 - 9 } Treatment & $g_{A}$ & $\gamma_{A}$ & $F_{A}$ & $\mathrm{E}_{1}\left[R_{A, 1}^{(14)}\right]-1$ & $g_{B}$ & $\gamma_{B}$ & $F_{B}$ & $\mathrm{E}_{1}\left[R_{B, 1}^{(14)}\right]-1$ & Subjects \\
\hline \hline $\mathbf{N}$ & $3 \%$ & - & - & $51.26 \%$ & $4 \%$ & - & - & $73.17 \%$ & $22(2011), 30$ \\
$\mathbf{O}_{\mathbf{B}}$ & $3 \%$ & - & - & $51.26 \%$ & $5 \%$ & $1 \%$ & - & $73.17 \%$ & $19(2011), 22$ \\
$\mathbf{F}_{\mathbf{B}}$ & $3 \%$ & - & - & $51.26 \%$ & $5 \%$ & - & $13 \%$ & $72.25 \%$ & $35(2011), 21$ \\
\hline $\mathbf{N}^{\mathbf{R e}}$ & $3 \%$ & - & - & $51.26 \%$ & $4 \%$ & - & - & $73.17 \%$ & 47 \\
$\mathbf{O}_{\mathbf{B}}^{\mathbf{R e}}$ & $3 \%$ & - & - & $51.26 \%$ & $5 \%$ & $1 \%$ & - & $73.17 \%$ & 44 \\
$\mathbf{F}_{\mathbf{B}}^{\mathbf{R e}}$ & $3 \%$ & - & - & $51.26 \%$ & $5 \%$ & - & $13 \%$ & $72.25 \%$ & 48 \\
\hline $\mathbf{O}_{\mathbf{A}}$ & $5 \%$ & $2 \%$ & - & $51.26 \%$ & $4 \%$ & - & - & $73.17 \%$ & 58 \\
$\mathbf{F}_{\mathbf{A}}$ & $5 \%$ & - & $24 \%$ & $50.48 \%$ & $4 \%$ & - & - & $73.17 \%$ & 35 \\
\hline \hline
\end{tabular}

Table 1: Overview of the experimental design. All data are from the sessions in 2017, unless noted otherwise.

$\tau$-period return from investing in mutual fund $X$ at time $t$ follows as

$$
\mathrm{E}_{t}\left[R_{\mathbf{F}, X, t}^{(\tau)}\right]=\left(1-F_{X}\right) \mathrm{E}_{t}\left[R_{X, t}^{(\tau)}\right]=\left(1-F_{X}\right)\left(1+g_{X}\right)^{\tau}
$$

The front-end load is paid for fund $B$ in treatments $\mathbf{F}_{\mathbf{B}}$ and $\mathbf{F}_{\mathbf{B}}^{\mathbf{R e}}$, and for fund $A$ in treatment $\mathbf{F}_{\mathbf{A}}$. The load is such that the net expected return of investing in the fund from the beginning is the same as in treatment $\mathbf{N}$.

\subsection{Treatments}

Every subject participates in one treatment only. In each treatment subjects could increase their wealth by investing in one of the two funds, $A$ or $B$, in three separate blocks of 15 decision periods each, as described in Section 2.1. We use the same return realizations in all treatments, but the realizations are different between the three blocks. Treatments $\mathbf{N}^{\mathbf{R e}}, \mathbf{O}_{\mathbf{B}}^{\mathbf{R e}}$, and $\mathbf{F}_{\mathbf{B}}^{\mathbf{R e}}$ differ from treatments $\mathbf{N}, \mathbf{O}_{\mathbf{B}}$, and $\mathbf{F}_{\mathbf{B}}$, respectively, only by the order in which the first two blocks are presented to the subjects. Table 1 summarizes the design. In addition, we take $\varepsilon=2 \%$.

For the baseline treatments $\mathbf{N}$ and $\mathbf{N}^{\mathbf{R e}}$, none of the two funds requires a fee. The growth constants are set to $g_{A}=3 \%$ and $g_{B}=4 \%$. As $\varepsilon=2 \%$, it implies that the realized return of fund $A$ is going to be either $1 \%$ or $5 \%$, and the realized return of fund $B$ is going to be either $2 \%$ or $6 \%$. There is a $25 \%$ probability that the realized return of investing in fund $A$ is higher than that of investing in fund $B$, i.e., when $\epsilon_{A, t}=2 \%$ and $\epsilon_{B, t}=-2 \%$. Investing in fund $B$ in every period gives an expected (net) return of about $73 \%$, whereas the net expected return of always investing in fund $A$ is around $51 \% .^{13}$

\footnotetext{
${ }^{13}$ Note that, although subjects need to make an investment decision for 15 consecutive periods there will only
} 
For the operating expenses treatments $\mathbf{O}_{\mathbf{B}}, \mathbf{O}_{\mathbf{B}}^{\mathbf{R e}}$, and $\mathbf{O}_{\mathbf{A}}$, there is an operating expenses fee for one of the funds. For treatments $\mathbf{O}_{\mathbf{B}}$ and $\mathbf{O}_{\mathbf{B}}^{\mathbf{R e}}$ the growth constants are equal to $g_{A}=3 \%$ and $g_{B}=5 \%$, with an operating expenses fee for fund $B$ equal to $\gamma_{B}=1 \%$. For treatment $\mathbf{O}_{\mathbf{A}}$ the growth constants are equal to $g_{A}=5 \%$ and $g_{B}=4 \%$ with an operating expenses fee for fund $A$ equal to $\gamma_{A}=2 \%$. Effectively, therefore, realized net returns of investing in fund $A$ and $B$ are exactly the same in treatments $\mathbf{O}_{\mathbf{B}}, \mathbf{O}_{\mathbf{A}}, \mathbf{N}$, and (subject to the swap of the first two blocks) in $\mathbf{O}_{\mathbf{B}}^{\mathbf{R e}}$ and $\mathbf{N}^{\mathbf{R e}}$, with expected net returns of investing in fund $B$ (4\%) always higher than those for investing in fund $A(3 \%)$. Note that gross expected returns for investing in fund $A$ are higher than for fund $B$ in treatment $\mathbf{O}_{\mathbf{A}}$, but lower in treatments $\mathbf{N}, \mathbf{N}^{\mathbf{R e}}, \mathbf{O}_{\mathbf{B}}$ and $\mathbf{O}_{\mathbf{B}}^{\mathbf{R e}}$.

In the front-end load treatments $\mathbf{F}_{\mathbf{B}}, \mathbf{F}_{\mathbf{B}}^{\mathbf{R e}}$, and $\mathbf{F}_{\mathbf{A}}$, a front-end load has to be paid for investing in one of the funds. For treatments $\mathbf{F}_{\mathbf{B}}$ and $\mathbf{F}_{\mathbf{B}}^{\mathbf{R e}}$ we take $g_{A}=3 \%$ and $g_{B}=5 \%$, and choose a front-end load for fund $B$ of $F_{B}=13 \%$. For these values, the expected return of investing in fund $B$ from the beginning of the block in treatments $\mathbf{F}_{\mathbf{B}}$ and $\mathbf{F}_{\mathbf{B}}^{\mathbf{R e}}$ is (roughly) equal to the expected return of investing in fund $B$ for the other treatments. For treatment $\mathbf{F}_{\mathbf{A}}$ we take (as for treatment $\mathbf{O}_{\mathbf{A}}$ ) growth rates of $g_{A}=5 \%$ and $g_{B}=4 \%$ and a front-end load for fund $A$ of $F_{A}=24 \%$. Again, for these values the expected return of investing in fund $A$ from the beginning of the block is (roughly) equal to the expected return of investing in fund $A$ for the other treatments. ${ }^{14}$ Note however that, whereas for the baseline and operating expenses treatments it is always optimal to switch from investing in fund $A$ to investing in fund $B$, this is not the case for the front-end load treatments. For treatments $\mathbf{F}_{\mathbf{B}}$ and $\mathbf{F}_{\mathbf{B}}^{\mathbf{R e}}$ this is only worthwhile if enough periods remain to 'earn back' the front-end load. In particular, switching from fund $A$ to fund $B$ later than period 7 decreases expected returns. ${ }^{15}$ For treatment $\mathbf{F}_{\mathbf{A}}$, on the other hand, it is always optimal to stay with fund $A$, once the front-end load has been paid.

be 14 return rates. It can be easily checked that investing in fund $B$ for all periods gives at least a net return of $32.0 \%$ (when all price shocks are negative) and at most a net return of $126.1 \%$ (when all price shocks are positive). The corresponding numbers for fund $A$ are $15.0 \%$ and $98.0 \%$, respectively. Moreover, the return of always investing in fund $A$ is going to be higher than the return of always investing in fund $B$ only if fund $A$ experiences at least four more positive price shocks than fund $B$ does.

${ }^{14}$ To be precise: for the expected returns of fund $B$ to be exactly the same in treatments $\mathbf{F}_{\mathbf{B}}$ and $\mathbf{F}_{\mathbf{B}}^{\mathbf{R e}}$ as in the other treatments, the constant $F_{B}$ has to satisfy $\left(1-F_{B}\right)\left(1+g_{B}\right)^{T}=\left(1+g_{B}-\gamma_{B}\right)^{T}$. For $g_{B}=0.05$, $\gamma_{B}=0.01$ and $T=14$ this gives $F_{B}^{*} \approx 0.1254$. We select $F_{B}=0.13$, as this is the closest integer (in percentage points) to $F_{B}^{*}$. In the same way, we find $F_{A}^{*} \approx 0.2360$ for treatment $\mathbf{F}_{\mathbf{A}}$, which we round to $F_{A}=0.24$. Note that the difference between expected returns for funds $A$ and $B$ in the different treatments is very small (see Table 1).

${ }^{15}$ It can be easily checked that $0.87 \times 1.05^{t} \geq 1.03^{t}$ if and only if $t \geq t^{*} \approx 7.24$ and choosing fund $B$ (and paying the front-end load) can only be profitable (in expectation) when at least 8 periods remain. 

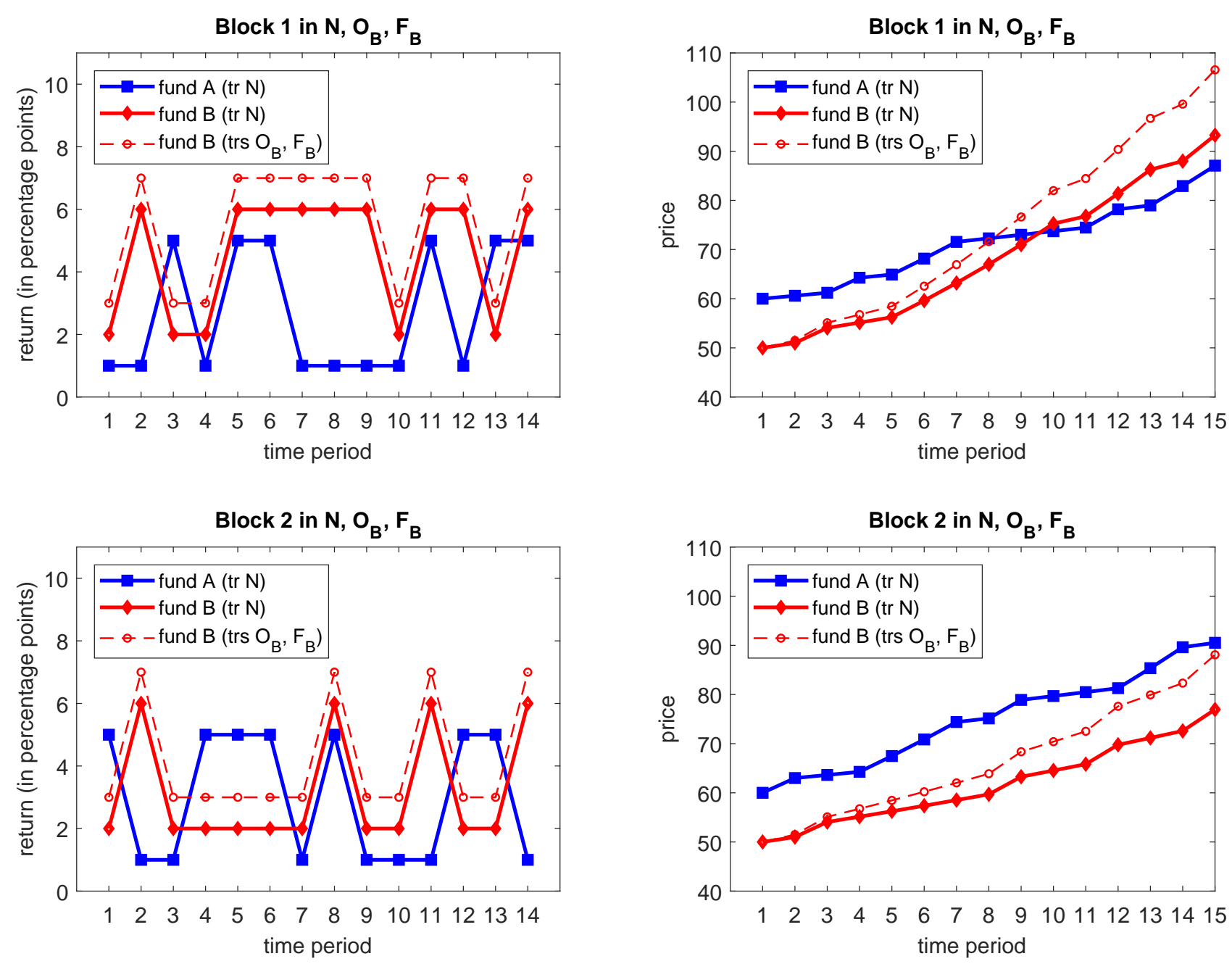

Figure 1: Generated time series in Blocks 1 and 2 for treatments $\mathbf{N}, \mathbf{O}_{\mathbf{B}}$ and $\mathbf{F}_{\mathbf{B}}$. Left: Gross returns. Right: Prices. Fund $A$ returns are the same in the three treatments. Fund $B$ returns in treatments $\mathbf{O}_{\mathbf{B}}$ and $\mathbf{F}_{\mathbf{B}}$ are one percentage point higher than returns in treatment $\mathbf{N}$. Prices are generated using the returns with initial values 60 and 50 for funds $A$ and $B$, respectively. The same time series are used in treatments $\mathbf{N}^{\mathbf{R e}}, \mathbf{O}_{\mathbf{B}}^{\mathbf{R e}}$ and $\mathbf{F}_{\mathbf{B}}^{\mathbf{R e}}$ for the second and first block, respectively.

\subsection{Blocks}

For each treatment the chosen parameters $\left(g_{A}, g_{B}, \gamma_{A}, \gamma_{B}, F_{A}, F_{B}\right)$ are the same in all three blocks. The only difference between blocks in the same treatment is that we use different seeds for generating the white noise processes, $\epsilon_{A, t}$ and $\epsilon_{B, t}$, and, hence, prices and returns. Within each block we use the same realization of the shocks in all treatments. Thus any difference we observe between treatments can be attributed to differences in the fee structure (and not in the return realizations). On the other hand, the difference between blocks within each treatment can be attributed to experience or to the difference in the return realizations.

Figure 1 shows the generated time series for Blocks 1 (top panels) and 2 (bottom panels) 


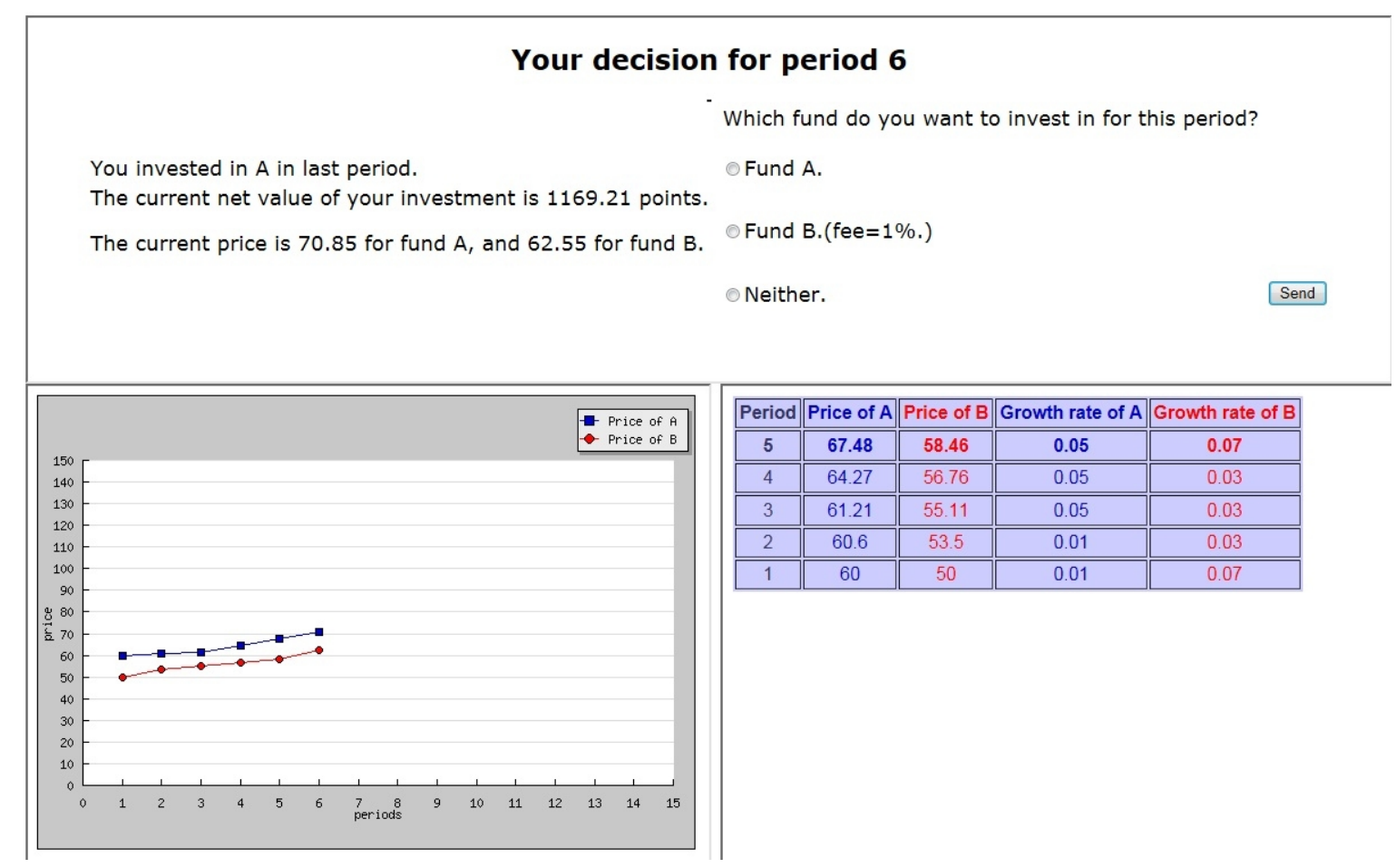

Figure 2: An example of the computer screen for treatment $\mathbf{O}_{\mathbf{B}}$.

in treatments $\mathbf{N}, \mathbf{O}_{\mathbf{B}}$, and $\mathbf{F}_{\mathbf{B}} \cdot{ }^{16}$ The left panels show the realized returns for funds $A$ and $B$. The right panels display the prices resulting from these returns, also shown to the subjects (see Figure 2), where we set the initial price of funds $A$ and $B$ equal to 60 and 50, respectively. ${ }^{17}$ For treatments $\mathbf{N}^{\mathbf{R e}}, \mathbf{O}_{\mathbf{B}}^{\mathbf{R e}}$, and $\mathbf{F}_{\mathbf{B}}^{\mathbf{R e}}$ the order of these time series is reversed: in those treatments subjects experience the relevant time series in the lower panels of Figure 1 in their first block, and the relevant time series in the upper panels in their second block. Unless specified differently, for the remainder of this paper Block 1 denotes the first block of time series used in the 'regular' treatments and simultaneously denotes the second block of time series used in the reversed order treatments (and similarly for Block 2).

In the first two blocks all subjects experienced exactly the same realizations of the shocks (but, as explained above, not in the same order for every treatment). For the third block we generated 10 additional sets of time series for fund $A$ and fund $B$ to get more variation in the underlying time series. Subjects in each treatment were allocated approximately evenly over these different time series in the third block. ${ }^{18}$

\footnotetext{
${ }^{16}$ Figure 8 in Online Appendix D compares in an analogous way the time series for the first two blocks in treatments $\mathbf{N}, \mathbf{O}_{\mathbf{A}}$, and $\mathbf{F}_{\mathbf{A}}$.

${ }^{17}$ We chose the initial price of fund $A$ to be higher than that of fund $B$ because then (given the higher expected return of the latter) prices of the two funds stay relatively close to each other over the 15 periods of the block. We cannot exclude a priori that the chosen values of the initial prices have an effect on subjects' choices, but since we use the same initial prices for each block and each treatment they cannot explain differences between blocks or treatments.

${ }^{18}$ We only used the third block for the sessions that were run in 2017 , see footnote 8 . This means that the total number of subjects for which we use decisions from Block 3 over the eight treatments is 305 . The time series of realized returns for Block 3 are presented in Figs. 9 and 10 in Online Appendix D.
} 
Each subject has full information about the price generating mechanisms. In the beginning of each block subjects start with an empty screen and make their first choice. Then, as the experiment evolves, subjects are shown a table with past realized returns and the corresponding past prices. They can also see the graph with the time series of past prices and the current net value of their portfolio. ${ }^{19}$ Figure 2 provides a typical example of the experimental screen. ${ }^{20}$ The subjects make a choice between investing in fund $A$, fund $B$ or neither of them in the decision box in the upper part of the screen.

Table 2 characterizes potential returns in different blocks under different behaviors. For Block 3 we report the average of possible returns over 10 time series. The third and fourth columns show the returns from investing for all 15 periods in fund $A$ or fund $B$, respectively. By construction of the experiment, these returns are similar in all treatments and exactly the same in the treatments with no front-end load. Due to the randomness in the realized returns, the return for always investing in fund $A$ is slightly less than the expected return of $51.26 \%$ in all blocks. The return for always investing in fund $B$ is higher than the expected return of $73.17 \%$ in Block 1, lower than the expected return in Block 2, and close to the expected return (on average) in Block 3. ${ }^{21}$ The next two columns show the ex post minimum and maximum possible total return a subject could earn (assuming the subject invests in every period). ${ }^{22}$ The last column shows the return from the "return chasing" strategy of investing in the fund that had the highest realized (gross) return in the previous period. ${ }^{23}$ For all treatments (except $\mathbf{O}_{\mathbf{A}}$ and $\mathbf{F}_{\mathbf{A}}$ ) in any period there is a $25 \%$ probability that the gross return on fund $A$ is higher than that on fund $B$ and, although this provides no information about future return differences, it may induce subjects to switch to (or remain with) fund $A$ - which is clearly not the (ex ante) optimal investment strategy. In the treatments with front-end load the return chasing strategy gives very low returns, because with this strategy the front-end load will typically be paid more than once. On the other hand, the difference between always investing in fund $B$ and chasing

\footnotetext{
${ }^{19}$ Alternatively we could have depicted returns instead of prices in the graph. We chose prices in order to make the realization of returns not too salient. Note that the table on the computer screen presents past prices as well as past returns for both funds, making the information in the graph effectively redundant. See Glaser et al. (2018) for an overview of the use of price and return graphs for mutual funds, and an analysis on how this information affects investors' expectations.

${ }^{20}$ Figure 2 (with superimposed comments) is shown to the subjects in treatments $\mathbf{O}_{\mathbf{B}}$ and $\mathbf{O}_{\mathbf{B}}^{\mathbf{R e}}$ as part of the instructions. The time series shown in this figure differs from those used in the experiment. The screens in the other treatments are similar to that shown in Figure 2 and adjusted accordingly. Specifically, in treatments $\mathbf{N}$ and $\mathbf{N}^{\mathbf{R e}}$ the fee information is absent; in treatment $\mathbf{O}_{\mathbf{A}}$ the fee information of $2 \%$ is displayed for fund $A$; in treatment $\mathbf{F}_{\mathbf{B}}$, the information for fund $B$ reads 'fee $=13 \%$ ', and in treatment $\mathbf{F}_{\mathbf{A}}$ the information for fund $A$ reads 'fee $=24 \%$ '.

${ }^{21}$ The number of positive shocks for fund $A$ are 6 in Block 1 and 7 in Block 2. For fund $B$ these numbers are 9 and 4, respectively. For the time series used in Block 3 the average number of positive price shocks for funds $A$ and $B$ are 6.1 and 7.0 respectively.

${ }^{22}$ In treatments $\mathbf{N}, \mathbf{O}_{\mathbf{B}}$, and $\mathbf{O}_{\mathbf{A}}$, such a subject would (by sheer bad or good luck) each period choose the fund that will have the lowest or highest realized return in that period. In treatments $\mathbf{F}_{\mathbf{B}}$ and $\mathbf{F}_{\mathbf{A}}$ the total return is maximal when the front-end load is paid at most once, and it is minimal when the front-end load is paid seven times, i.e., when a subject switches between funds $A$ and $B$ as often as possible.

${ }^{23}$ The calculations assume that in the first period fund $B$ is chosen.
} 


\begin{tabular}{|c|c|c|c|c|c|c|}
\hline Block & Treatment & $\begin{array}{c}\text { Always } \\
\text { A }\end{array}$ & $\begin{array}{c}\text { Always } \\
B\end{array}$ & $\begin{array}{l}\text { Minimum } \\
\text { possible }\end{array}$ & $\begin{array}{l}\text { Maximum } \\
\text { possible }\end{array}$ & $\begin{array}{l}\text { "Return } \\
\text { chasing" }\end{array}$ \\
\hline \multirow{2}{*}{1} & $\overline{\mathrm{N}, \mathrm{O}_{\mathrm{B}}}$ & $4 \overline{45.11 \%}$ & $86.53 \%$ & $36.94 \%$ & $97.67 \%$ & $82.96 \%$ \\
\hline & $\mathbf{F}_{\mathrm{B}}$ & $45.11 \%$ & $85.42 \%$ & $-37.39 \%$ & $85.49 \%$ & $55.23 \%$ \\
\hline \multirow{2}{*}{$\left(2\right.$ for $\left.\mathbf{N}^{\mathbf{R e}}, \mathrm{O}_{\mathbf{B}}^{\mathbf{R e}}, \mathbf{F}_{\mathbf{B}}^{\mathbf{R e}}\right)$} & $\mathrm{O}_{\mathrm{A}}$ & $45.11 \%$ & $86.53 \%$ & $36.94 \%$ & $97.67 \%$ & $53.83 \%$ \\
\hline & $\mathbf{F}_{\mathrm{A}}$ & $44.48 \%$ & $86.53 \%$ & $-73.96 \%$ & $86.53 \%$ & $-40.14 \%$ \\
\hline \multirow{2}{*}{2} & $\mathbf{N}, \mathrm{O}_{\mathrm{B}}$ & $50.86 \%$ & $53.90 \%$ & $26.78 \%$ & $83.13 \%$ & $50.92 \%$ \\
\hline & $\mathbf{F}_{\mathrm{B}}$ & $50.86 \%$ & $53.26 \%$ & $-39.64 \%$ & $56.24 \%$ & $7.37 \%$ \\
\hline \multirow{2}{*}{$\left(1\right.$ for $\left.\mathbf{N}^{\mathbf{R e}}, \mathbf{O}_{\mathbf{B}}^{\mathbf{R e}}, \mathbf{F}_{\mathbf{B}}^{\mathbf{R e}}\right)$} & $\mathrm{O}_{\mathrm{A}}$ & $50.86 \%$ & $53.90 \%$ & $26.78 \%$ & $83.13 \%$ & $43.77 \%$ \\
\hline & $\mathrm{F}_{\mathrm{A}}$ & $50.09 \%$ & $53.90 \%$ & $-74.96 \%$ & $53.90 \%$ & $-21.98 \%$ \\
\hline \multirow{4}{*}{3} & $\mathrm{~N}, \mathrm{O}_{\mathrm{B}}$ & $47.14 \%$ & $72.92 \%$ & $34.46 \%$ & $89.15 \%$ & $64.59 \%$ \\
\hline & $F_{B}$ & $47.14 \%$ & $72.02 \%$ & $-37.07 \%$ & $72.68 \%$ & $14.78 \%$ \\
\hline & $\mathrm{O}_{\mathrm{A}}$ & $47.14 \%$ & $72.92 \%$ & $34.46 \%$ & $89.15 \%$ & $53.00 \%$ \\
\hline & $\mathbf{F}_{\mathrm{A}}$ & $46.46 \%$ & $72.92 \%$ & $-74.73 \%$ & $72.92 \%$ & $-13.24 \%$ \\
\hline
\end{tabular}

Table 2: Realized returns in different treatments and blocks for different types of behavior. For Block 3 the (unweighted) average for 10 time series is shown.

returns is not very large in treatments $\mathbf{N}$ and $\mathbf{O}_{\mathbf{B}}$. In fact, in Block 1 there are only two periods in which fund $A$ does better than fund $B$, so the strategies lead to very similar behavior. In Block 2 there are 6 periods when fund $A$ has a higher return, and in three of them, the return of fund $A$ will be larger again in the following period. Finally, the return chasing strategy leads to substantially lower returns than optimal in treatment $\mathbf{O}_{\mathbf{A}}$, where the gross returns are higher for fund $A$ than for fund $B$ with a probability of $75 \%$ (even if net returns are higher only with a probability of $25 \%$ ).

\section{Hypotheses}

We designed our experiment such that in each treatment subjects essentially face the same choice between funds, with expected net returns for each fund the same across all treatments (provided that that fund is chosen from the beginning). Therefore one might conjecture that aggregate investment behavior is independent of the treatment, and that the fee structure will have no impact on choice behavior. This leads to the following set of hypotheses, which we will test in Section 4.

First, there should not be a significant difference between treatments where an operating expenses fee is imposed by one of the funds, and treatments where no fees are charged. Although the choice problem is framed differently in the two types of treatments, expected and realized net returns of both funds are exactly the same in these treatments.

Hypothesis 1. There is not a significant difference in subjects' frequency of choosing fund $B$ (against $A$ ) and subjects' earnings between treatments $\mathbf{O}_{\mathbf{B}}, \mathbf{O}_{\mathbf{A}}$, and $\mathbf{N}$. Likewise, there is not 
a significant difference between treatments $\mathbf{O}_{\mathbf{B}}^{\mathbf{R e}}$ and $\mathbf{N}^{\mathbf{R e}}$.

If we do find a statistically significant difference between some of these treatments, it can be attributed to the way the returns of the funds are presented. We confront this hypothesis with the data in Section 4.2.

Similarly, we do not expect to see a difference between the treatments with an operating expenses fee and a front-end load.

Hypothesis 2. There is not a significant difference in subjects' frequency of choosing fund $B$ (against $A$ ) and subjects' earnings between treatments $\mathbf{F}_{\mathbf{B}}$ and $\mathbf{O}_{\mathbf{B}}$, between treatments $\mathbf{F}_{\mathbf{B}}^{\mathbf{R e}}$ and $\mathbf{O}_{\mathbf{B}}^{\mathbf{R e}}$, and between treatments $\mathbf{F}_{\mathbf{A}}$ and $\mathbf{O}_{\mathbf{A}}$.

Contrary to the comparison between treatments without fees and treatments with operating expenses fees, there exist explanations other than framing for a possible significant difference between front-end load treatments and treatments with an operating expenses fee.

On the one hand, for treatments that do not involve a front-end load it is straightforward to understand which of the two funds generates a higher expected net return (4\% for $B$ is clearly higher than $3 \%$ for $A$ ). However, in treatments with a front-end load the comparison between the two funds requires a non-trivial computation, which may lead to uncertainty for the subject about how to evaluate the fund that charges a front-end load. ${ }^{24}$ Moreover, the front-end loads in treatments $\mathbf{F}_{\mathbf{B}}, \mathbf{F}_{\mathbf{B}}^{\mathbf{R e}}$, and $\mathbf{F}_{\mathbf{A}}$ are much higher, and therefore much more salient, than the operating expenses fees in treatments $\mathbf{O}_{\mathbf{B}}, \mathbf{O}_{\mathbf{B}}^{\mathbf{R e}}$, and $\mathbf{O}_{\mathbf{A}}$, respectively. These two effects might lead to under-investment in fund $B$ in treatments $\mathbf{F}_{\mathbf{B}}$ and $\mathbf{F}_{\mathbf{B}}^{\mathbf{R e}}$ with respect to the operating expenses fee treatments, and a larger investment in fund $B$ in treatment $\mathbf{F}_{\mathbf{A}}$ than in $\mathbf{O}_{\mathbf{A}}$. On the other hand, the fact that the front-end load has to be paid every time that the subject starts to invest in the front-end load fund implies that switching back and forth between funds is much more costly in the front-end load treatments than in the operating expenses treatments. In that sense, the front-end load may serve as a commitment device and force the subject to exert more effort into thinking about the investment decision at the start of the experiment, or at the start of a new block. This might increase the fraction of subjects choosing fund $B$ in treatments $\mathbf{F}_{\mathbf{B}}$ and $\mathbf{F}_{\mathbf{B}}^{\mathbf{R e}}$, and steer more subjects away from fund $A$ in treatment $\mathbf{F}_{\mathbf{A}}$. We test Hypothesis 2 and discuss the cognitive effort and commitment device explanations in Section 4.3.

The final hypothesis focuses on the comparison between different blocks in the same treatment. Although the actual realizations of returns are different between blocks, subjects' de-

\footnotetext{
${ }^{24}$ See Bossaerts et al. (2018), who study the effect of the computational complexity of valuating securities on market prices.
} 
cisions should be driven by expected, instead of realized, returns. This gives the following hypothesis.

Hypothesis 3. The frequencies of choosing fund B (against $A$ ) are not significantly different between blocks in the same treatment.

There are two possible explanations for a rejection of this hypothesis. First, although realized returns do not convey additional information about future returns, the subjects may respond to realized returns anyway: if the relative performance of fund $A$ is better in one block than in some other block, subjects may choose fund $A$ more often in the former. For example, the return realizations for our Blocks 1 and 2, although generated by the same data generating process, are quite different, with fund $B$ outperforming fund $A$ in 12 of the 14 periods in Block 1 and in only eight of the 14 periods in Block 2. If (some) subjects exhibit "return chasing behavior" we might expect a lower frequency of choices for fund $B$ in Block 2 than in Block 1 .

Second, as subjects gain more experience with the decision environment they may learn to make better decisions. Under learning we would expect that the fraction of choices for fund $B$ will be higher in the third block than in the second block, and higher in the second block than in the first block. To analyze this effect we can use the treatments with a reversed order of blocks. For example, the second block of treatment $\mathbf{N}^{\mathbf{R e}}$ uses the same time series as the first block of treatment $\mathbf{N}$. Hence, a significantly higher frequency of choices for fund $B$ in the second block of $\mathbf{N}^{\mathbf{R e}}$ than in the first block of $\mathbf{N}$ would suggest that experience or learning may explain (part of) the difference between blocks in the same treatment. In Section 4.4 we test Hypothesis 3 and analyze learning and return chasing.

\section{Experimental Results}

In this section we present and analyze the experimental data. We will have a first look at the data in Section 4.1 and subsequently compare the operating expenses treatments with the treatments without fees in Section 4.2 and the front-end load treatments with the operating expenses treatments in Section 4.3. Finally, in Section 4.4 we discuss the differences between blocks.

\subsection{An Overview of the Experimental Data}

Figure 3 shows, for different treatments, the histograms of the number of choices for fund $B$, i.e., how often subjects invest in fund $B$ during a block. Table 3 shows the mean and median 

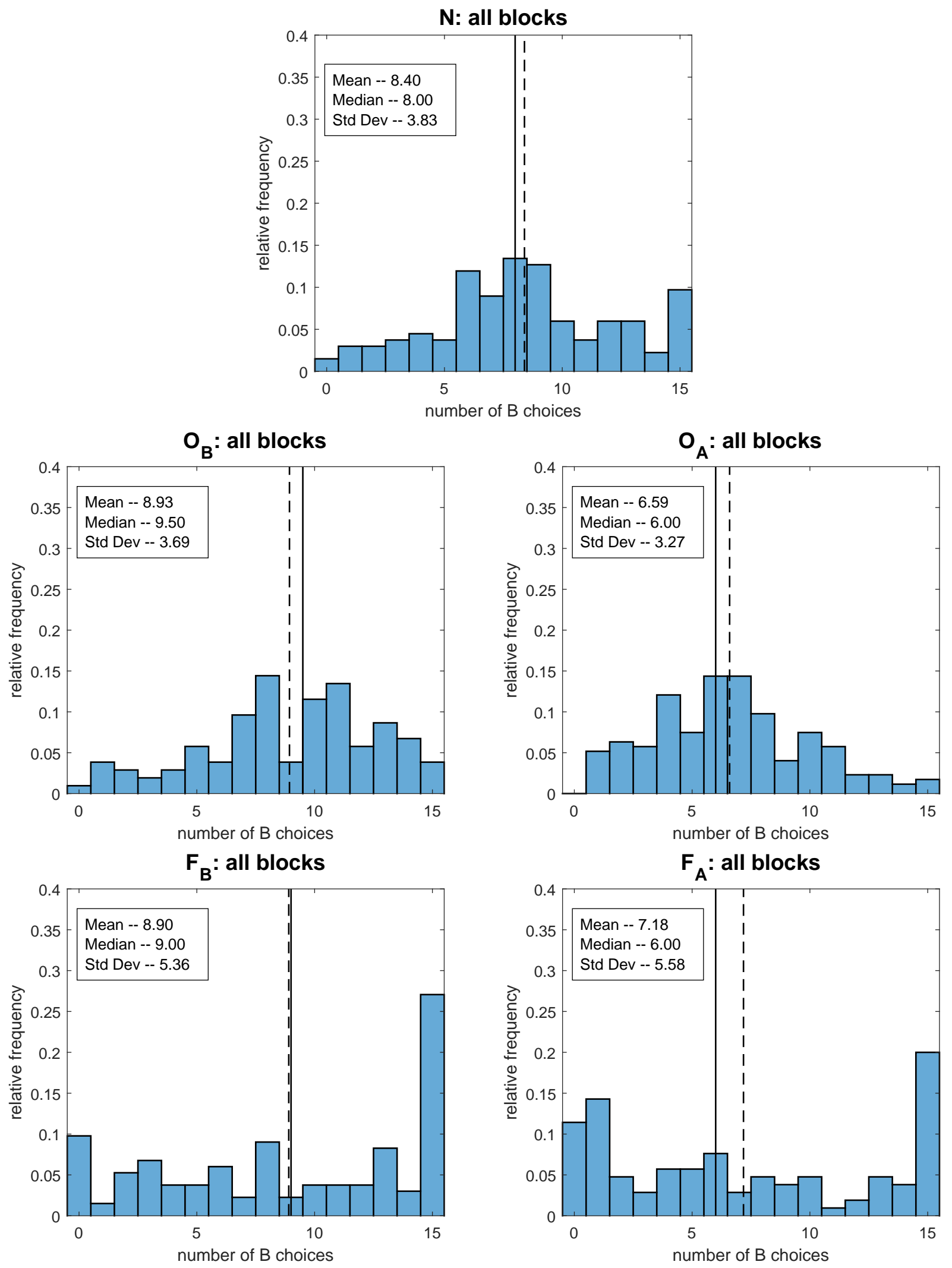

Figure 3: Histograms of the number of choices for fund $B$ in different treatments. The solid vertical line shows the median and the dashed vertical line shows the mean.

of this number for each block and treatment, along with some other variables that we will discuss later in this section. Note that the number of times a subject can choose $B$ in a block 


\begin{tabular}{|c|c|c|c|c|c|c|c|c|c|}
\hline \multirow{2}{*}{ Treatment } & \multirow{2}{*}{ Block } & \multicolumn{3}{|c|}{ Fraction of Choosing } & \multicolumn{4}{|c|}{ Median of } & \multirow{2}{*}{$\begin{array}{c}\text { Number of } \\
\text { Observations }\end{array}$} \\
\hline & & $A$ & $B$ & Neither & $B$-choices & Earnings & Efficiency & Switches & \\
\hline \multirow{4}{*}{$\mathbf{N}$} & Block 1 & 6.40 & 8.37 & 0.23 & $\overline{8}$ & 1629.27 & 0.87 & $\overline{5}$ & 52 \\
\hline & Block 2 & 7.54 & 7.44 & 0.02 & 7 & 1523.99 & 0.99 & 5 & 52 \\
\hline & Blocks 3 & 4.90 & 10.10 & 0.00 & 10 & 1598.99 & 0.93 & 4 & 30 \\
\hline & All & 6.51 & 8.40 & 0.10 & 8 & 1560.02 & 0.94 & 5 & 134 \\
\hline \multirow{4}{*}{$\mathrm{O}_{\mathrm{B}}$} & Block 1 & 5.22 & 9.59 & 0.20 & 10 & 1693.17 & 0.91 & 3 & 41 \\
\hline & Block 2 & 7.27 & 7.61 & 0.12 & 8 & 1494.96 & 0.97 & 4 & 41 \\
\hline & Blocks 3 & 4.64 & 10.18 & 0.18 & 10.5 & 1677.67 & 0.97 & 5 & 22 \\
\hline & All & 5.90 & 8.93 & 0.16 & 9.5 & 1568.96 & 0.95 & 4 & 104 \\
\hline \multirow{4}{*}{$\mathrm{F}_{\mathrm{B}}$} & Block 1 & 4.63 & 10.13 & 0.25 & 11 & 1559.43 & 0.84 & 1 & 56 \\
\hline & Block 2 & 6.79 & 8.04 & 0.18 & 7 & 1474.74 & 0.96 & 1 & 56 \\
\hline & Blocks 3 & 7.00 & 7.95 & 0.05 & 8 & 1502.25 & 0.87 & 1 & 21 \\
\hline & All & 5.91 & 8.90 & 0.19 & 9 & 1502.25 & 0.88 & 1 & 133 \\
\hline \multirow{4}{*}{$\mathbf{N}^{\mathrm{Re}}$} & Block 2 & 7.04 & 7.68 & 0.28 & 8 & 1509.19 & 0.98 & 5 & 47 \\
\hline & Block 1 & 4.68 & 10.19 & 0.13 & 11 & 1727.17 & 0.93 & 4 & 47 \\
\hline & Blocks 3 & 4.45 & 10.53 & 0.02 & 11 & 1630.20 & 0.95 & 4 & 47 \\
\hline & All & 5.39 & 9.47 & 0.14 & 10 & 1598.39 & 0.95 & 5 & 141 \\
\hline \multirow{4}{*}{$\mathrm{O}_{\mathrm{B}}^{\mathrm{Re}}$} & Block 2 & 7.09 & 7.86 & 0.05 & 7 & 1523.84 & 0.99 & 5 & 44 \\
\hline & Block 1 & 4.61 & 10.39 & 0.00 & 10 & 1709.93 & 0.92 & 5 & 44 \\
\hline & Blocks 3 & 2.91 & 12.09 & 0.00 & 13 & 1661.22 & 0.99 & 2.5 & 44 \\
\hline & All & 4.87 & 10.11 & 0.02 & 10 & 1644.79 & 0.97 & 4.5 & 132 \\
\hline \multirow{4}{*}{$F_{B}^{R e}$} & Block 2 & 7.25 & 7.48 & 0.27 & 7 & 1387.86 & 0.91 & 1 & 48 \\
\hline & Block 1 & 3.96 & 10.83 & 0.21 & 13 & 1715.61 & 0.93 & 1 & 48 \\
\hline & Blocks 3 & 2.65 & 12.17 & 0.19 & 14 & 1637.86 & 0.98 & 1 & 48 \\
\hline & All & 4.62 & 10.16 & 0.22 & 11.5 & 1532.59 & 0.94 & 1 & 144 \\
\hline \multirow{4}{*}{$\mathrm{O}_{\mathrm{A}}$} & Block 1 & 8.02 & 6.50 & 0.48 & 6.5 & 1552.70 & 0.83 & 6.5 & 58 \\
\hline & Block 2 & 8.12 & 6.69 & 0.19 & 6 & 1494.38 & 0.97 & 6 & 58 \\
\hline & Blocks 3 & 8.31 & 6.59 & 0.10 & 6 & 1583.30 & 0.89 & 6 & 58 \\
\hline & All & 8.15 & 6.59 & 0.26 & 6 & 1538.35 & 0.91 & 6 & 174 \\
\hline \multirow{4}{*}{$\mathbf{F}_{\mathrm{A}}$} & Block 1 & 8.26 & 6.49 & 0.26 & 6 & 1444.82 & 0.77 & 1 & 35 \\
\hline & Block 2 & 6.94 & 8.00 & 0.06 & 8 & 1472.47 & 0.96 & 1 & 35 \\
\hline & Blocks 3 & 7.86 & 7.06 & 0.09 & 6 & 1444.82 & 0.83 & 1 & 35 \\
\hline & All & 7.69 & 7.18 & 0.13 & 6 & 1444.82 & 0.82 & 1 & 105 \\
\hline
\end{tabular}

Table 3: Number of individual choices (averaged over subjects), medians of choices for fund $B$, earnings, efficiencies, and switches for different treatments and blocks.

lies between 0 and 15. For Figure 3 we pool the experimental data over blocks in the same treatment, so that the number of observations equals the number of subjects in a treatment times the number of blocks in which they make decisions - see the last column of Table 3 for the number of observations in each treatment. Moreover, for Figure 3 we also pool the data from treatments $\mathbf{N}$ and $\mathbf{N}^{\mathbf{R e}}$, from treatments $\mathbf{O}_{\mathbf{B}}$ and $\mathbf{O}_{\mathbf{B}}^{\mathbf{R e}}$, and from treatments $\mathbf{F}_{\mathbf{B}}$ and $\mathbf{F}_{\mathbf{B}}^{\mathbf{R e}}$, respectively. $^{25}$ The solid and dashed vertical lines in each histogram show the median and mean number of choices for fund $B$, respectively. Note that it is quite rare that a subject does not invest in either of the two funds, as can be seen in the fifth column of Table 3, which is unsurprising as returns for both funds are strictly positive (with the possible exception of the fund for which a front-end load has to be paid).

Several interesting observations come to the fore when we look at the data presented in Figure 3 and Table 3. First, for all treatments there is a substantial dispersion in how often

\footnotetext{
${ }^{25}$ Online Appendix D contains the histograms of the number of choices for fund $B$ for every block and every treatment separately.
} 
subjects choose fund $B$, and in none of the treatments the mean or median number of choices for fund $B$ equals 15 , which it would be under rational choice. Instead, from Table 3 we see that for most treatments and blocks the mean and median of the number of choices for fund $B$ are between 7.5 and 11 (they are the highest for Block 3 of treatment $\mathbf{F}_{\mathbf{B}}^{\mathbf{R e}}$, where they are 12.17 and 14, respectively). Second, although the histograms for the treatments without a fee and those with an operating expenses fee for fund $B$ are quite similar, the histogram for treatment $\mathrm{O}_{\mathrm{A}}$ seems to be shifted to the left somewhat. A similar picture emerges when comparing the histogram for treatments $\mathbf{F}_{\mathbf{B}}$ and $\mathbf{F}_{\mathbf{B}}^{\mathbf{R e}}$ with the histogram for treatment $\mathbf{F}_{\mathbf{A}}$. This suggests that subjects in treatments where fund $A$ charges a fee tend to choose fund $B$ less often than subjects do in the other treatments. In fact, Table 3 shows that subjects in treatments $\mathbf{O}_{\mathbf{A}}$ and $\mathbf{F}_{\mathbf{A}}$ choose the suboptimal fund $A$ more often than fund $B{ }^{26}$ Third, we find a distinct difference when comparing the histograms of number of choices for fund $B$ between the frontend load treatments and the other treatments, with the variation in that number much larger in the front-end load treatments. Moreover, the mode of the histograms for the front-end load treatments is at 15, whereas the mode of the other treatments typically lies between 6 and 10 . Finally, from Table 3 we see that for the treatments without fees, or the treatments with a fee for fund $B$, there is a consistent difference between behavior in the different blocks. On the one hand, the mean and median of the number of choices for fund $B$ are highest in Block 3 for five of these six treatments, which is consistent with learning of subjects between blocks. On the other hand, for all these six treatments the mean and the median of number of choices for fund $B$ is lower for the time series of returns used in Block 2 (where fund $A$ does relatively well) than for the time series used in Block 1, which is consistent with return chasing.

Figure 3 and Table 3 therefore suggest that there exist differences in subjects' behavior between blocks as well as between treatments. In Figure 4 we illustrate how these differences translate into the performance of subjects by plotting the cumulative empirical distribution of subjects' earnings in each treatment. Earnings are lower in the front-end load treatments: for about $23 \%$ of the observations in these treatments earnings in a block are below 1300 points, which almost never happens in the other treatments. Earnings in treatment $\mathbf{O}_{\mathbf{A}}$ also tend to be lower than those in the remaining four treatments $\left(\mathbf{N}, \mathbf{N}^{\mathbf{R e}}\right.$, and, in particular, $\mathbf{O}_{\mathbf{B}}$ and $\left.\mathbf{O}_{\mathbf{B}}^{\mathbf{R e}}\right){ }^{27}$ On the other hand, there are also more observations in treatments $\mathbf{F}_{\mathbf{B}}$ and $\mathbf{F}_{\mathbf{B}}^{\mathbf{R e}}$ where earnings are very high (e.g., more than 1800 points in a block) than in the other treatments.

Specific realizations of the returns may have a substantial effect on earnings (see Table 2).

\footnotetext{
${ }^{26}$ The mean and median of the $B$-choices is less than 7.5 in all but one of the six blocks of treatments $\mathbf{O}_{\mathbf{A}}$ and $\mathbf{F}_{\mathbf{A}}$. (For only four of the other 18 blocks the mean and/or median of $B$-choices is lower than 7.5.)

${ }^{27}$ This is consistent with the seventh column of Table 3 which shows the median of the earnings per block for each treatment. This median is the lowest in the front-end load treatments and treatment $\mathbf{O}_{\mathbf{A}}$. The mean earnings (not reported in Table 3) tell the same story: averaged over the three blocks and over treatments, earnings correspond to returns of 1472.2 in the front-end load treatments, 1547.6 in treatment $\mathbf{O}_{\mathbf{A}}$, and 1611.7 in the other four treatments.
} 


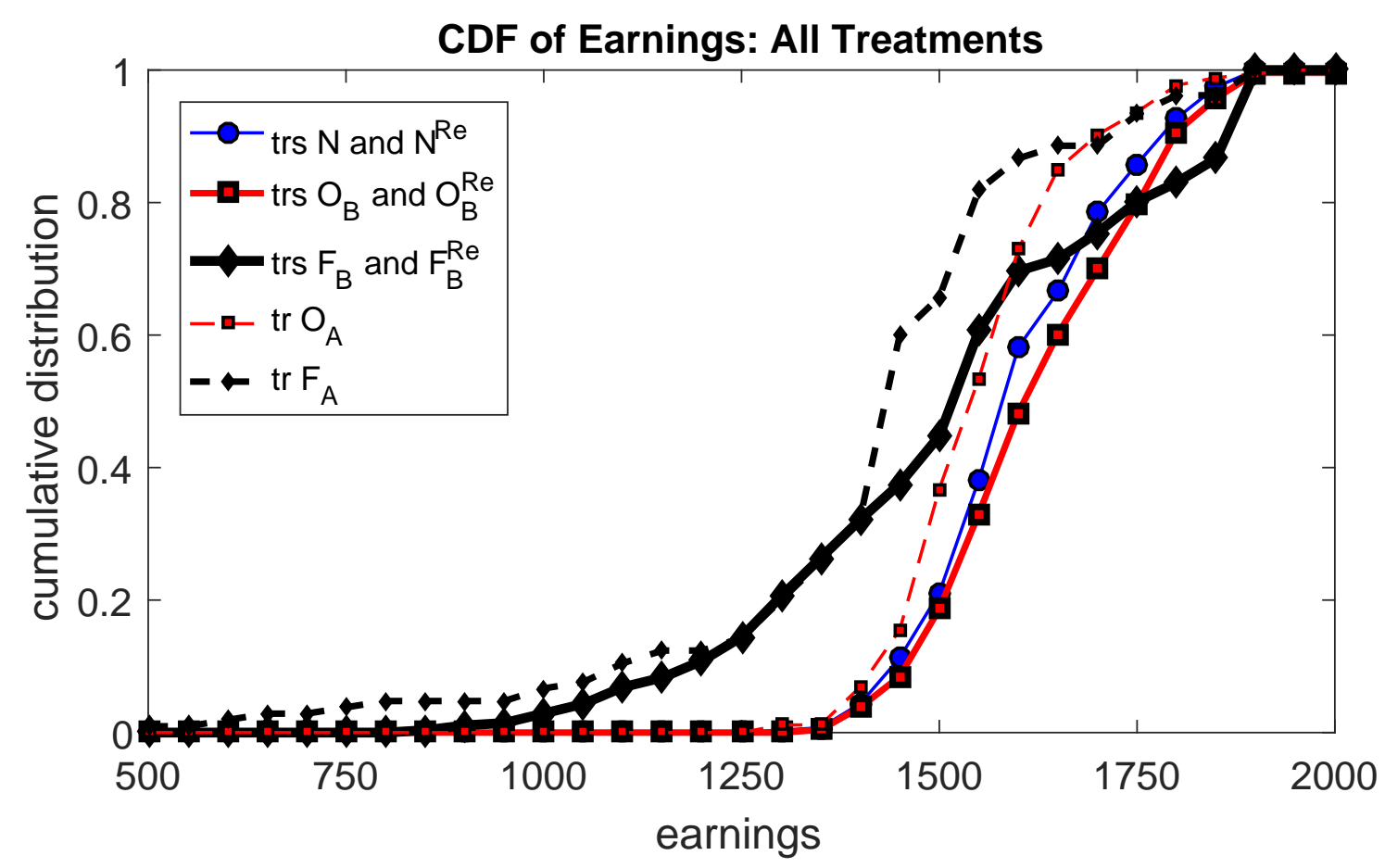

Figure 4: The empirical cumulative distribution of earnings.

To correct for this, we normalize the earnings by dividing the realized number of points every subject gets in each block by the realized number of points under ex-ante optimal behavior of investing in $B$ every period in the block. We will refer to these normalized earnings as efficiencies. ${ }^{28}$ The histograms of efficiencies are shown in Figure $5 .{ }^{29}$ Consistent with our earlier findings the histogram for the treatments without fees $\left(\mathbf{N}\right.$ and $\left.\mathbf{N}^{\mathbf{R e}}\right)$ is similar to the histogram for the treatments with an operating expenses fee for fund $B\left(\mathbf{O}_{\mathbf{B}}\right.$ and $\left.\mathbf{O}_{\mathbf{B}}^{\mathbf{R e}}\right)$. For treatment $\mathrm{O}_{\mathbf{A}}$ efficiencies tend to be lower, whereas for the front-end load treatments the dispersion in efficiencies is much larger than in the other treatments, with a substantial fraction of the efficiencies below 0.70 (whereas almost all efficiencies in the other treatments are higher than 0.70). Note that the histograms for the treatments without a fee, or with a fee for fund $B$, have a clear mode at 1 , whereas the histogram for treatment $\mathbf{O}_{\mathbf{A}}$ does not exhibit an obvious mode. The histogram for treatment $\mathbf{F}_{\mathbf{A}}$ does have a mode at 1 , but also a second mode at 0.7 .

The rest of the paper is devoted to testing the hypotheses formulated in Section 3. We will apply two types of statistical tests. First, we use the Mann-Whitney-Wilcoxon (MWW) test at subject level. This test allows us to determine the statistical significance of the differences between treatments in, for example, the number of times subjects invest in fund $B$ and in subjects' earnings. The $p$-values of the MWW test for various hypotheses are collected in Table 7 of Appendix B. Second, we use the Kolmogorov-Smirnov (KS) test to evaluate whether

\footnotetext{
${ }^{28}$ Note that this efficiency can be larger than 1 due to particular realizations of the returns.

${ }^{29}$ See Fig. 18 in Online Appendix D for the corresponding CDFs of efficiencies. This CDF of efficiencies is quite similar to the CDF of earnings from Fig. 4.
} 

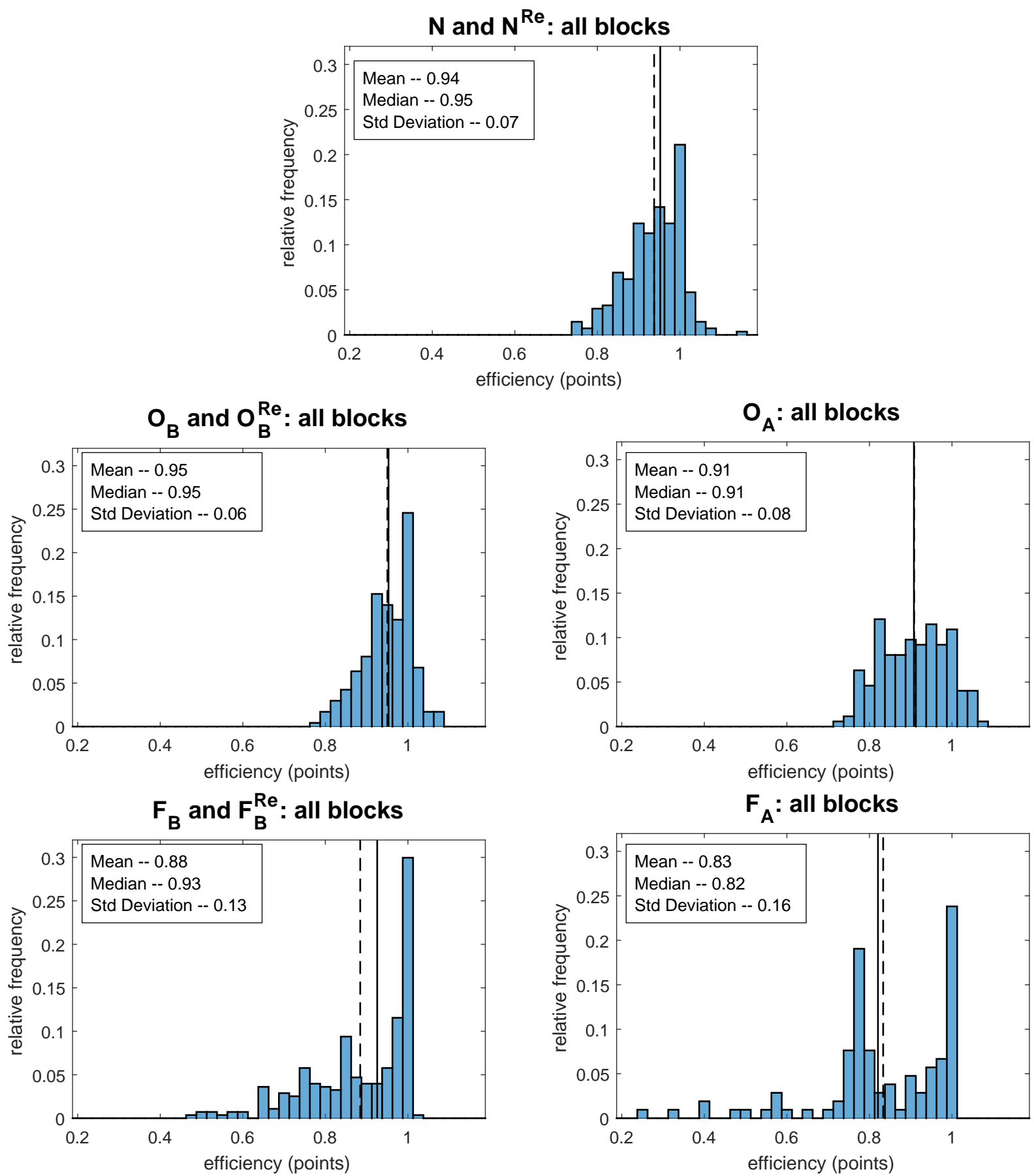

Figure 5: Histograms of efficiencies in different treatments.

distributions are statistically different or not. The $p$-values for the KS test can be found in Table 8 of Appendix B. We set the significance level at $5 \%$ for all tests.

\subsection{Operating Expenses Fees and Gross Return Illusion}

Visual inspection of Figures 3 and 5 suggests that behavior of subjects is not strongly affected when operating expenses fees have to be paid for fund $B$. There is a larger difference when 
the operating expenses have to be paid for fund $A$. This is confirmed by a closer look at Table 3. The mean and median of the number of choices for fund $B$ is slightly lower in each block of treatment $\mathbf{N}$ than in the corresponding block of $\mathbf{O}_{\mathbf{B}}$, but substantially higher than in the corresponding block of treatment $\mathbf{O}_{\mathbf{A}}$. Similarly, the mean number of choices for fund $B$ is higher in treatment $\mathbf{O}_{\mathbf{B}}^{\mathbf{R e}}$ than in treatment $\mathbf{N}^{\mathbf{R e}}$ for each block (although this is not true for the median).

The results of both the MWW and the KS test are consistent with this impression. When we specifically look at the number of choices for fund $B$, we find a significant difference when treatment $\mathbf{O}_{\mathbf{A}}$ is compared with either treatment $\mathbf{O}_{\mathbf{B}}$ or treatment $\mathbf{N}$. The differences between treatments $\mathbf{O}_{\mathbf{B}}$ and $\mathbf{N}$ and between treatments $\mathbf{O}_{\mathbf{B}}^{\mathbf{R e}}$ and $\mathbf{N}^{\mathbf{R e}}$ are not significant. We get the same results if we compare subjects' earnings and efficiencies between treatments (except for the difference in efficiencies between treatments $\mathbf{O}_{\mathbf{B}}^{\mathbf{R e}}$ and $\mathbf{N}^{\mathbf{R e}}$, which is significant - see Tables 7 and 8 in Appendix B, where we pool the data from the three blocks, for $p$-values of these tests). Thus we partly reject Hypothesis 1 .

Result 1. We find a significant difference in subjects' behavior between treatment $\mathbf{O}_{\mathbf{A}}$ on the one hand, and treatments $\mathbf{N}$ and $\mathbf{O}_{\mathbf{B}}$ on the other hand. Differences between treatments $\mathbf{N}$ and $\mathbf{O}_{\mathbf{B}}$ are not significant, and neither are the differences between treatments $\mathbf{N}^{\mathbf{R e}}$ and $\mathbf{O}_{\mathbf{B}}^{\mathbf{R e}}$.

This result suggests that subjects, to some extent, ignore the operating expenses fee and are driven by gross, instead of net, returns. Recall that, for each of these treatments, expected net returns are $3 \%$ and $4 \%$ for funds $A$ and $B$, respectively. Increasing expected gross return for a fund to exactly offset an operating expenses fee, increases the number of choices for that fund (fund $B$ in treatments $\mathbf{O}_{\mathbf{B}}$ and $\mathbf{O}_{\mathbf{B}}^{\mathbf{R e}}$ and fund $A$ in treatment $\mathbf{O}_{\mathbf{A}}$ ). The effect for $\mathbf{O}_{\mathbf{A}}$ is much larger than for treatments $\mathbf{O}_{\mathbf{B}}$ and $\mathbf{O}_{\mathbf{B}}^{\mathbf{R e}}$, where the effect is not significant. This is consistent with the fact that the operating expenses fee is twice as large in treatment $\mathbf{O}_{\mathbf{A}}$. Moreover, ignoring the operating expenses fee in treatment $\mathrm{O}_{\mathrm{B}}$ or $\mathrm{O}_{\mathrm{B}}^{\mathrm{Re}}$ does not change the ordering in the funds (fund $B$ is preferred over fund $A$ both on the basis of expected net returns $-4 \%$ versus $3 \%$ - and on the basis of expected gross returns - 5\% versus $3 \%$ ). However, ignoring the operating expenses fee in treatment $\mathbf{O}_{\mathbf{A}}$ reverses the ordering of the funds (fund $A$ now has an expected gross return $5 \%$ which is higher than $4 \%$ return of fund $B$, although in terms of expected net returns fund $B$ is still more attractive). This gross return illusion may explain why we find a significant difference when an operating expenses fee has to be paid for fund $A .^{30}$

\footnotetext{
${ }^{30}$ An alternative explanation may be that subjects interpret a (higher) fee for a fund as a signal of higher quality of that fund. Our current design is not very well suited to separate such a higher price means higher quality illusion from gross return illusion, although one would expect that the former also manifests itself in a significant difference between treatments $\mathbf{O}_{\mathbf{B}}\left(\mathbf{O}_{\mathrm{B}}^{\mathrm{Re}}\right)$ and $\mathbf{N}\left(\mathbf{N}^{\mathrm{Re}}\right)$.
} 


\subsection{Front-End Loads and Lock-in}

From Figure 3 we see that the means and medians of the number of choices for fund $B$ in the front-end load treatments $\left(\mathbf{F}_{\mathbf{B}}, \mathbf{F}_{\mathbf{B}}^{\mathbf{R e}}, \mathbf{F}_{\mathbf{A}}\right)$ are similar to those of their operating expenses counterparts $\left(\mathrm{O}_{\mathbf{B}}, \mathrm{O}_{\mathbf{B}}^{\mathrm{Re}}\right.$, and $\mathbf{O}_{\mathbf{A}}$, respectively), although the distributions of these choices are quite different. Indeed, the KS test reveals significant differences in the distributions between each front-end load treatment and the corresponding operating expenses treatment, whereas the MWW test finds no significant differences between the median number of choices for fund $B$. In contrast, median earnings and efficiencies in the front-end load treatments are lower than in the corresponding operating expenses treatments (see Table 3) and these differences are statistically significant (see Tables 7 and 8 in Appendix B). This apparent contradiction between the high number of choices for fund $B$ and low earnings may be explained by the large heterogeneity in the front-end load treatments, illustrated by the histograms of efficiencies in the lower panels of Figure 5. Some subjects do very well, but there are also many subjects with efficiencies that are quite low. ${ }^{31}$

Although fund $B$ is chosen most of the time in the majority of the treatments, fund $A$ is chosen quite often as well. In the treatments without a front-end load a vast majority of the subjects chooses fund $A$ now and then. In the front-end load treatments, on the other hand, we more often see that a subject chooses the same fund (either fund $A$ or fund $B$ ) for 15 consecutive periods (see Figure 3 ). In fact, a subject chooses the same fund for all periods in a block in $36.8 \%$ of the cases in treatments $\mathbf{F}_{\mathbf{B}}$ and $\mathbf{F}_{\mathbf{B}}^{\mathbf{R e}}$ and in $32.4 \%$ of the cases in treatment $\mathbf{F}_{\mathbf{A}}$. In most of these cases the subjects invest in the ex ante optimal fund $B$ for 15 periods, but not always. ${ }^{32}$ In contrast, for only $8.6 \%$ of the observations in treatments $\mathbf{N}, \mathbf{N}^{\mathbf{R e}}, \mathbf{O}_{\mathbf{B}}$ and $\mathbf{O}_{\mathbf{B}}^{\mathbf{R e}}$ a subject chooses the same fund for all 15 periods in a block; for treatment $\mathbf{O}_{\mathbf{A}}$ this number is especially low, $1.7 \%$.

Based upon the analysis above we conclude the following.

Result 2. We reject Hypothesis 2: there is a significant difference in subjects' behavior in the front-end load treatments, when compared to the corresponding operating expenses treatments. In particular, a substantially higher fraction of subjects makes decisions consistent with rational choice (investing in fund $B$ for all 15 periods) in the front-end load treatments.

We propose two possible explanations for the substantial difference between individual choices in the front-end load treatments and the other treatments. The first explanation relates

\footnotetext{
${ }^{31}$ Pooling all the data from the different front-end load treatments we find that in about $30 \%$ of the cases efficiency is lower than 0.80 , and in about $29 \%$ of the cases it is at least 1.00 . These numbers are $4 \%$ and $22 \%$, respectively, for all other treatments (i.e., without front-end load) combined.

${ }^{32}$ Investing for 15 consecutive periods in fund $B$ happens for $28.5 \%$ of all observations in treatments $\mathbf{F}_{\mathbf{B}}$ and $\mathbf{F}_{\mathbf{B}}^{\mathbf{R e}}$ and for $21 \%$ of all observations in treatment $\mathbf{F}_{\mathbf{A}}$.
} 


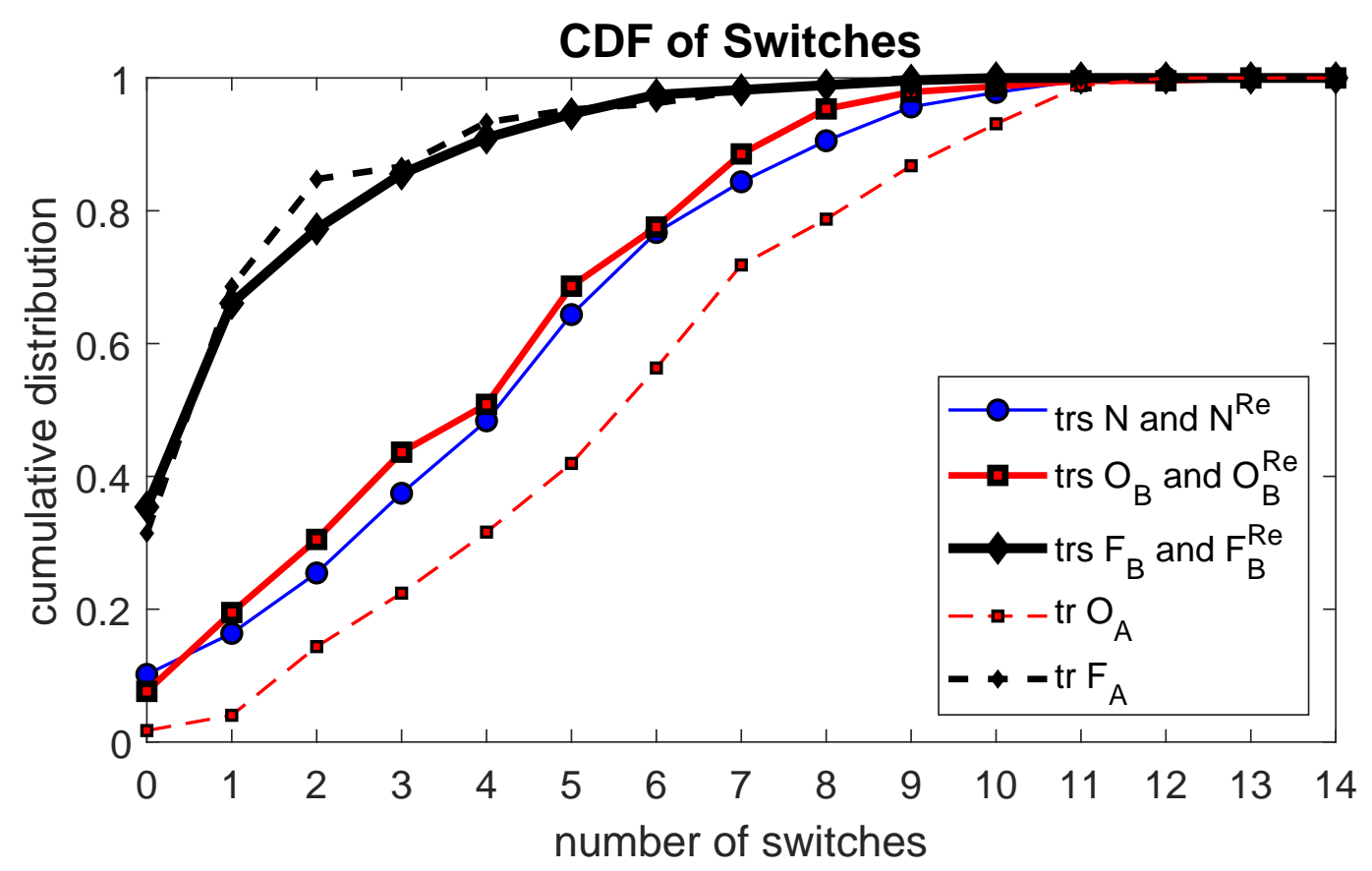

Figure 6: The empirical cumulative distribution of switches.

to the observation that after the front-end load is paid it is never optimal to invest in the other fund. The front-end load is a sunk cost and expected returns (excluding the front-end load) of the fund that charges the front-end load are always higher than those of the other fund. In the treatments where none of the funds charges a front-end load such a lock-in is absent. The second explanation is that subjects, given that they understand that switching between funds is prohibitively costly in the front-end load treatments, may exert more cognitive effort (see e.g. Brañas-Garza et al., 2012) in these treatments and conclude already at the start of the experiment that they should choose fund $B$ in every period.

Both explanations imply that the subjects are less likely to switch between funds in the frontend load treatments. To confirm this we plot the empirical cumulative distribution function (CDF) of the number of switches ${ }^{33}$ for different treatments in Figure 6. The empirical CDF for switches in treatments $\mathbf{F}_{\mathbf{B}}, \mathbf{F}_{\mathbf{B}}^{\mathbf{R e}}$ and $\mathbf{F}_{\mathbf{A}}$ is shifted to the left substantially, with respect to the empirical CDFs for switches in the other treatments. Moreover, the median number of switches in each block of each front-end load treatment is 1, whereas it ranges between 2.5 and 6.5 in the blocks of the other treatments (see the penultimate column of Table 3). ${ }^{34}$ The MWW and KS tests confirm that the number of switches and their distributions are significantly different when comparing the front-end load treatments with the other treatments, see Tables 7 and 8

\footnotetext{
${ }^{33}$ Switching is defined as a choice in period $t>1$ that is different from the choice made in period $t-1$. The maximum number of switches per block is 14 .

${ }^{34}$ The same conclusion can be drawn by considering the average number of switches per block. In treatments $\mathbf{N}, \mathbf{N}^{\mathbf{R e}}, \mathbf{O}_{\mathbf{B}}, \mathbf{O}_{\mathbf{B}}^{\mathbf{R e}}$ and $\mathbf{O}_{\mathbf{A}}$ this number (4.54, 4.52, 4.15, 4.27 and 5.98, respectively) is substantially higher than the average number of switches in treatments $\mathbf{F}_{\mathbf{B}}, \mathbf{F}_{\mathbf{B}}^{\mathbf{R e}}$ and $\mathbf{F}_{\mathbf{A}}$ (1.80, 1.33 and 1.47, respectively).
} 


\begin{tabular}{|c|c|c|c|c|c|c|c|c|c|}
\hline \multirow{2}{*}{ Treatment } & \multirow{2}{*}{ Block } & \multicolumn{7}{|c|}{ Number of times the front-load was paid } & \multirow{2}{*}{$\begin{array}{c}\text { Number of } \\
\text { observations }\end{array}$} \\
\hline & & 0 & 1 & 2 & 3 & 4 & 5 & 6 or more & \\
\hline \multirow{3}{*}{$\mathbf{F}_{\mathbf{B}}$} & Block 1 & 3 & 33 & 8 & 9 & 3 & 0 & 0 & 56 \\
\hline & Block 2 & 7 & 34 & 11 & 3 & 1 & 0 & 0 & 56 \\
\hline & Blocks 3 & 3 & 13 & 2 & 2 & 1 & 0 & 0 & 21 \\
\hline \multirow{4}{*}{$\mathbf{F}_{\mathrm{B}}^{\mathrm{Re}}$} & Block 2 & 8 & 25 & 11 & 3 & 1 & 0 & 0 & 48 \\
\hline & Block 1 & 2 & 40 & 5 & 1 & 0 & 0 & 0 & 48 \\
\hline & Blocks 3 & 0 & 43 & 4 & 0 & 1 & 0 & 0 & 48 \\
\hline & $\begin{array}{c}\text { All for fund } B \\
\text { (in } \% \text { out of } 277 \text { ) }\end{array}$ & $\begin{array}{c}23 \\
(8.3 \%)\end{array}$ & $\begin{array}{c}188 \\
(67.9 \%)\end{array}$ & $\begin{array}{c}41 \\
(14.8 \%)\end{array}$ & $\begin{array}{c}18 \\
(6.5 \%)\end{array}$ & $\begin{array}{c}7 \\
(2.53 \%)\end{array}$ & $\begin{array}{c}0 \\
(0 \%)\end{array}$ & $\begin{array}{c}0 \\
(0 \%)\end{array}$ & 277 \\
\hline \multirow{6}{*}{$\mathrm{F}_{\mathrm{A}}$} & Block 1 & 3 & 24 & 2 & 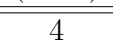 & 1 & 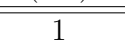 & 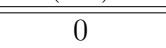 & 35 \\
\hline & Block 2 & 9 & 23 & 1 & 1 & 1 & 0 & 0 & 35 \\
\hline & Blocks 3 & 10 & 24 & 1 & 0 & 0 & 0 & 0 & 35 \\
\hline & $\begin{array}{c}\text { All for fund } A \\
\text { (in } \% \text { out of } 105 \text { ) }\end{array}$ & $\begin{array}{c}22 \\
(21.0 \%)\end{array}$ & $\begin{array}{c}71 \\
(67.6 \%)\end{array}$ & $\begin{array}{c}4 \\
(3.8 \%)\end{array}$ & $\begin{array}{c}5 \\
(4.8 \%)\end{array}$ & $\begin{array}{c}2 \\
(1.9 \%)\end{array}$ & $\begin{array}{c}1 \\
(1.0 \%)\end{array}$ & $\begin{array}{c}0 \\
(0 \%)\end{array}$ & 105 \\
\hline & & \multicolumn{7}{|c|}{ Number of $B$-runs started in block } & Number of \\
\hline & & 0 & 1 & 2 & 3 & 4 & 5 & 6 or more & observations \\
\hline $\mathbf{N}$ & $\begin{array}{c}\text { All } \\
\text { (in } \% \text { out of } 134 \text { ) }\end{array}$ & $\begin{array}{c}2 \\
(1.5 \%)\end{array}$ & $\begin{array}{c}22 \\
(16.4 \%)\end{array}$ & $\begin{array}{c}31 \\
(23.1 \%)\end{array}$ & $\begin{array}{c}43 \\
(32.1 \%)\end{array}$ & $\begin{array}{c}21 \\
(15.7 \%)\end{array}$ & $\begin{array}{c}14 \\
(10.4 \%)\end{array}$ & $\begin{array}{c}1 \\
(0.7 \%)\end{array}$ & 134 \\
\hline $\mathrm{N}^{\mathrm{Re}}$ & $\begin{array}{c}\text { All } \\
\text { (in } \% \text { out of } 141 \text { ) }\end{array}$ & $\begin{array}{c}3 \\
(2.1 \%)\end{array}$ & $\begin{array}{c}26 \\
(18.4 \%)\end{array}$ & $\begin{array}{c}33 \\
(23.4 \%)\end{array}$ & $\begin{array}{c}32 \\
(22.7 \%)\end{array}$ & $\begin{array}{c}31 \\
(22.0 \%)\end{array}$ & $\begin{array}{c}13 \\
(9.2 \%)\end{array}$ & $\begin{array}{c}3 \\
(2.1 \%)\end{array}$ & 141 \\
\hline $\mathrm{O}_{\mathrm{B}}$ & $\begin{array}{c}\text { All } \\
\text { (in \% out of 104) }\end{array}$ & $\begin{array}{c}1 \\
(1.0 \%)\end{array}$ & $\begin{array}{c}26 \\
(25.0 \%)\end{array}$ & $\begin{array}{c}25 \\
(24.0 \%)\end{array}$ & $\begin{array}{c}27 \\
(26.0 \%)\end{array}$ & $\begin{array}{c}20 \\
(19.2 \%)\end{array}$ & $\begin{array}{c}2 \\
(1.9 \%)\end{array}$ & $\begin{array}{c}3 \\
(2.9 \%)\end{array}$ & 104 \\
\hline \multirow[t]{3}{*}{$\mathrm{O}_{\mathrm{B}}^{\mathrm{Re}}$} & $\begin{array}{c}\text { All } \\
\text { (in } \% \text { out of 132) }\end{array}$ & $\begin{array}{c}0 \\
(0 \%)\end{array}$ & $\begin{array}{c}27 \\
(20.5 \%)\end{array}$ & $\begin{array}{c}31 \\
(23.5 \%)\end{array}$ & $\begin{array}{c}37 \\
(28.0 \%)\end{array}$ & $\begin{array}{c}26 \\
(19.7 \%)\end{array}$ & $\begin{array}{c}10 \\
(7.6 \%)\end{array}$ & $\begin{array}{c}1 \\
(0.8 \%)\end{array}$ & 132 \\
\hline & & \multicolumn{7}{|c|}{ Number of $A$-runs started in block } & Number of \\
\hline & & 0 & 1 & 2 & 3 & 4 & 5 & 6 or more & observations \\
\hline $\mathrm{O}_{\mathrm{A}}$ & $\begin{array}{c}\text { All } \\
(\% \text { out of } 174)\end{array}$ & $\begin{array}{c}3 \\
(1.7 \%)\end{array}$ & $\begin{array}{c}10 \\
(5.7 \%)\end{array}$ & $\begin{array}{c}34 \\
(19.5 \%)\end{array}$ & $\begin{array}{c}42 \\
(24.1 \%)\end{array}$ & $\begin{array}{c}52 \\
(29.9 \%)\end{array}$ & $\begin{array}{c}21 \\
(12.1 \%)\end{array}$ & $\begin{array}{c}12 \\
(6.9 \%)\end{array}$ & 174 \\
\hline
\end{tabular}

Table 4: The number of times subjects started to invest to fund $B$ (or fund $A$ for treatments $\mathbf{F}_{\mathbf{A}}$ and $\mathbf{O}_{\mathbf{A}}$ ) by choosing it in the first period of block or by switching from the other choice. For treatments $\mathbf{F}_{\mathbf{B}}, \mathbf{F}_{\mathbf{B}}^{\mathbf{R e}}$ and $\mathbf{F}_{\mathbf{A}}$, this is the number of times the subjects paid the front-end load fee. The last column gives the total number of individual observations.

in Appendix B. ${ }^{35}$

As mentioned above, it can never be optimal to pay the front-end load more than once. We now investigate which fraction of the subjects in treatments $\mathbf{F}_{\mathbf{B}}, \mathbf{F}_{\mathbf{B}}^{\mathbf{R e}}$ and $\mathbf{F}_{\mathbf{A}}$ seem to understand this. Table 4 shows how often subjects in those treatments pay the front-end load, that is, how often they start to invest in fund $B$ for treatments $\mathbf{F}_{\mathbf{B}}$ and $\mathbf{F}_{\mathbf{B}}^{\mathbf{R e}}$ and in fund $A$ for treatment $\mathbf{F}_{\mathbf{A}}$. For reference, in the lower part of Table 4 we show how often subjects in the treatments without front-end load start a "run" of one or more periods of investing in fund $B$ (or fund $A$ for treatment $\mathbf{O}_{\mathbf{A}}$ ), which they can do free of an explicit charge.

Table 4 again reveals a large contrast between treatments with a front-end load and the other treatments. In the treatments without a front-end load the number of times subjects start to invest in fund $B$ (fund $A$ for treatment $\mathbf{O}_{\mathbf{A}}$ ) is often 2,3 or 4 in a block; these account

\footnotetext{
${ }^{35}$ One reason for subjects to switch relatively often in treatments where no front-end load needs to be paid may also be that, even if a subject understands that choosing $B$ in every period is the optimal decision, he/she is still curious about what happens if $A$ is chosen instead, which is not very costly in these treatments. See, for example, Blume and Ortmann (2007), who find that subjects may feel curious about other actions and deviate from the efficient equilibrium even after they have played it for a long time.
} 
for about $70 \%$ of the observations. For only $16 \%$ of the observations subjects invest in fund $B$ (fund $A$ in $\mathbf{O}_{\mathbf{A}}$ ) exactly once. In contrast, in a majority of the observations (68\%) from the front-end load treatments, subjects invest only once in the fund that charges a fee. This finding is consistent with the lock-in explanation given above. Support for the cognitive effort argument is weaker. First, in almost a quarter $(23.8 \%)$ of the blocks in treatments $\mathbf{F}_{\mathbf{B}}$ and $\mathbf{F}_{\mathbf{B}}^{\mathbf{R e}}$ subjects pay the front-end load more than once, which is clearly suboptimal. This even happens in $11.4 \%$ of the blocks in treatment $\mathbf{F}_{\mathbf{A}}$, where the front-end load is much higher. ${ }^{36}$ Second, in treatment $\mathbf{F}_{\mathbf{A}}$ paying the front-load fee is never optimal, and yet a vast majority of subjects $(79 \%)$ do it.

We identified a substantial number of subjects who invest exactly once in the fund for which a front-end load is charged. Another question is how long these subjects stay in this fund. Recall that for treatments $\mathbf{F}_{\mathbf{B}}$ and $\mathbf{F}_{\mathbf{B}}^{\mathbf{R e}}$ the expected returns are maximized when the subject invests in fund $B$ for all 15 periods. The front-end load is recovered (in expectation) if the subject invests for at least eight consecutive periods in fund $B$. For $\mathbf{F}_{\mathbf{A}}$ it is never optimal to invest in fund $A$, but as soon as a subject invests in that fund it is suboptimal to switch back to fund $B$.

It turns out that of the 188 cases in treatments $\mathbf{F}_{\mathbf{B}}$ and $\mathbf{F}_{\mathbf{B}}^{\mathbf{R e}}$ where a subject only started to invest in fund $B$ once, $79(42 \%)$ lasted for the full block of 15 periods. ${ }^{37}$ This behavior is consistent with the cognitive effort hypothesis. In 111 (59\%) of these 188 cases the investment lasted for at least 13 periods and for 148 (79\%) of these cases it lasted at least eight periods (that is, in expectation, the front-end load is recovered from the investment). Summarizing, those subjects in treatments $\mathbf{F}_{\mathbf{B}}$ and $\mathbf{F}_{\mathbf{B}}^{\mathbf{R e}}$ that understand that they should pay the front-end load not more than once will typically get locked into fund $B$, resulting in high payoffs. The subjects that pay the front-end load more than once are unlikely to obtain a good payoff.

Lock-in into the fund that charges a front-end load may also occur when that fund is not the optimal choice. In fact, in 71 of the 105 cases $(68 \%)$ in treatment $\mathbf{F}_{\mathbf{A}}$, the subject invests in fund $A$ exactly once, which is very similar to treatments $\mathbf{F}_{\mathbf{B}}$ and $\mathbf{F}_{\mathbf{B}}^{\mathbf{R e}}$. In 12 of these 71 cases $(17 \%)$ the investment takes 15 periods and in 31 cases (44\%) it takes at least 13 periods. Investments in the front-end load fund, conditional on that there is only one such investment by the subject, therefore tend to last not as long as in treatments $\mathbf{F}_{\mathbf{B}}$ and $\mathbf{F}_{\mathbf{B}}^{\mathbf{R e}}$, although - once locked in - it is still optimal to stay with that fund. ${ }^{38}$ Note that, after paying the front-end

\footnotetext{
${ }^{36}$ The highest expected payoff for paying the front-end load twice - by investing for only one period in fund $A$, in between two longer investment runs in fund $B$ - equals 1470 points, which is lower than the expected number of points (1512) from investing in fund $A$ in every period. For treatment $\mathbf{F}_{\mathbf{A}}$ paying the front-end load twice gives a highest expected return of 1133 points. Paying the front-end load even more than twice will obviously decrease earnings only further.

${ }^{37}$ These 79 cases correspond to $28.5 \%$ of all 277 individual blocks in treatments $\mathbf{F}_{\mathbf{B}}$ and $\mathbf{F}_{\mathbf{B}}^{\mathbf{R e}}$. In treatments $\mathbf{N}, \mathbf{N}^{\mathbf{R e}}, \mathbf{O}_{\mathbf{B}}, \mathbf{O}_{\mathbf{B}}^{\mathbf{R e}}$ together only in 35 of the 511 blocks $(6.8 \%)$ the subject invested in fund $B$ for all periods.

${ }^{38}$ The mean duration of the investments in the front-end load fund - if there is a single investment - is 11.4
} 
load, the difference between expected returns in treatment $\mathbf{F}_{\mathbf{A}}$ is $1 \%$, whereas this difference is $2 \%$ in treatments $\mathbf{F}_{\mathbf{B}}$ and $\mathbf{F}_{\mathbf{B}}^{\mathbf{R e}}$, see Table 1. This may explain why subjects are locked-in for a longer period on average in the latter treatments than in the former.

A final remarkable finding is that in treatment $\mathbf{F}_{\mathbf{A}}$ a substantial number of subjects make the optimal choice of never investing in fund $A$. This happens in 22 out of 105 cases $(21 \%)$, which is much more often than in any of the treatments where no front-end load is charged. This suggests that some subjects consistently choose the optimal fund because the suboptimal fund charges a front-end load. This may be due to higher cognitive efforts by those subjects, although the lock-in effect seems to be much stronger. ${ }^{39}$ Note that expected earnings for these 22 cases are substantially higher than the expected earnings of investing in fund $A$ at least once (since the latter are bounded from above by always investing in fund $A$ ). This explains the low average and median profits in treatment $\mathbf{F}_{\mathbf{A}}$ : in a vast majority of the cases individual earnings are low, either because the subject is locked-in in the suboptimal fund, or because the subject pays the front-end load more than once.

Our analysis reveals a substantial heterogeneity between subjects behavior in the front-end load treatments. On the one hand, many subjects understand that they should not pay the front-end load more than once, and therefore get locked-in into the front-end load fund. This also happens regularly when it is the inferior fund that charges the front-end load, suggesting that the lock-in effect is stronger than the cognitive effort effect (although there is a substantial number of subjects that steer clear from the inferior fund, when that fund charges a front-end load). On the other hand, there are also quite some subjects that do pay the front-end load more than once, which is clearly suboptimal.

To investigate whether we can explain that behavior by the subjects' individual characteristics, we collected data on age and gender and, for the sessions that we ran in 2017, we also measured the subjects' cognitive ability by letting subjects take the Cognitive Reflection Test (see Frederick, 2005, for a description). We conjecture that subjects with a lower CRT score are more inclined to pay the front-end load more than once. To analyze that we classify subjects as 'non-switchers' if they pay the front-end load at most once in each of the three blocks, and as 'switchers' otherwise. We estimate a logit model to try to explain the probability that a subject is a switcher by his/her age, gender and CRT score. However, the coefficient for the CRT score is not statistically significant and neither are the coefficients on age and gender, see Table 9 in Appendix B.

periods for treatments $\mathbf{F}_{\mathbf{B}}$ and $\mathbf{F}_{\mathbf{B}}^{\mathbf{R e}}$ combined, and 10.3 periods for treatment $\mathbf{F}_{\mathbf{A}}$; the median length is 14 periods for $\mathbf{F}_{\mathbf{B}}$ and $\mathbf{F}_{\mathbf{B}}^{\mathbf{R e}}$ combined and 11 periods for $\mathbf{F}_{\mathbf{A}}$.

${ }^{39} \mathrm{An}$ alternative explanation is that subjects want to avoid the large and very salient front-end load. However, if that would be the case we should also see much more subjects in treatments $\mathbf{F}_{\mathbf{B}}$ and $\mathbf{F}_{\mathbf{B}}^{\mathbf{R e}}$ only investing in fund $A$. This only happens in 23 of the 277 cases $(8.3 \%)$ in these treatments. 


\subsection{Differences between Blocks: Learning and Return Chasing}

In this section we take a more detailed look at the differences between blocks within treatments. We have seen that this difference can be substantial, as for example in treatments $\mathbf{O}_{\mathbf{B}}^{\mathbf{R e}}$ and $\mathbf{F}_{\mathbf{B}}^{\mathbf{R e}}$, where the median number of choices for fund $B$ is 7 in the first block and 13 and 14, respectively, in the third block, see Table 3. Indeed, when we consider pairwise differences in the number of choices for fund $B$ between blocks in the same treatment (i.e., comparing, for each treatment, Blocks 1 and 2, Blocks 2 and 3 and Blocks 1 and 3) we find that 10 of these 24 differences are statistically significant, according to the MWW test. Only for treatments $\mathbf{F}_{\mathbf{B}}$, $\mathbf{O}_{\mathbf{A}}$ and $\mathbf{F}_{\mathbf{A}}$ none of the three differences are significant. ${ }^{40}$ From this we conclude the following.

Result 3. We reject Hypothesis 3: there exist significant differences in the number of times subjects choose fund $B$ between at least two blocks in five of the eight treatments.

Figure 7 sheds some light on the dynamics of subjects' behavior. It plots, for each treatment, the time series of the fraction of subjects choosing $B$ in the three blocks (in the order in which subjects experience these blocks - the blocks are separated by the dashed vertical lines). Figure 7 illustrates that differences between and within blocks indeed exist.

As mentioned in Section 3 there may be two explanations for the differences between blocks. When subjects go from one block to the next they (i) have gained more experience with the experiment; and (ii) are subjected to a new realization of the time series of returns. From the additional experience with the experiment subjects may learn that it is optimal to invest in fund $B$. Indeed, it follows from Table 3, and is illustrated by Figure 7, that the median and mean of the number of choices for fund $B$ is highest in the third block for five of the eight treatments (the exceptions are treatments $\mathbf{F}_{\mathbf{B}}, \mathbf{O}_{\mathbf{A}}$ and $\mathbf{F}_{\mathbf{A}}$ again). Moreover, for many blocks the fraction of choices for fund $B$ seems to increase during the block (note that period-to-period variations in this fraction are lower in the front-end load treatments than in the other treatments, due to the lock-in discussed above).

Alternatively, variations in realized returns during a block may also explain the differences in subjects' behavior. Although the time series in the different blocks are generated by the same underlying data generating process, subjects may be (partly) driven by return chasing, that is, a tendency to choose the fund that had a larger (gross) return in the previous period. This is supported by the observation that for seven of the eight treatments the median number

\footnotetext{
${ }^{40}$ In particular, all three differences in treatment $\mathbf{O}_{\mathrm{B}}^{\mathbf{R e}}$ are significant, as are two of the three differences in each of the treatments $\mathbf{N}, \mathbf{N}^{\mathbf{R e}}$ and $\mathbf{F}_{\mathbf{B}}^{\mathbf{R e}}$, and one difference in treatment $\mathbf{O}_{\mathbf{B}}$. See Table 7 in Appendix B. The $\mathrm{KS}$ test is broadly consistent with this finding, although the difference in treatment $\mathbf{O}_{\mathbf{B}}$ is not significant at the $5 \%$ level according to that test (but it is significant at the $10 \%$ level, see Table 8 in Appendix B). Note that when comparing the number of choices for fund $B$ from Blocks 1 or 2 with Block 3 we only use data from the sessions from 2017.
} 

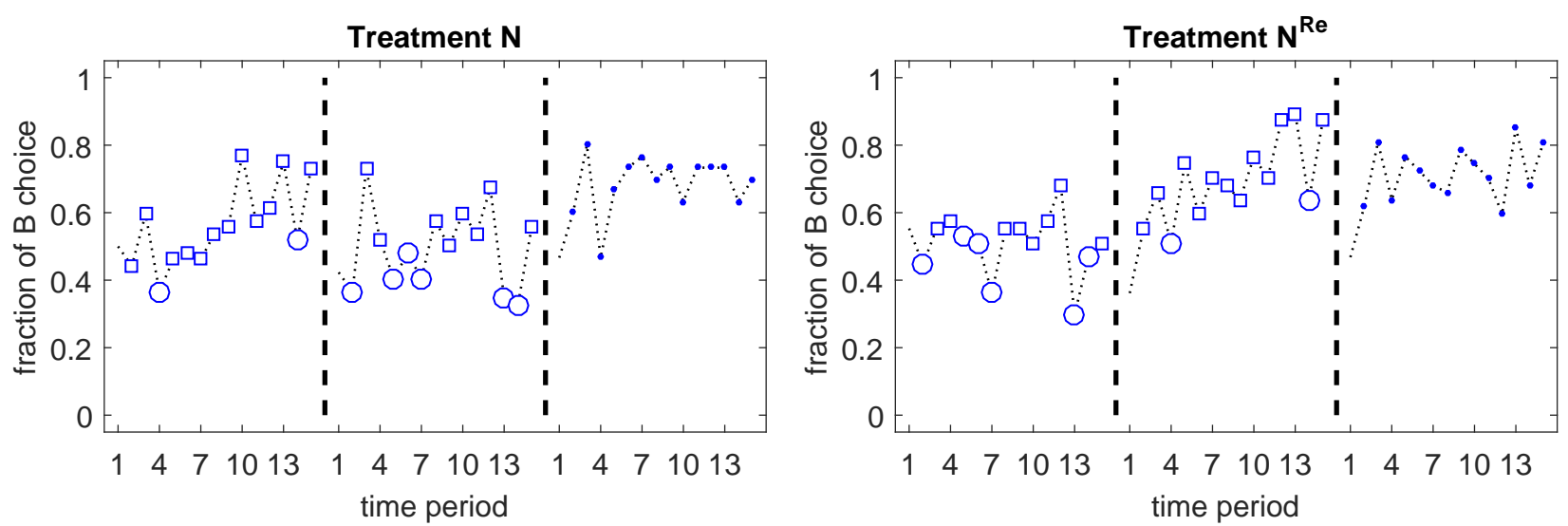

Treatment $O_{B}$
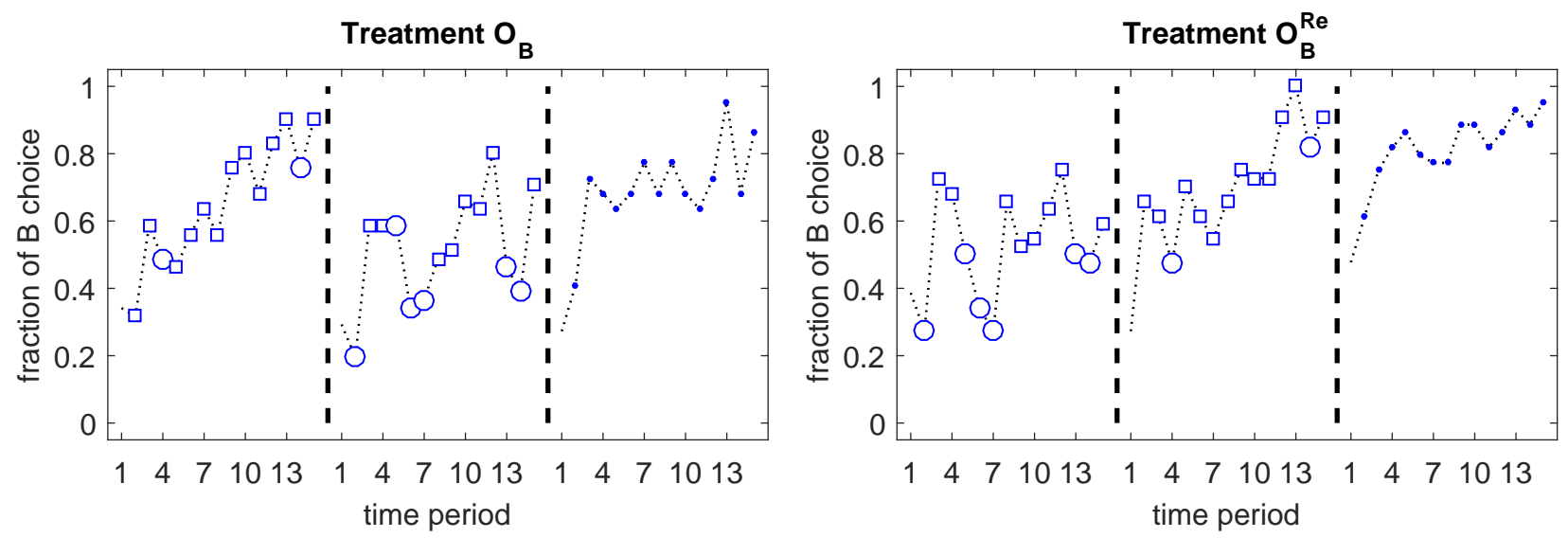

Treatment $\mathrm{F}_{\mathrm{B}}$
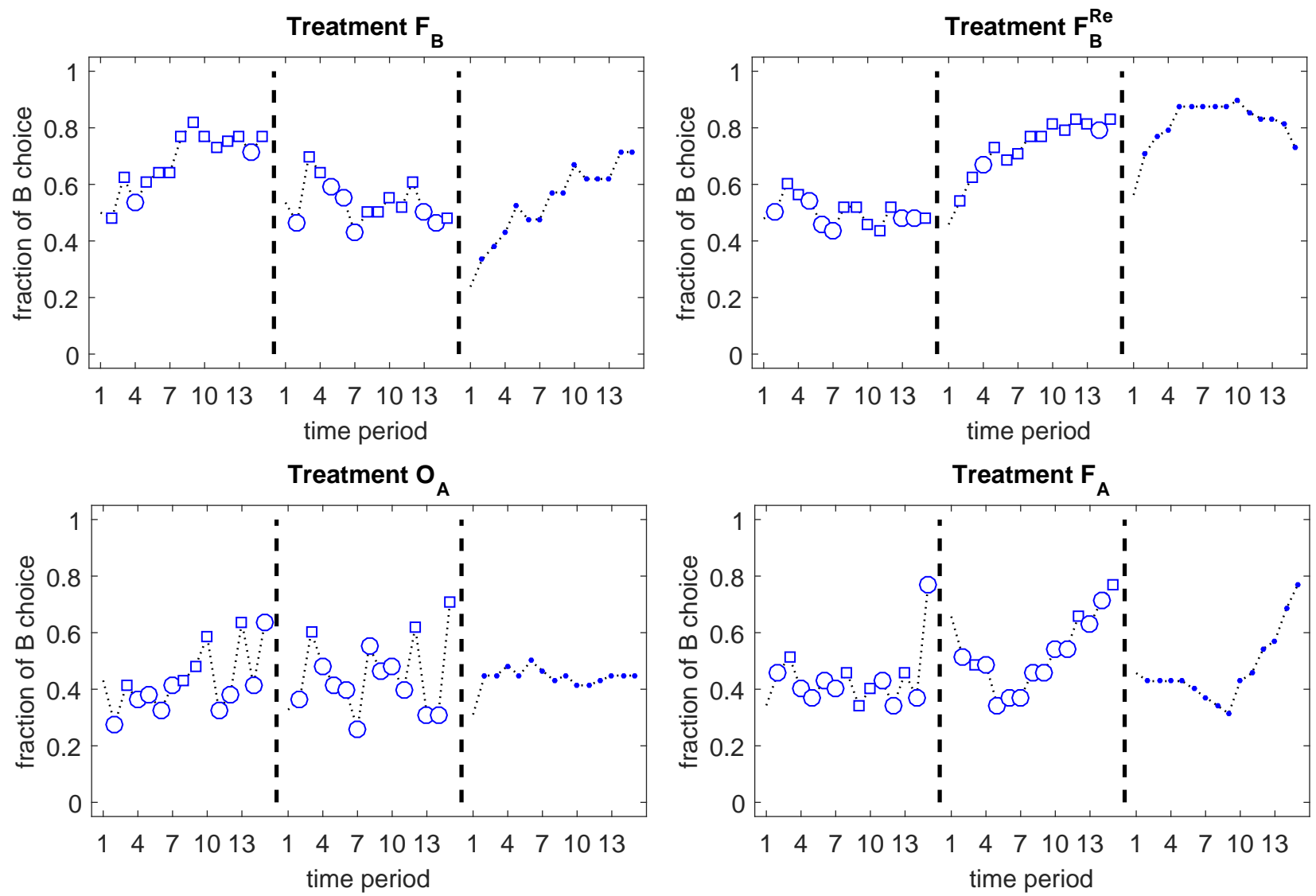

Figure 7: The time series of fraction of the $B$-choices (the blocks are divided by the vertical dashed lines). For the first two blocks the circled markers indicate those instances when in the previous period the realized gross return of $A$ was larger than the realized gross return of $B$. The squares indicate instances where in the previous period the realized gross return of fund $B$ was larger than that of fund $A$. 
of choices for fund $B$ is higher for the time series of returns used in Block 1 than for those used in Block 2 (recall that for the reverse order treatments the time series used in the first and second block are swapped, and that relative performance of fund $A$ is higher in Block 2 than in Block 1). Four of these differences are significant, according to the MWW test. Also note that the increase in the fraction of subjects choosing fund $B$ during the block seems to be more pronounced in blocks where the time series of returns from Block 1 are used than in the blocks where the time series from Block 2 are used. This suggests that, as subjects receive more information during the block that fund $B$ is the better choice, it becomes increasingly likely that they choose fund $B$.

The three reverse order treatments allow for a direct test of the effect of experience. In particular, if experience with another block does not have an effect then subjects' behavior in the first block of, e.g., treatment $\mathbf{N}$ should not be significantly different from subjects' behavior in the second block of treatment $\mathbf{N}^{\mathbf{R e}}$, where the same time series of realized returns is used. It turns out that of the six comparisons of a block in a reverse order treatment with its counterpart in the corresponding benchmark treatment the only significant difference is for the time series of returns used in Block 2 in treatments $\mathbf{N}$ and $\mathbf{N}^{\mathbf{R e}}{ }^{41}$ Therefore there is only a weak effect of the order in which time series are presented to the subjects in the first two blocks, which suggests that subjects do not learn between the first and second block. As an additional test of learning we consider subjects' behavior in the third block. The realized differences in returns between funds $B$ and $A$ for the times series used in Block 3 are higher, on average, than for the time series used in Block 2, but lower than for those used in Block 1 (see Table 2). If learning does not effect subjects' behavior, but the realization of the returns does, then the number of choices for fund $B$ in Block 3 should be higher than in Block 2, but lower than in Block 1. Indeed, the median of the number of choices for fund $B$ is higher in Block 3 than in Block 2 for all but two treatments. For four of these treatments these differences, which are consistent with learning and with return chasing, are significant. However, the number of choices for fund $B$ is also higher in Block 3 than in Block 1 for four treatments (with the difference significant for treatments $\mathbf{N}$ and $\mathbf{O}_{\mathbf{B}}^{\mathbf{R e}}$ ) which is not consistent with return chasing, but can be explained by learning. Taken together, these results suggest that learning between blocks does play a role, but that its effect is larger from the second to the third block than from the first to the second block. Further evidence for learning is provided by the front-end load treatments, where the fraction of subjects paying the front-end load more than once decreases over the three blocks, see Table $4 .^{42}$

\footnotetext{
${ }^{41}$ According to both the MWW and KS test, see the last six rows of Tables 7 and 8 in the appendix.

${ }^{42} \mathrm{~A}$ fraction of $34 \%$ of the subjects in treatments $\mathbf{F}_{\mathbf{B}}$ and $\mathbf{F}_{\mathbf{B}}^{\mathbf{R e}}$ pay the front-end load at least two times in the first block they experience, but this percentage decreases to $20 \%$ in the second block and to $14 \%$ in the third block. A similar effect occurs for treatment $\mathbf{F}_{\mathbf{A}}$, where the fraction of subjects paying the front-end load at least twice decreases from $23 \%$ in the first block to $9 \%$ in the second block and $3 \%$ in the third block.
} 


\begin{tabular}{c|c|c|c|c}
\hline \hline Treatment & Block 1 & Block 2 & Block 3 & All \\
\hline $\mathbf{N}$ & $44.23 \%(56.18 \%)$ & $38.78 \%(50.14 \%)$ & $51.94 \%(68.81 \%)$ & $43.84 \%(56.66 \%)$ \\
$\mathbf{N}^{\mathbf{R e}}$ & $57.45 \%(70.21 \%)$ & $43.62 \%(50.91 \%)$ & $49.47 \%(71.88 \%)$ & $50.18 \%(64.34 \%)$ \\
\hline $\mathbf{O}_{\mathbf{B}}$ & $62.20 \%(66.03 \%)$ & $39.02 \%(52.26 \%)$ & $45.08 \%(70.78 \%)$ & $49.44 \%(61.61 \%)$ \\
$\mathbf{O}_{\mathbf{B}}^{\mathbf{R e}}$ & $64.77 \%(72.24 \%)$ & $39.39 \%(53.41 \%)$ & $67.05 \%(82.95 \%)$ & $57.07 \%(69.53 \%)$ \\
$\mathbf{O}_{\mathbf{A}}$ & $39.08 \%(43.35 \%)$ & $40.28 \%(45.44 \%)$ & $41.73 \%(44.83 \%)$ & $40.36 \%(44.54 \%)$ \\
\hline $\mathbf{F}_{\mathbf{B}}$ & $62.50 \%(68.75 \%)$ & $50.00 \%(53.57 \%)$ & $46.03 \%(55.10 \%)$ & $54.64 \%(60.20 \%)$ \\
$\mathbf{F}_{\mathbf{B}}^{\mathbf{R e}}$ & $72.92 \%(74.11 \%)$ & $48.26 \%(50.00 \%)$ & $82.29 \%(82.89 \%)$ & $67.82 \%(69.00 \%)$ \\
$\mathbf{F}_{\mathbf{A}}$ & $44.13 \%(43.88 \%)$ & $49.35 \%(52.45 \%)$ & $43.39 \%(47.14 \%)$ & $45.62 \%(47.82 \%)$ \\
\hline \hline
\end{tabular}

Table 5: The fraction of choices for fund $B$ in periods that immediately follow a period where the realized return of $A$ was larger than that of fund realized return of $B$. The fraction in parentheses refer to the (unconditional) fraction of choices for fund $B$ in periods $2-15$ of that block.

We continue by investigating whether part of subjects' behavior can be explained by return chasing as well. To start with, the markers in the first two blocks in each panel of Figure 7 characterize the realized returns of funds $A$ and $B$ from the previous period. In particular, circles indicate when the gross return of fund $A$ was higher than that of fund $B$ in the previous period, and squares refer to instances where the gross return of fund $B$ was higher than that of fund $A .{ }^{43}$ Using these markers we see that, at least in the first two blocks, there is a tendency for the fraction of subjects choosing fund $B$ to be low after a period in which fund $A$ had a higher return than fund $B$, suggesting that return chasing indeed helps in explaining subjects' behavior. This suggestion of return chasing is quantified in Table 5. This table shows, for each treatment and block, the fraction of choices for fund $B$ in periods immediately preceded by a period in which the return for fund $A$ was higher than that of fund $B$. The numbers in parentheses indicate the fraction of choices for fund $B$ in all periods in that block (where we excluded the first period in each block, to facilitate comparisons).

Table 5 shows that for each treatment the fraction of choices for fund $B$ is smaller after a positive return difference for fund $A$, with the effect particularly strong in treatments $\mathbf{N}, \mathbf{N}^{\mathbf{R e}}$, $\mathbf{O}_{\mathbf{B}}, \mathbf{O}_{\mathbf{B}}^{\mathbf{R e}}$, and return chasing therefore indeed seems to play an important role in subjects' behavior. Note that in the treatments where a fee is paid for fund $A$ (i.e., treatments $\mathbf{O}_{\mathbf{A}}$ and $\mathbf{F}_{\mathbf{A}}$ ) the fraction of choices for fund $A$ are higher than in the other treatments, as discussed above (see, e.g., Table 3). This can also be explained in part by return chasing, as it occurs

\footnotetext{
${ }^{43}$ Note that, because subjects experience different time series in the third block of the experiment, we cannot characterize periods in that block in this way.
} 
more often in these treatments that the gross return in the previous period was higher for fund $A$ than for fund $B$.

Both learning and return chasing therefore seem to play a role in the differences between blocks in the same treatment. In order to capture these two effects we estimate, for each treatment, the following logit or discrete choice model:

$$
n_{B, t}=\frac{\exp \left(\beta_{0}+\beta_{1}\left(r_{B, t-1}-r_{A, t-1}\right)+\beta_{2} \sum_{s=1}^{t-1}\left(r_{B, s}-r_{A, s}\right)+\beta_{3} t+\beta_{4} B_{2}+\beta_{5} B_{3}\right)}{1+\exp \left(\beta_{0}+\beta_{1}\left(r_{B, t-1}-r_{A, t-1}\right)+\beta_{2} \sum_{s=1}^{t-1}\left(r_{B, s}-r_{A, s}\right)+\beta_{3} t+\beta_{4} B_{2}+\beta_{5} B_{3}\right)} .
$$

Here $n_{B, t}$ is the fraction of subjects choosing fund $B$ in period $t$ in that treatment, $r_{A, t-1}$ and $r_{B, t-1}$ are the realized gross returns (in decimals) of funds $A$ and $B$ in period $t-1$, respectively, $t \in\{2, \ldots, 15\}$ is the period in the block, and $B_{2}\left(B_{3}\right)$ is a dummy variable that equals 1 if the observation is from the second block (the third block) the subject experiences, and 0 otherwise. The coefficient $\beta_{0}$ represents a predisposition towards choosing fund $B$ and the coefficient $\beta_{1}$, sometimes referred to as the intensity of choice, captures how sensitive subjects are with respect to the return difference from the previous period. ${ }^{44}$ As argued above, the fraction of subjects choosing fund $B$ may increase during the block if information that fund $B$ is the better choice accumulates as the block evolves. This effect is measured by coefficient $\beta_{2}$. The coefficient $\beta_{3}$ measures whether, during the block, subjects learn to choose fund $B$, independent of the past returns of the funds in that block. The coefficients $\beta_{4}$ and $\beta_{5}$ measure whether there is learning between blocks. Given our discussion above we expect that both return chasing and learning within and between blocks help explain the fraction of subjects choosing fund $B$. That is, we expect that $\beta_{1}>0$ and that either $\beta_{2}>0$ or $\beta_{3}>0$. Moreover, we expect that the effect of learning between blocks is higher from the second to the third block than from the first to the second block (where learning seems to be limited), which would mean that $\beta_{5}>2 \beta_{4} \geq 0$.

Table 6 gives the results of the estimations, which - to a considerable extent - are in line with the discussion above. First, consider treatments $\mathbf{N}, \mathbf{N}^{\mathbf{R e}}, \mathbf{O}_{\mathbf{B}}$ and $\mathbf{O}_{\mathbf{B}}^{\mathbf{R e}}$. These treatments are characterized by return chasing ( $\beta_{1}$ positive and strongly significant), learning within blocks through return differences ( $\beta_{2}$ positive and significant, but $\beta_{3}$ not significant) and learning between blocks most prevalent from the second to the third block ( $\beta_{5}$ positive and significant, but $\beta_{4}$ not significant). The only exception is treatment $\mathbf{O}_{\mathbf{B}}$, where most of the learning between blocks takes place between the first and second block. ${ }^{45}$ The estimated discrete choice

\footnotetext{
${ }^{44}$ This terminology is used in the Heterogeneous Agent Models approach to financial markets, see, e.g., Hommes (2013). There is a growing literature that focuses on fitting the discrete choice model to experimental or empirical data, see, e.g., Branch (2004), Boswijk et al. (2007), Anufriev and Hommes (2012), and Anufriev et al. (2013). Anufriev et al. (2016) and Anufriev et al. (2018) recently estimated the values of the predisposition effect and the intensity of choice for laboratory experiments on fund choice, where, as opposed to the present paper, subjects do not know the data generating process.

${ }^{45}$ Moreover, for treatment $\mathbf{O}_{\mathbf{B}}$ the coefficient $\beta_{0}$ is significant and negative, which is somewhat unexpected at first sight. However given that the expected value of $r_{B}-r_{A}$ is equal to 0.02 , it is still consistent with the
} 


\begin{tabular}{l|cc|ccc|ccc}
\hline \hline \multirow{2}{*}{ Variables } & \multicolumn{2}{|c}{ Treatment $\mathbf{N}$} & \multicolumn{3}{c}{ Treatments $\mathbf{~}$} & \multicolumn{3}{c}{ Treatments $\mathbf{F}$} \\
\cline { 2 - 9 } & $\mathbf{N}$ & $\mathbf{N}^{\mathbf{R e}}$ & $\mathbf{O}_{\mathbf{B}}$ & $\mathbf{\mathbf { O } _ { \mathbf { B } } ^ { \mathbf { R e } }}$ & $\mathbf{O}_{\mathbf{A}}$ & $\mathbf{F}_{\mathbf{B}}$ & $\mathbf{F}_{\mathbf{B}}^{\mathbf{R e}}$ & $\mathbf{F}_{\mathbf{A}}$ \\
\hline Const, $\beta_{0}$ & $-0.300^{*}$ & 0.131 & $-0.782^{* * *}$ & -0.189 & $-0.511^{* * *}$ & $-0.327^{*}$ & $0.590^{* * *}$ & $-0.693^{* * *}$ \\
& $(0.167)$ & $(0.160)$ & $(0.206)$ & $(0.184)$ & $(0.127)$ & $(0.197)$ & $(0.172)$ & $(0.162)$ \\
Past Return Diff, $\beta_{1}$ & $8.988^{* * *}$ & $8.742^{* * *}$ & $13.037^{* * *}$ & $11.345^{* * *}$ & $10.791^{* * *}$ & 3.350 & -0.531 & $4.598^{* *}$ \\
& $(2.126)$ & $(1.767)$ & $(2.669)$ & $(1.993)$ & $(1.516)$ & $(2.497)$ & $(1.866)$ & $(1.933)$ \\
Sum of Past Ret Diffs, $\beta_{2}$ & $2.630^{* *}$ & $3.319^{* * *}$ & $6.427^{* * *}$ & $4.732^{* * *}$ & $1.427^{*}$ & $4.288^{* * *}$ & $7.555^{* * *}$ & $-1.784^{*}$ \\
& $(1.123)$ & $(0.939)$ & $(1.399)$ & $(1.074)$ & $(0.781)$ & $(1.277)$ & $(1.022)$ & $(0.997)$ \\
Period in Block, $\beta_{3}$ & -0.007 & -0.007 & -0.043 & -0.010 & $0.031^{* *}$ & -0.043 & $-0.123^{* * *}$ & $0.051^{* * *}$ \\
& $(0.019)$ & $(0.015)$ & $(0.033)$ & $(0.025)$ & $(0.013)$ & $(0.031)$ & $(0.023)$ & $(0.016)$ \\
Dummy Block 2, $\beta_{4}$ & 0.336 & 0.188 & $0.810^{* * *}$ & -0.015 & $0.494^{* * *}$ & 0.071 & -0.037 & 0.155 \\
& $(0.219)$ & $(0.178)$ & $(0.264)$ & $(0.192)$ & $(0.156)$ & $(0.251)$ & $(0.182)$ & $(0.198)$ \\
Dummy Block 3, $\beta_{5}$ & $0.860^{* * *}$ & $0.530^{* * *}$ & $0.868^{* * *}$ & $0.987^{* * *}$ & $0.221^{* *}$ & 0.167 & $0.931^{* * *}$ & 0.055 \\
& $(0.163)$ & $(0.142)$ & $(0.203)$ & $(0.162)$ & $(0.112)$ & $(0.185)$ & $(0.152)$ & $(0.142)$ \\
\hline Observations & 1260 & 1974 & 924 & 1848 & 2436 & 882 & 2016 & 1470 \\
McFadden R $\mathrm{R}^{2}$ & 0.041 & 0.052 & 0.089 & 0.110 & 0.022 & 0.034 & 0.098 & 0.021 \\
\hline \hline
\end{tabular}

Table 6: Estimated coefficients of the discrete choice model (1) for different treatments using the data from 2017 experiments only. Standard deviations are in parentheses. Coefficients with ${ }^{*},{ }^{* *}$ or ${ }^{* * *}$ correspond to significance at $10 \%, 5 \%$ and $1 \%$ level respectively.

model for treatment $\mathbf{O}_{\mathbf{A}}$ differs a bit from the other treatments without front-end loads. It is characterized by a predisposition toward fund $A$ and return chasing, but learning within or between blocks seems to be modest. ${ }^{46}$

The results are not as clear for the front-end load treatments. Obviously, given that the front-end load may have to be paid when subjects switch between funds, return chasing is not so prevalent in these treatments and indeed $\beta_{1}$ is only significant for treatment $\mathbf{F}_{\mathbf{A}}$. Instead, lock-in in fund $B$ (fund $A$ ) is captured by the significant positive (negative) value for $\beta_{0}$ for treatment $\mathbf{F}_{\mathbf{B}}\left(\mathbf{F}_{\mathbf{A}}\right)$. The evidence on learning within blocks is mixed: four of the six coefficients are significant, but the coefficients $\beta_{2}$ and $\beta_{3}$ have opposite signs, implying that the net effect of learning within a block is limited in the front-end load treatments. This is not unexpected: although fund $B$ is the ex-ante optimal fund, it is never optimal to switch from fund $A$ to fund $B$ in treatment $\mathbf{F}_{\mathbf{A}}$, and not optimal after period $t=7$ in the other two front-end load treatments. Finally, there is little evidence of learning between blocks in the front-end loads (the only significant coefficient is $\beta_{5}$ for treatment $\mathbf{F}_{\mathbf{B}}$ ).

We therefore find, in particular for the treatments where none of the funds charges a frontend load, that return chasing, learning within blocks, and learning between the second and third block, are important drivers of subjects' choice behavior.

majority of the subjects choosing fund $B$. Plugging in the estimated coefficients from Table 6 for treatment $\mathbf{O}_{\mathbf{B}}$ into Equation (1) and letting $r_{B}-r_{A}=0.02$ we predict, halfway each block, $n_{B, 8} \approx 0.52$ for the first block, $n_{B, 8} \approx 0.71$ for the second block and $n_{B, 8} \approx 0.72$ for the third block.

${ }^{46}$ The coefficient $\beta_{2}$ is not significant, and although $\beta_{3}$ is significant, it is rather small. There is some learning from the first to the second block but, remarkably, some of that is neutralized in the next block, since $\beta_{5}<\beta_{4}$. 


\section{Conclusion}

The experiment presented in this paper is aimed at studying how mutual fund choice is affected by the fees charged by these funds. Subjects have to choose between two experimental funds, where the expected net return of fund $B$ is higher than that of fund $A$. We impose different fee structures across treatments, but in such a way that expected (and realized) net returns of the funds are independent of the treatment. Our prediction is that subjects' choice behavior is the same in each of these treatments.

We find that introducing a small operating expenses fee for fund $B$, accompanied by an increase in gross returns of the same size, increases investment in fund $B$, but this increase is not significant. However, when we increase gross returns for fund $A$ such that they become larger than gross returns for fund $B$, and combine this with an operating expenses fee that keeps expected net returns of fund $A$ at the original level (i.e., below those of fund $B$ ) we see a substantial and significant decrease in investment in fund $B$. Although the decision environment is very stylized and transparent, gross return illusion seems to play an important role and subjects exhibit a tendency to ignore the fee they have to pay.

Although the front-end load is much more salient than the operating expenses fee, it does not seem to discourage investors. In fact, total investment in the fund that charges the frontend load is unaffected. However, the front-end load does lead to "lock-in" of subjects into the fund that charges the load. Remarkably, this lock-in also occurs when the inferior fund charges a front-end load, although in that case we simultaneously observe a substantial fraction of subjects that never pays the front-end load. Quite a number of subjects therefore appear to use the front-end load as a commitment device to consistently choose the optimal fund, either because the subject gets locked-in into that fund, or because he/she does not want to become locked-in into the inferior fund. ${ }^{47}$ Besides that, there are also a considerable number of subjects that pay the front-end load more than once, which is clearly suboptimal. As a consequence, there is substantial variation in individual earnings when one of the funds charges a front-end load, with average earnings also lower than in the operating expenses treatments. Our results suggest that, in a more general decision environment where some funds charge front-end loads and other funds charge operating expenses fees, investors may eventually tend to choose the latter, either because the front-end load is more salient (it is not ignored by our subjects to the extent that the operating expenses fee is), or because average earnings are lower in the frontend load treatments. This would be consistent with the decreasing popularity of front-end load funds, which has been documented by, for example, Barber et al. (2005).

\footnotetext{
${ }^{47} \mathrm{An}$ interesting direction for future research is to investigate what happens if, after a number of periods, fund $A$ becomes (much) more attractive than fund $B$ and subjects should switch to fund $A$. In this way we can test whether the sunk-cost fallacy, see Friedman et al. (2007) and the status quo bias, see Brown and Kagel (2009), play a role in the choice between mutual funds.
} 
Finally, we find that differences between blocks in the same treatment can be partly explained by return chasing and learning. Since realized returns do not affect future expected returns - and subjects are informed about this - it is odd that return chasing is so prevalent in our experiment, although it is a robust feature of earlier experiments as well (see, e.g., Wilcox, 2003 and Choi et al., 2010). Our decision environment seems to be more stylized and transparent than these earlier experiments, so it is difficult to attribute return chasing to the limited understanding subjects have of the experiment (see, e.g., Chou et al., 2009, Kirchler et al., 2012, however, for studies that show that subjects are easily confused about their experimental environment). Return chasing behavior may therefore be something deeply built in the "animal spirit" of human beings. Moreover, although in some of the treatments subjects seem to make better choices as they gain more experience with the decision environment, learning does not eradicate the errors in their decision making.

In the empirical literature a number of arguments have been forwarded to explain the large dispersion in fees, such as non-portfolio differentiation, search costs and asymmetric information. Our experiment shows that there is a tendency for subjects to ignore fees and make suboptimal decisions even in an environment where these arguments have no bite, illustrating that these decision errors are very persistent and difficult to eliminate. Note that the mutual fund industry attracts a considerable fraction of novice investors that are likely to be subject to the same types of biases as our experimental subjects. Our study suggests that there may be substantial scope for mutual fund firms to exploit the bias in investment decisions by mutual fund investors. This highlights the desirability for regulatory authorities to exert effort in enhancing the transparency of the mutual fund industry, and the level of financial literacy in society. At a minimum there is a need for full disclosure of the fees of mutual funds, and these fees should be made very salient in the prospectuses of those funds. Unfortunately, our results suggest that this may not be sufficient, and stricter regulation might be required. 


\section{References}

Anufriev M., Bao T., Tuinstra J., 2016. Microfoundations for switching behavior in heterogeneous agent models: An experiment. Journal of Economic Behavior \& Organization 129, $74-99$.

Anufriev M., Chernulich A., Tuinstra J., 2018. A laboratory experiment on the heuristic switching model. Journal of Economic Dynamics \& Control 91, 21-42.

Anufriev M., Hommes C., 2012. Evolutionary selection of individual expectations and aggregate outcomes in asset pricing experiments. American Economic Journal: Microeconomics 4, 35 -64 .

Anufriev M., Hommes C.H., Philipse R.H., 2013. Evolutionary selection of expectations in positive and negative feedback markets. Journal of Evolutionary Economics 23, 663-688.

Asparouhova E., Bossaerts P., Copic J., Cornell B., Cvitanic J., Meloso D., 2015. Competition in portfolio management: theory and experiment. Management Science 61, 1868-1888.

Asparouhova E., Hertzel M., Lemmon M., 2009. Inference from streaks in random outcomes: Experimental evidence on beliefs in regime shifting and the law of small numbers. Management Science 55, 1766-1782.

Barber B.M., Odean T., Zheng L., 2005. Out of sight, out of mind: The effects of expenses on mutual fund flows. The Journal of Business 78, 2095-2120.

Bloomfield R., Hales J., 2002. Predicting the next step of a random walk: experimental evidence of regime-shifting beliefs. Journal of Financial Economics 65, 397-414.

Blume A., Ortmann A., 2007. The effects of costless pre-play communication: Experimental evidence from games with pareto-ranked equilibria. Journal of Economic Theory 132, 274290.

Bossaerts P., Bowman E., Huang S., Murawski C., Tang S., Yadav N., 2018. Asset pricing under computational complexity Working paper.

Boswijk P., Hommes C., Manzan S., 2007. Behavioral heterogeneity in stock prices. Journal of Economic Dynamics \& Control 31, 1938-1970.

Brañas-Garza P., García-Muñoz T., González R., 2012. Cognitive effort in the beauty contest game. Journal of Economic Behavior \& Organization 83, 254-260.

Branch W., 2004. The theory of rationally heterogeneous expectations: Evidence from survey data on inflation expectations. Economic Journal 114, 592-621. 
Brocas I., Carrillo J.D., Giga A., Zapatero F., 2015. Risk aversion in a dynamic asset allocation experiment. Technical Report No. 10332, CEPR. Available at https://cepr.org/active/publications/discussion_papers/dp.php?dpno=10332.

Brown A.L., Kagel J.H., 2009. Behavior in a simplified stock market: the status quo bias, the disposition effect and the ostrich effect. Annals of Finance 5, 1-14.

Carhart M.M., 1997. On persistence in mutual fund performance. The Journal of Finance 52, $57-82$.

Choi J., Laibson D., Madrian B., Metrick A., 2009. Reinforcement learning and savings hehavior. Journal of Finance 64, 2515-2534.

Choi J.J., Laibson D., Madrian B.C., 2010. Why does the law of one price fail? an experiment on index mutual funds. Review of Financial Studies 23, 1405-1432.

Chordia T., 1996. The structure of mutual fund charges. Journal of Financial Economics 41, $3-39$.

Chou E., McConnell M., Nagel R., Plott C.R., 2009. The control of game form recognition in experiments: understanding dominant strategy failures in a simple two person guessing game. Experimental Economics 12, 159-179.

Cooper M., Halling M., Yang W., 2018. The persistence of fee dispersion among mutual funds. Technical Report No. 14-11, Swedish House of Finance. Available at: https: //ssrn. com/abstract $=1456079$.

Ehm C., Müller S., Weber M., 2014. When risk and return are not enough: The role of loss aversion in private investors' choice of mutual fund fee structures. Technical report. Available at https://ssrn. com/abstract=2252646.

Elton E.J., Gruber M.J., Busse J.A., 2004. Are investors rational? choices among index funds. Journal of Finance 59, 261-288.

Frederick S., 2005. Cognitive reflection and decision making. Journal of Economic Perspectives $19,25-42$.

Friedman D., Pommerenke K., Lukose R., Milam G., Huberman B.A., 2007. Searching for the sunk cost fallacy. Experimental Economics 10, 79-104.

Gil-Bazo J., Ruiz-Verdú P., 2008. When cheaper is better: Fee determination in the market for equity mutual funds. Journal of Economic Behavior \& Organization 67, 871-885.

Gil-Bazo J., Ruiz-Verdú P., 2009. The relation between price and performance in the mutual fund industry. The Journal of Finance 64, 2153-2183. 
Glaser M., Iliewa Z., Weber M., 2018. Thinking about prices versus thinking about returns in financial markets. Journal of Finance Forthcoming.

Hendricks D., Patel J., Zeckhauser R., 1993. Hot hands in mutual funds: Short-run persistence of relative performance, 1974-1988. The Journal of Finance 48, 93-130.

Hommes C., 2013. Behavioral Rationality and Heterogeneous Expectations in Complex Economic Systems. Cambridge University Press.

Hortaçsu A., Syverson C., 2004. Product differentiation, search costs, and competition in the mutual fund industry: A case study of s\&p 500 index funds. The Quarterly Journal of Economics 119, 403-456.

Investment Company Institute, 2018. 2018 Investment Company Fact Book: A Review of Trends and Activities in the Investment Company Industry. Available at https://www.ici.org/pdf/2018_factbook.pdf.

Jain P., Wu J., 2000. Truth in mutual fund advertising: Evidence on future performance and fund flows. Journal of Finance 55, 937-958.

Khorana A., Servaes H., 2012. What drives market share in the mutual fund industry? Review of Finance 16, 81-113.

Khorana A., Servaes H., Tufano P., 2009. Mutual fund fees around the world. Review of Financial Studies 22, 1279-1310.

Kirchler M., Huber J., Stöckl T., 2012. Thar she bursts: Reducing confusion reduces bubbles. The American Economic Review 102, 865-883.

Offerman T., Sonnemans J., 2004. Whats causing overreaction? an experimental investigation of recency and the hothand effect. Scandinavian Journal of Economics 106, 533-554.

Powdthavee N., Riyanto Y., 2015. Would you pay for transparently useless advice? a test of boundaries of beliefs in the folly of predictions. Review of Economics and Statistics 97, $257-272$.

Sirri E., Tufano P., 1998. Costly search and mutual fund flows. Journal of Finance 53, 15891622.

Stöckl T., Huber J., Kirchler M., Lindner F., 2015. Hot hand and gambler's fallacy in teams: Evidence from investment experiments. Journal of Economic Behavior \& Organization 117, 327-339.

Wilcox R.T., 2003. Bargain hunting or star gazing? investors preferences for stock mutual funds. Journal of Business 76, 645-663. 
Yuan J., Sun G., Siu R., 2014. The lure of illusory luck: How much are people willing to pay for random shocks. Journal of Economic Behavior \& Organization 106, 269-280.

Zheng L., 1999. Is money smart? a study of mutual fund investors' fund selection ability. Journal of Finance 54, 901-933. 


\section{APPENDIX}

\section{A Experimental Instructions}

These are the experimental instructions for the different treatments. For this purpose those parts that were shown only in certain treatments are included in squared brackets, preceded by the indication of which treatment this part belongs to.

General information. In this experiment you are asked to make subsequent investment decisions. You will start with 1000 points which you can invest. In every subsequent period you will have the possibility to reinvest your accumulated points. In every period you can only invest all of your points in fund $A$, all of your points in fund $B$, or invest in neither of the two funds. [Treatments $\mathbf{O}_{\mathbf{B}}, \mathbf{O}_{\mathbf{B}}^{\mathbf{R e}}, \mathbf{F}_{\mathbf{B}}, \mathbf{F}_{\mathbf{B}}^{\mathbf{R e}}$ : Fund $B$ charges a fee for investment, fund $A$ does not.] [Treatments $\mathbf{O}_{\mathbf{A}}, \mathbf{F}_{\mathbf{A}}$ : Fund $A$ charges a fee for investment, fund $F$ does not.] Your earnings from the experiment will depend upon how well your investments will do.

The funds and their prices. The price of fund $A$ is $P_{A}(t)$ in period $t$, and the price of fund $B$ is $P_{B}(t)$ in period $t$. Over time prices of the funds grow in the following way. The price of fund $A$ in period $t+1$ is equal to $\left(1+g_{A}\right)$ times the price of fund $A$ in period $t$, that is

$$
P_{A}(t+1)=\left(1+g_{A}\right) \times P_{A}(t)
$$

The growth rate $g_{A}$ can only take one of two values. [Treatments $\mathbf{N}, \mathbf{N}^{\mathbf{R e}}, \mathbf{O}_{\mathbf{B}}, \mathbf{O}_{\mathbf{B}}^{\mathbf{R e}}, \mathbf{F}_{\mathbf{B}}$, $\mathbf{F}_{\mathbf{B}}^{\mathbf{R e}}$ : It is either equal to 0.05 , or it is equal to 0.01.] [Treatments $\mathbf{O}_{\mathbf{A}}, \mathbf{F}_{\mathbf{A}}$ : It is either equal to 0.07 , or it is equal to 0.03.] Both values are equally likely to occur (that is, both occur with the probability equal to 0.5 ). The history of values of $g_{A}$ does not influence the probability of either value occurring.

[Treatments $\mathbf{N}, \mathbf{N}^{\mathbf{R e}}, \mathbf{O}_{\mathbf{A}}, \mathbf{F}_{\mathbf{A}}$ : Similarly, the price of fund $B$ grows with growth rate $g_{B}$, which could either be 0.06 or 0.02.] [Treatments $\mathbf{O}_{\mathbf{B}}, \mathbf{O}_{\mathbf{B}}^{\mathbf{R e}}, \mathbf{F}_{\mathbf{B}}, \mathbf{F}_{\mathbf{B}}^{\mathbf{R e}}$ : Similarly, the price of fund $B$ grows with growth rate $g_{B}$, which could either be 0.07 or 0.03.] Again both values are equally likely to occur. The price of fund $B$ in period $t$ therefore is

$$
P_{B}(t+1)=\left(1+g_{B}\right) \times P_{B}(t)
$$

Prices of the two funds do not influence each other. Moreover, your decisions will not influence the price of the two funds. 
Example: [Treatments $\mathbf{N}, \mathbf{N}^{\mathbf{R e}}, \mathbf{O}_{\mathbf{B}}, \mathbf{O}_{\mathbf{B}}^{\mathbf{R e}}, \mathbf{F}_{\mathbf{B}}, \mathbf{F}_{\mathbf{B}}^{\mathbf{R e}}$ : Suppose the price of fund $A$ is equal to 50 in period 1 , and the growth rate in period 1 is equal to 0.05 . In that case we have $P_{A}(2)=1.05 \times 50=52.5$. If the growth rate in period 2 is given by 0.01 then the price in period 3 will be given by $P_{A}(3)=52.5 \times 1.01=53.03$, and so on.] [Treatments $\mathbf{O}_{\mathbf{A}}, \mathbf{F}_{\mathbf{A}}$ : Suppose the price of fund $A$ is equal to 60 in period 1 , and the growth rate in period 1 is equal to 0.07 . In that case we have $P_{A}(2)=1.07 \times 60=64.2$. If the growth rate in period 2 is given by 0.03 then the price in period 3 will be given by $P_{A}(3)=64.2 \times 1.03=66.12$, and so on.]

[Treatments $\mathrm{O}_{\mathbf{B}}, \mathrm{O}_{\mathbf{B}}^{\mathrm{Re}}$ : Fees for fund $B$. Each period that you invest your points in fund $B$ you will have to pay fees to the fund manager. This fee equals $1 \%$ of your accumulated points at the beginning of that period. Fund $A$ does not charge any fees.]

[Treatment $\mathrm{O}_{\mathrm{A}}$ : Fees for fund $A$. Each period that you invest your points in fund $A$ you will have to pay fees to the fund manager. This fee equals $2 \%$ of your accumulated points at the beginning of that period. Fund $B$ does not charge any fees.]

[Treatments $\mathbf{F}_{\mathbf{B}}, \mathbf{F}_{\mathbf{B}}^{\mathbf{R e}}$ : Fees for fund $B$. In each period that you start to invest in fund $B$ you will have to pay a fee to the fund manager. This fee equals $13 \%$ of your accumulated points at the beginning of that period. Suppose that you invest in fund $B$ from period 1 until period 5, and then invest in $A$ from period 6 until period 10, and then go back to fund $B$ in period 11. Then as a fee you have to pay $13 \%$ of your initial points in period 1, you do not have to pay a fee in periods 2 until 10, but in period 11 you then have to pay $13 \%$ of the points you accumulated until the beginning of period 11. Fund $A$ does not charge any fees.]

[Treatment $\mathbf{F}_{\mathbf{A}}$ : Fees for fund $A$. In each period that you start to invest in fund $A$ you will have to pay a fee to the fund manager. This fee equals $24 \%$ of your accumulated points at the beginning of that period. Suppose that you invest in fund $A$ from period 1 until period 5, and then invest in $B$ from period 6 until period 10, and then go back to fund $A$ in period 11. Then as a fee you have to pay $24 \%$ of your initial points in period 1 , you do not have to pay a fee in periods 2 until 10, but in period 11 you then have to pay $24 \%$ of the points you accumulated until the beginning of period 11. Fund $B$ does not charge any fees.]

Investing. If you invest your points in one of the two funds, the number of points you have will grow. [Treatments $\mathbf{N}, \mathbf{N}^{\mathbf{R e}}, \mathrm{O}_{\mathbf{B}}, \mathrm{O}_{\mathbf{B}}^{\mathrm{Re}}, \mathbf{F}_{\mathbf{B}}, \mathbf{F}_{\mathbf{B}}^{\mathbf{R e}}$ : For example, suppose you invest your 1000 points in fund $A$ in period 1 , when the price of fund $A$ is $P_{A}(1)=50$, and you keep your points in fund $A$ until period 6. By then the price of fund $A$ has grown to, for example, $P_{A}(6)=60$.] [Treatments $\mathbf{O}_{\mathbf{A}}, \mathbf{F}_{\mathbf{A}}$ : For example, suppose you invest your 1000 points in fund $B$ in period 1 , when the price of fund $B$ is $P_{B}(1)=50$, and you keep your points in fund $B$ until period 6 . By then the price of fund $B$ has grown to, for example, $P_{B}(6)=60$.] Then 
your points will have increased up to

$$
1000 \times \frac{60}{50}=1200
$$

[Treatments $\mathbf{N}, \mathbf{N}^{\mathbf{R e}}$ : If you then decide to invest these points in fund $B$ for the next two periods and, for example $P_{B}(6)=56, P_{B}(7)=59$ and $P_{B}(8)=61$, your total number of points at the end of period 8 will be equal to

$$
\left.1200 \times \frac{61}{56}=1307.14 .\right]
$$

[Treatments $\mathrm{O}_{\mathbf{B}}, \mathrm{O}_{\mathbf{B}}^{\mathrm{Re}}$ : If you then decide to invest these points in fund $B$ for the next two periods and, for example $P_{B}(6)=55, P_{B}(7)=57$ and $P_{B}(8)=61$, your total number of points at the end of period 7 will be equal to

$$
1200 \times \frac{57}{55}-1200 \times 1 \%=1231.64
$$

Your total number of points at the end of period 8 will be (after subtracting the $1 \%$ fee again)

$$
1231.64 \times \frac{61}{57}-1231.64 \times 1 \%=1305.75 \text {. }
$$

[Treatment $\mathrm{O}_{\mathrm{A}}$ : If you then decide to invest these points in fund $A$ for the next period and, for example $P_{A}(6)=66, P_{A}(7)=68$, your total number of points at the end of period 7 will be equal to

$$
\left.1200 \times \frac{68}{66}-1200 \times 1 \%=1224.36 .\right]
$$

[Treatments $\mathbf{F}_{\mathbf{B}}, \mathbf{F}_{\mathbf{B}}^{\mathbf{R e}}$ : If you then decide to invest these points in fund $B$ for the next two periods and, for example $P_{B}(6)=55, P_{B}(7)=57$ and $P_{B}(8)=61$, your total number of points at the end of period 8 will be (after subtracting the $13 \%$ fee for fund $B$ that you will have to pay in period 7 )

$$
\left.(1200-1200 \times 13 \%) \times \frac{61}{55}=1157.89 .\right]
$$

Note that your points will remain constant in the periods in which you invest in none of the two funds.

[Treatment $\mathbf{F}_{\mathbf{A}}$ : If you then decide to invest these points in fund $A$ for the next two periods and, for example $P_{A}(6)=66, P_{A}(7)=68$ and $P_{A}(8)=72$, your total number of points at the end of period 8 will be (after subtracting the $24 \%$ fee for fund $A$ that you will have to pay in 
period 8)

$$
\left.(1200-1200 \times 24 \%) \times \frac{72}{66}=1004.15 .\right]
$$

Note that your points will remain constant in the periods in which you invest in none of the two funds.

Your task. The experiment consists of three parts of 15 periods. In each part you start out with 1000 points, and you can increase the number of points by investing in the two funds $A$ and $B$. In every period you have three options. Either to invest all of your points in fund $A$, or to invest all of your points in fund $B$, or to invest your points in neither fund. You are allowed to switch between funds as often as you want to, but you do not have to.

After the first 15 periods are finished, the experiment will be restarted. Your initial points will be reset to 1000 points and the prices of funds $A$ and $B$ will be reset to their initial values again. [Treatments $\mathbf{N}, \mathbf{N}^{\mathbf{R e}}$ : The values that the growth rates of the two prices can take are the same again (0.05 and 0.01 for fund $A$, with equal probability, and 0.06 and 0.02 for fund $B$, also with equal probability).] [Treatments $\mathbf{O}_{\mathbf{B}}, \mathbf{O}_{\mathbf{B}}^{\mathbf{R e}}, \mathbf{F}_{\mathbf{B}}, \mathbf{F}_{\mathbf{B}}^{\mathbf{R e}}$ : The values that the growth rates of the two prices can take are the same again (0.05 and 0.01 for fund $A$, with equal probability, and 0.07 and 0.03 for fund $B$, also with equal probability).] [Treatments $\mathbf{O}_{\mathbf{A}}, \mathbf{F}_{\mathbf{A}}$ : The values that the growth rates of the two prices can take are the same again (0.07 and 0.03 for fund $A$, with equal probability, and 0.06 and 0.02 for fund $B$, also with equal probability).] Because these values are random, the actual growth rates in this second part of 15 periods will, most likely, be different for the actual growth rates in the first part of 15 periods.

After the second part of 15 periods, the experiment will be restarted in the same way as described above for another 15 periods.

Information. The information that you have at the beginning of time $t$, when you have to make your investment decision for period $t$, consists of the current prices, all past prices and all past growth rates of both funds. The current prices are shown in the top part of the computer screen. Both past prices and past growth rates are shown in a table on the computer screen. The prices of the funds are also shown in a graph on the screen. Moreover, we show your total accumulated (from the beginning of the current part) number of points in the top part of the computer screen.

Earnings. After the experiment you are paid out according to only one of the three parts. For which part you are paid is determined randomly, and with equal probability. You will be paid for the total number of points, and for each point you will receive 1 euro cent. For 
example, suppose in the first part your initial number of points increased from 1000 to 1800 points, in the second part your number of points increased from 1000 to 1400 points, and in the final part your number of points increased from 1000 to 1600 points. Then you will earn 18 euros if you are paid according to the first part, and 14 euros if you are paid according to the second part and 16 euros if you are paid according to the final part.

\section{B Additional Data and Analysis}

Here we collect the results and statistics that have been used for the analysis reported in the main text.

Table 7 collects the $p$-values of several Mann-Whitney-Wilcoxon tests for comparison between different blocks and treatments. The table is divided into three horizontal parts depending on which hypothesis is tested. The upper part of the table (first four rows) collects the results of testing Hypothesis 1. The next part (next five rows) collects the results of testing Hypothesis 2. Finally, the lower part of the table (remaining rows) are used for testing Hypothesis 3. Different columns of the table collect the statistics for the hypothesis about different data. The second column shows the $p$-values for the test when the number of choices of fund $B$ are compared. The third column shows the $p$-values for the comparison of earnings. The fourth column shows the $p$-values for the test for the comparison of efficiencies (defined as the return earned divided by the return that could be earned using the rational strategy of investing every period in fund $B$ ). Finally, the last column shows the values for the test for the comparison of frequency of switching. Superscript ${ }^{a}$ is used to indicate the occasions when the null hypothesis that the number of $B$-choices (resp., earnings, efficiency, number of switches) is the same can be rejected at the significance level of $5 \%$.

Table 8 displays the $p$-value of the Kolmogorov-Smirnov test for comparison between different blocks and treatments. It is organized in the same way as Table 7. Superscript ${ }^{a}$ indicates the cases when the null hypothesis that the $B$-choices (resp., earnings, efficiency, number of switches) come from the same distribution can be rejected at the significance level of $5 \%$.

Table 9 collects the results of estimation of logit model that we performed in an attempt to identify the behavior in treatments with the front-end load with subjects' characteristics, see the discussion at the end of Section 4.3. For subjects in the sessions ran in 2017 we collected data on age, gender and the CRT score. We classify all subjects in the front-end load treatments as 'switchers' when, for at least one of the blocks, they paid the front-end load at least twice, and 'non-switchers' otherwise (i.e., they paid the front-end load at most once in each of the three blocks). We then estimate a logit model that explains this binary variable by 


\begin{tabular}{|c|c|c|c|c|}
\hline $\begin{array}{l}\text { Data to } \\
\text { compare }\end{array}$ & \multicolumn{4}{|c|}{$\begin{array}{l}p \text {-values for the MWW test for differences for: } \\
\text { choices of } B \quad \text { earnings efficiency switches }\end{array}$} \\
\hline$\overline{\mathrm{N} \text { vs } \mathrm{O}_{\mathrm{B}}}$ & 0.187 & 0.547 & 0.592 & 0.219 \\
\hline $\mathrm{N}$ vs $\mathrm{O}_{\mathbf{A}}$ & $0.000^{a}$ & $0.004^{a}$ & $0.006^{a}$ & $0.000^{a}$ \\
\hline $\mathrm{O}_{\mathrm{B}}$ vs $\mathrm{O}_{\mathrm{A}}$ & $0.000^{a}$ & $0.002^{a}$ & $0.001^{a}$ & $0.000^{a}$ \\
\hline $\mathrm{N}^{\mathrm{Re}}$ vs $\mathrm{O}_{\mathrm{B}}^{\mathrm{Re}}$ & 0.279 & 0.107 & $0.030^{a}$ & 0.645 \\
\hline $\mathbf{F}_{\mathrm{B}}$ vs $\mathrm{O}_{\mathrm{B}}$ & 0.527 & $0.000^{a}$ & $0.001^{a}$ & $0.000^{a}$ \\
\hline $\mathbf{F}_{\mathbf{B}}$ vs $\mathbf{N}$ & 0.256 & $0.000^{a}$ & $0.001^{a}$ & $0.000^{a}$ \\
\hline $\mathbf{F}_{\mathrm{B}}^{\mathrm{Re}}$ vs $\mathrm{O}_{\mathrm{B}}^{\mathrm{Re}}$ & 0.108 & $0.000^{a}$ & $0.001^{a}$ & $0.000^{a}$ \\
\hline $\mathbf{F}_{\mathbf{B}}^{\mathbf{R e}}$ vs $\mathbf{N}^{\mathbf{R e}}$ & $0.010^{a}$ & $0.012^{a}$ & 0.231 & $0.000^{a}$ \\
\hline $\mathbf{F}_{\mathbf{A}}$ vs $\mathrm{O}_{\mathrm{A}}$ & 0.777 & $0.000^{a}$ & $0.000^{a}$ & $0.000^{a}$ \\
\hline $\mathbf{N}$ (b1 vs b2) & 0.197 & $0.000^{a}$ & $0.000^{a}$ & 0.748 \\
\hline $\mathrm{O}_{\mathrm{B}}(\mathrm{b} 1 \mathrm{vs} \mathrm{b} 2)$ & $0.033^{a}$ & $0.000^{a}$ & $0.000^{a}$ & 0.336 \\
\hline $\mathbf{F}_{\mathbf{B}}$ (b1 vs b2) & 0.059 & $0.001^{a}$ & 0.101 & 0.645 \\
\hline $\mathbf{N}^{\mathbf{R e}}$ (b1 vs b2) & $0.001^{a}$ & $0.000^{a}$ & $0.000^{a}$ & 0.167 \\
\hline $\mathrm{O}_{\mathbf{B}}^{\mathbf{R e}}(\mathrm{b} 1$ vs b2) & $0.000^{a}$ & $0.000^{a}$ & $0.000^{a}$ & 0.119 \\
\hline $\mathbf{F}_{\mathbf{B}}^{\mathbf{R e}}(\mathrm{b} 1 \mathrm{vs} \mathrm{b} 2)$ & $0.002^{a}$ & $0.000^{a}$ & 0.525 & $0.036^{a}$ \\
\hline $\mathrm{O}_{\mathbf{A}}(\mathrm{b} 1 \mathrm{vs} \mathrm{b} 2)$ & 0.822 & $0.001^{a}$ & $0.000^{a}$ & 0.408 \\
\hline $\mathbf{F}_{\mathbf{A}}(\mathrm{b} 1$ vs b2) & 0.200 & 0.299 & $0.000^{a}$ & 0.038 \\
\hline $\mathbf{N}(\mathrm{b} 2$ vs b3) & $0.017^{a}$ & $0.000^{a}$ & $0.001^{a}$ & 0.817 \\
\hline $\mathrm{O}_{\mathbf{B}}(\mathrm{b} 2$ vs b3) & 0.062 & $0.000^{a}$ & 0.360 & 0.609 \\
\hline $\mathbf{F}_{\mathbf{B}}(\mathrm{b} 2$ vs b3) & 0.318 & 0.034 & 0.632 & 0.696 \\
\hline $\mathbf{N}^{\mathbf{R e}}$ (b2 vs b3) & $0.000^{a}$ & $0.000^{a}$ & $0.005^{a}$ & $0.043^{a}$ \\
\hline $\mathrm{O}_{\mathbf{B}}^{\mathbf{R e}}(\mathrm{b} 2 \mathrm{vs} \mathrm{b} 3)^{\prime}$ & $0.000^{a}$ & $0.000^{a}$ & 0.460 & $0.001^{a}$ \\
\hline $\mathbf{F}_{\mathbf{B}}^{\mathbf{R e}}$ (b2 vs b3) & $0.000^{a}$ & $0.000^{a}$ & $0.012^{a}$ & $0.034^{a}$ \\
\hline $\mathrm{O}_{\mathbf{A}}(\mathrm{b} 2$ vs b3) & 0.846 & $0.004^{a}$ & $0.000^{a}$ & 0.707 \\
\hline $\mathbf{F}_{\mathbf{A}}(\mathrm{b} 2$ vs b3) & 0.505 & 0.126 & 0.069 & 0.178 \\
\hline $\mathbf{N}$ (b1 vs b3) & $0.029^{a}$ & 0.935 & $0.001^{a}$ & 0.396 \\
\hline $\mathrm{O}_{\mathbf{B}}(\mathrm{b} 1 \mathrm{vs} \mathrm{b} 3)$ & 0.233 & 0.699 & $0.004^{a}$ & 0.813 \\
\hline $\mathbf{F}_{\mathbf{B}}(\mathrm{b} 1$ vs b3) & 0.830 & 0.669 & 0.302 & 0.772 \\
\hline $\mathbf{N}^{\mathbf{R e}}(\mathrm{b} 1$ vs b3) & 0.254 & $0.003^{a}$ & $0.043^{a}$ & 0.584 \\
\hline $\mathrm{O}_{\mathbf{B}}^{\mathbf{R e}}(\mathrm{b} 1 \mathrm{vs}$ b3) & $0.003^{a}$ & 0.214 & $0.000^{a}$ & $0.034^{a}$ \\
\hline $\mathbf{F}_{\mathbf{B}}^{\mathbf{R e}}$ (b1 vs b3) & 0.244 & 0.091 & 0.083 & 0.944 \\
\hline $\mathrm{O}_{\mathrm{A}}(\mathrm{b} 1 \mathrm{vs} \mathrm{b} 3)$ & 0.965 & 0.888 & $0.000^{a}$ & 0.249 \\
\hline $\mathbf{F}_{\mathbf{A}}(\mathrm{b} 1$ vs b3) & 0.623 & 0.211 & $0.000^{a}$ & $0.000^{a}$ \\
\hline $\mathbf{N}$ vs $\mathbf{N}^{\mathbf{R e}}$ (b1) & $0.003^{a}$ & $0.005^{a}$ & $0.005^{a}$ & 0.466 \\
\hline $\mathbf{N}$ vs $\mathbf{N}^{\mathbf{R e}}(\mathrm{b} 2)$ & 0.725 & 0.410 & 0.410 & 0.226 \\
\hline $\mathrm{O}_{\mathbf{B}}$ vs $\mathbf{O}_{\mathbf{B}}^{\mathbf{R e}}(\mathrm{b} 1)$ & 0.325 & 0.171 & 0.171 & 0.277 \\
\hline $\mathbf{O}_{\mathbf{B}}$ vs $\mathbf{O}_{\mathbf{B}}^{\mathbb{R e}}(\mathrm{b} 2)$ & 0.940 & 0.285 & 0.285 & 0.063 \\
\hline $\mathbf{F}_{\mathbf{B}}$ vs $\mathbf{F}_{\mathbf{B}}^{\mathbf{R e}}(\mathrm{b} 1)$ & 0.428 & 0.125 & 0.125 & 0.120 \\
\hline $\mathbf{F}_{\mathbf{B}}$ vs $\mathbf{F}_{\mathbf{B}}^{\mathbf{R e}}(\mathrm{b} 2)$ & 0.534 & 0.441 & 0.441 & 0.460 \\
\hline
\end{tabular}

Table 7: $p$-values for the Mann-Whitney-Wilcoxon tests of various hypotheses analyzed in the paper. The superscript ${ }^{a}$ is used to indicate the occasions when the null hypothesis that the number of $B$-choices (resp., earnings, efficiency, number of switches) is the same can be rejected at the significance level of $5 \%$. 


\begin{tabular}{|c|c|c|c|c|}
\hline $\begin{array}{l}\text { Data to } \\
\text { compare }\end{array}$ & \multicolumn{4}{|c|}{$\begin{array}{l}p \text {-values for the KS test for differences in distributions for: } \\
\begin{array}{lll}\text { choices of } B \quad \text { earnings efficiency } & \text { switches }\end{array}\end{array}$} \\
\hline $\mathrm{N}$ vs $\mathrm{O}_{\mathrm{B}}$ & 0.076 & 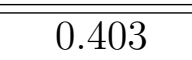 & 0.280 & 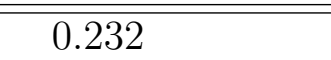 \\
\hline $\mathbf{N}$ vs $\mathbf{O}_{\mathbf{A}}$ & $0.000^{a}$ & $0.029^{a}$ & $0.033^{a}$ & $0.000^{a}$ \\
\hline $\mathrm{O}_{\mathrm{B}}$ vs $\mathrm{O}_{\mathrm{A}}$ & $0.000^{a}$ & $0.002^{a}$ & $0.001^{a}$ & $0.000^{a}$ \\
\hline $\mathbf{N}^{\mathrm{Re}}$ vs $\mathrm{O}_{\mathrm{B}}^{\mathrm{Re}}$ & 0.781 & 0.179 & $0.037^{a}$ & 0.979 \\
\hline 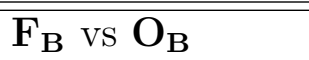 & 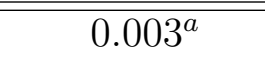 & 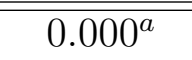 & 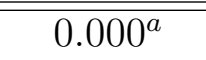 & 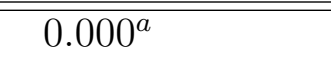 \\
\hline $\mathbf{F}_{\mathbf{B}}$ vs $\mathbf{N}$ & $0.006^{a}$ & $0.000^{a}$ & $0.000^{a}$ & $0.000^{a}$ \\
\hline $\mathbf{F}_{\mathbf{B}}^{R e}$ vs $\mathbf{O}_{\mathbf{B}}^{R e}$ & $0.007^{a}$ & $0.000^{a}$ & $0.000^{a}$ & $0.000^{a}$ \\
\hline $\mathbf{F}_{\mathbf{B}}^{\mathbf{R e}}$ vs $\mathbf{N}^{\mathbf{R e}}$ & $0.000^{a}$ & $0.000^{a}$ & $0.001^{a}$ & $0.000^{a}$ \\
\hline $\mathbf{F}_{\mathbf{A}} \operatorname{vs} \mathbf{O}_{\mathbf{A}}$ & $0.004^{a}$ & $0.000^{a}$ & $0.000^{a}$ & $0.000^{a}$ \\
\hline$\overline{\mathrm{N}}$ (b1 vs b2) & 0.065 & $0.000^{a}$ & $0.000^{a}$ & 0.858 \\
\hline $\mathrm{O}_{\mathrm{B}}(\mathrm{b} 1 \mathrm{vs} \mathrm{b} 2)$ & 0.086 & $0.000^{a}$ & $0.000^{a}$ & 0.548 \\
\hline $\mathbf{F}_{\mathbf{B}}(\mathrm{b} 1 \mathrm{vs} \mathrm{b} 2)$ & 0.050 & $0.000^{a}$ & 0.050 & 0.746 \\
\hline $\mathbf{N}^{\mathbf{R e}}$ (b1 vs b2) & $0.024^{a}$ & $0.000^{a}$ & $0.000^{a}$ & 0.466 \\
\hline $\mathbf{O}_{\mathbf{B}}^{\mathbf{R e}}$ (b1 vs b2) & $0.000^{a}$ & $0.000^{a}$ & $0.000^{a}$ & 0.595 \\
\hline $\mathbf{F}_{\mathbf{B}}^{\mathbf{R e}}(\mathrm{b} 1$ vs b2) & $0.026^{a}$ & $0.000^{a}$ & 0.333 & 0.220 \\
\hline $\mathrm{O}_{\mathbf{A}}(\mathrm{b} 1$ vs b2) & 0.765 & $0.011^{a}$ & $0.000^{a}$ & 0.765 \\
\hline $\mathbf{F}_{\mathbf{A}}(\mathrm{b} 1$ vs b2) & 0.168 & $0.024^{a}$ & $0.000^{a}$ & 0.168 \\
\hline $\mathbf{N}(\mathrm{b} 2$ vs b3) & 0.109 & $0.000^{a}$ & $0.005^{a}$ & 0.936 \\
\hline $\mathrm{O}_{\mathbf{B}}(\mathrm{b} 2$ vs b3) & 0.332 & $0.000^{a}$ & 0.332 & 0.821 \\
\hline $\mathbf{F}_{\mathbf{B}}(\mathrm{b} 2 \mathrm{vs} \mathrm{b} 3)$ & 0.154 & $0.011^{a}$ & 0.797 & 0.797 \\
\hline $\mathbf{N}^{\mathbf{R e}}(\mathrm{b} 2$ vs b3) & $0.000^{a}$ & $0.000^{a}$ & 0.078 & 0.321 \\
\hline $\mathrm{O}_{\mathrm{B}}^{\mathbf{R e}}(\mathrm{b} 2$ vs b3) & $0.000^{a}$ & $0.000^{a}$ & 0.595 & $0.004^{a}$ \\
\hline $\mathbf{F}_{\mathbf{B}}^{\mathbf{R e}}(\mathrm{b} 2$ vs b3) & $0.000^{a}$ & $0.000^{a}$ & $0.014^{a}$ & 0.139 \\
\hline $\mathrm{O}_{\mathrm{A}}(\mathrm{b} 2$ vs b3) & 0.977 & $0.001^{a}$ & $0.000^{a}$ & 0.765 \\
\hline $\mathbf{F}_{\mathbf{A}}(\mathrm{b} 2$ vs b3) & 0.839 & $0.005^{a}$ & $0.011^{a}$ & 0.640 \\
\hline $\mathbf{N}$ (b1 vs b3) & $0.026^{a}$ & 0.537 & $0.011^{a}$ & 0.936 \\
\hline $\mathrm{O}_{\mathrm{B}}$ (b1 vs b3) & 0.563 & 0.821 & $0.014^{a}$ & 0.979 \\
\hline $\mathbf{F}_{\mathbf{B}}(\mathrm{b} 1$ vs b3) & 1.000 & 0.304 & 0.304 & 0.973 \\
\hline $\mathbf{N}^{\mathbf{R e}}(\mathrm{b} 1 \mathrm{vs}$ b3) & 0.466 & $0.006^{a}$ & 0.131 & 0.812 \\
\hline $\mathrm{O}_{\mathrm{B}}^{\mathrm{Re}}$ (b1 vs b3) & $0.004^{a}$ & 0.179 & $0.000^{a}$ & $0.034^{a}$ \\
\hline $\mathbf{F}_{\mathbf{B}}^{\mathbf{R e}}(\mathrm{b} 1 \mathrm{vs} \mathrm{b} 3)^{\prime}$ & 0.333 & $0.001^{a}$ & 0.220 & 1.000 \\
\hline $\mathrm{O}_{\mathrm{A}}(\mathrm{b} 1 \mathrm{vs} \mathrm{b} 3)$ & 0.607 & 0.324 & $0.000^{a}$ & 0.324 \\
\hline $\mathbf{F}_{\mathbf{A}}(\mathrm{b} 1$ vs b3) & 0.281 & $0.049^{a}$ & $0.000^{a}$ & $0.024^{a}$ \\
\hline $\mathbf{N}$ vs $\mathbf{N}^{\mathbf{R e}}$ (b1) & $0.015^{a}$ & $0.009^{a}$ & $0.009^{a}$ & 0.658 \\
\hline $\mathbf{N}$ vs $\mathbf{N}^{\mathbf{R e}}(\mathrm{b} 2)$ & 0.872 & 0.502 & 0.502 & 0.135 \\
\hline $\mathrm{O}_{\mathbf{B}} \operatorname{vs} \mathrm{O}_{\mathbf{B}}^{\operatorname{Re}}(\mathrm{b} 1)$ & 0.317 & 0.179 & 0.179 & 0.418 \\
\hline $\mathbf{O}_{\mathbf{B}}$ vs $\mathbf{O}_{\mathbf{B}}^{\mathrm{Re}}(\mathrm{b} 2)$ & 0.930 & 0.130 & 0.130 & 0.370 \\
\hline $\mathbf{F}_{\mathbf{B}}$ vs $\mathbf{F}_{\mathbf{B}}^{\mathbf{R e}}(\mathrm{b} 1)$ & 0.762 & 0.228 & 0.228 & 0.163 \\
\hline $\mathbf{F}_{\mathbf{B}}$ vs $\mathbf{F}_{\mathbf{B}}^{\mathbf{R e}}(\mathrm{b} 2)$ & 0.659 & 0.457 & 0.457 & 0.928 \\
\hline
\end{tabular}

Table 8: $p$-values for the Kolmogorov-Smirnov test of various hypotheses analyzed in the paper. The superscript ${ }^{a}$ is used to indicate the occasions when the null hypothesis that the $B$-choices (resp., earnings, efficiency, number of switches) come from the same distribution can be rejected at the significance level of $5 \%$. 


\begin{tabular}{l|cccc|c}
\hline \hline & All Blocks & Block 1 & Block 2 & Block 3 & OLS on "All-Count" \\
\hline Age & 0.135 & 0.135 & -0.436 & 0.245 & 0.00238 \\
& $(0.277)$ & $(0.277)$ & $(0.391)$ & $(0.347)$ & $(0.13)$ \\
CRT-score & 0.0244 & 0.0244 & 0.123 & 0.0417 & 0.00372 \\
& $(0.223)$ & $(0.223)$ & $(0.3)$ & $(0.3)$ & $(0.107)$ \\
Male & -0.508 & -0.508 & -0.957 & $-1.569^{*}$ & $-0.416^{*}$ \\
& $(0.475)$ & $(0.475)$ & $(0.726)$ & $(0.82)$ & $(0.227)$ \\
Constant & -2.289 & -2.289 & 7.215 & -6.214 & 0.984 \\
& $(5.576)$ & $(5.576)$ & $(7.789)$ & $(6.995)$ & $(2.619)$ \\
Observations & 84 & 84 & 84 & 84 & 84 \\
R-squared & 0.012 & 0.012 & 0.047 & 0.068 & 0.043 \\
\hline \hline
\end{tabular}

Table 9: The results of the regression of the "switcher" variable on CRT and other individual characteristics. Standard deviations are in parentheses. Coefficients with $*$, ** or *** correspond to significance at $10 \%, 5 \%$ and $1 \%$ level, respectively.

the subject's age, gender, and CRT score as explanatory variables. Table 9 presents the results of this regression for all observations (second column) and also by block (columns 3-5), where we classify a subject as a 'switcher' when he/she pays the front-end load at least twice in that block. In addition, we run an OLS regression of the number of blocks in which a subject is classified as a 'switcher' (this variable "All-Count" can therefore take on the values 0, 1, 2 and $3)$, with the same explanatory variables, see the last column of Table 9.

The coefficient on the CRT score is not statistically significant and has a positive sign. Neither the coefficients on age and gender are statistically significant at the $5 \%$ level. 


\title{
ONLINE APPENDIX
}

\section{Control Questions, CRT test, and Questionnaire}

\section{C.1 Control Questions with Answers}

\author{
Treatments $\mathbf{N}, \mathrm{N}^{\mathrm{Re}}$
}

1. Suppose that in the current period the price of fund $A$ is 70 and the price of fund $B$ is 74.1. You have 700 points in the current period and you choose to invest in fund $A$. Suppose that in the next period the price of funds $A$ and $B$ turned out to be 73.5 and 76.3, respectively. How many points do you have at the beginning of the next period? [735]

2. You have 1100 points at the beginning of the current period and want to invest in fund $B$. Would your investment decision from the previous period (i.e., in which fund you invested previously) matter for the number of points you will earn? [No]

\section{Treatments $\mathrm{O}_{\mathrm{B}}, \mathrm{O}_{\mathrm{B}}^{\mathrm{Re}}$}

1. Suppose that in the current period the price of fund $A$ is 70 and the price of fund $B$ is 74.1. You have 700 points in the current period and you choose to invest in fund $A$. Suppose that in the next period the price of funds $A$ and $B$ turned out to be 73.5 and 76.3, respectively. How many points do you have at the beginning of the next period? $[735]$

2. Suppose you have 600 points and you invest your points in fund $B$ whose price in the current period is 57 . Fund $B$ charges a fee of $1 \%$. How much fee would you pay for this period? [6]

3. You have 1100 points at the beginning of the current period and want to invest in fund $B$. Would your investment decision from the previous period (i.e., in which fund you invested previously) matter for the number of points you will earn? [No]

Note: For treatment $\mathbf{O}_{\mathbf{A}}$, in question 2 , we used fund $A$ charging $2 \%$ fee, instead of fund $B$ charging $1 \%$ fee, to keep consistency with the design. 


\section{Treatment $\mathbf{F}_{\mathbf{B}}, \mathbf{F}_{\mathrm{B}}^{\mathrm{Re}}$}

1. Suppose that in the current period the price of fund $A$ is 70 and the price of fund $B$ is 74.1. You have 700 points in the current period and you choose to invest in fund $A$ for which there is no fee. Suppose that in the next period the price of funds $A$ and $B$ turned out to be 73.5 and 76.3 , respectively. How many points do you have at the beginning of the next period? [735]

2. Suppose you invested in fund $A$ in the last period, you have 1000 points at the beginning of this period and want to invest in fund $B$ in this period. Fund $B$ charges a fee of $13 \%$. How much fee would you pay? [130]

3. Recall that fund $A$ does not charge a fee, and fund $B$ charges a fee of $13 \%$. You have 1100 points at the beginning of the current period and want to invest in fund $B$. Would your investment decision from the previous period (i.e., in which fund you invested previously) matter for the number of points you will earn? [Yes]

Note: For treatment $\mathbf{F}_{\mathbf{A}}$, in question 2, we used fund $A$ charging a fee of $24 \%$, instead of fund $B$ charging a fee of $13 \%$, to keep consistency with the design.

\section{C.2 Questionnaire}

You have made your decision for all periods! Here is a questionnaire on your backgrounds. Please fill in and press "send" to submit. After that you will see the payment page:

1. Age:

2. Gender:

3. Have you come to an experiment before?
A No
B Once
C More than once

4. How do you think of the instruction of this experiment?
A It is not clear at all.
B It is understandable, with some places a little unclear.
C It is very clear. 
5. What suggestions do you have for the instruction? (Open question)

6. How do you describe you strategy in this experiment? (Open question)

\section{C.3 CRT test}

For the CRT test that subjects in 2017 sessions had to complete after the questionnaire, we used the standard 3 questions (see, e.g., Figure 1 in Frederick, 2005).

1. A bat and a ball cost $\$ 1.10$ in total. The bat costs $\$ 1.00$ more than the ball. How much does the ball cost? [ 5 cents]

2. If it takes 5 machines 5 minutes to make 5 widgets, how long would it take 100 machines to make 100 widgets? [5 minutes]

3. In a lake, there is a patch of lily pads. Every day, the patch doubles in size. If it takes 48 days for the patch to cover the entire lake, how long would it take for the patch to cover half of the lake? [47 days]

\section{Additional Figures and Tables}

This Appendix contains additional figures and tables.

Fig. 8 is similar to Fig. 1 of the paper; it compares the time series of returns and prices that were used and shown to the participants in blocks 1 and 2 for treatments $\mathbf{N}, \mathbf{O}_{\mathbf{A}}$ and $\mathbf{F}_{\mathbf{A}}$. In the last two treatments the return time series of fund $A$ are shifted up by 2 percentage points.

Figure 9 and Figure 10 show the 10 time series of returns and prices that were used and shown to the participants in Block 3. In each row there are 4 panels which show (from left to right): returns in treatments $\mathbf{N}, \mathbf{O}_{\mathbf{B}}$ and $\mathbf{F}_{\mathbf{B}}$; prices in treatments $\mathbf{N}, \mathbf{O}_{\mathbf{B}}$ and $\mathbf{F}_{\mathbf{B}}$; returns in treatments $\mathbf{N}, \mathbf{O}_{\mathbf{A}}$ and $\mathbf{F}_{\mathbf{A}}$; prices in treatments $\mathbf{N}, \mathbf{O}_{\mathbf{A}}$ and $\mathbf{F}_{\mathbf{A}}$.

Figures 11, 12, 13, 14, and 15 present the histograms of $B$-choices by each block and treatment. In each row, the left three panels show the data for blocks 1, 2 and 3, respectively, and the right panel gives the data pooled over the blocks. Figure 11 show these histograms for treatment $\mathbf{N}$ (upper row), treatment $\mathbf{N}^{\mathbf{R e}}$ (middle row), and these two treatments with combined data (lower row). Figures 12 and 13 are similar for treatments $\mathbf{O}_{\mathbf{B}}-\mathbf{O}_{\mathbf{B}}^{\mathbf{R e}}$ and $\mathbf{F}_{\mathbf{B}}-\mathbf{F}_{\mathbf{B}}^{\mathbf{R e}}$, respectively. Finally, Figures 14 and 15 show the histograms for treatments $\mathbf{O}_{\mathbf{A}}$ and $\mathbf{F}_{\mathbf{A}}$. 

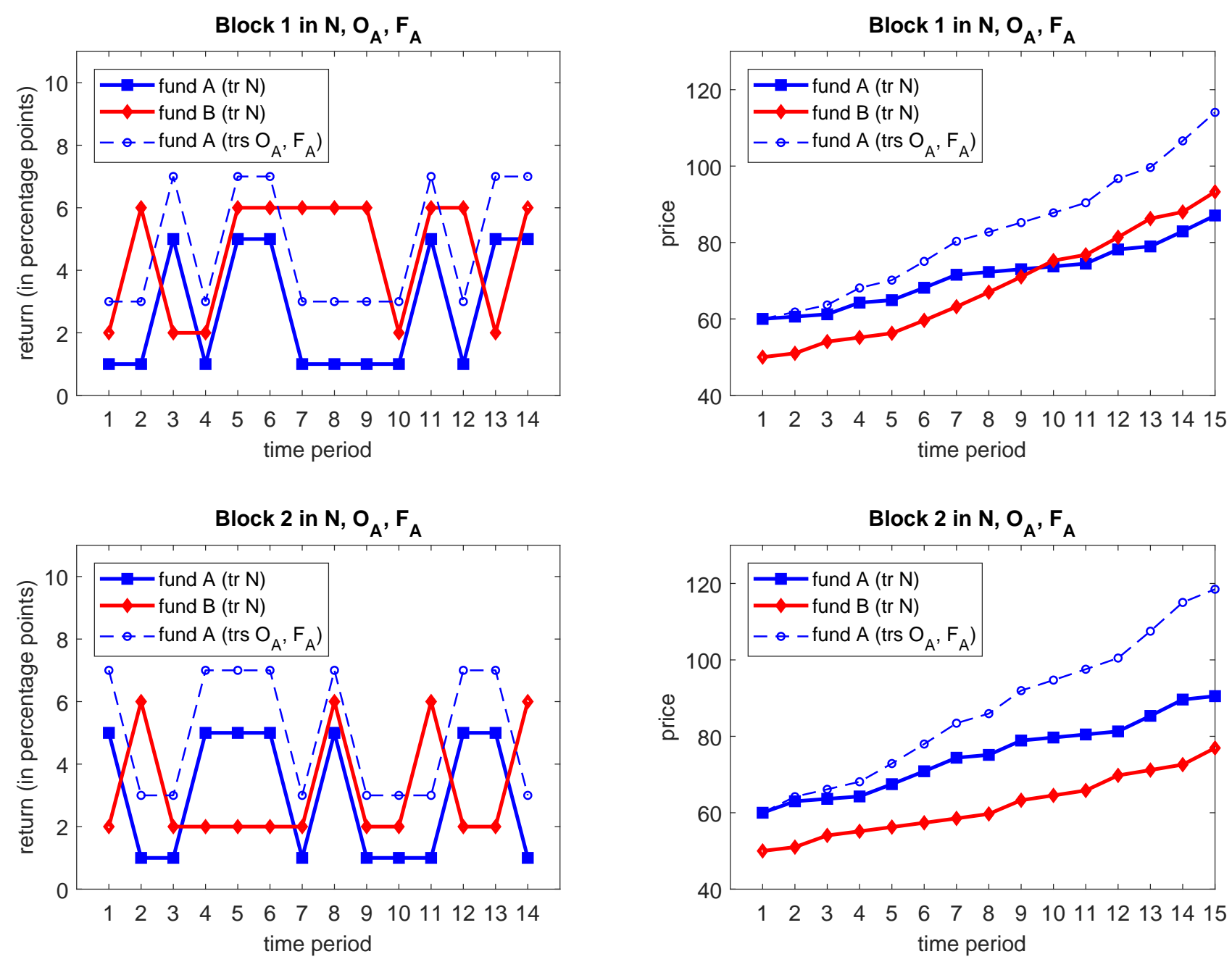

Figure 8: Generated time series in blocks 1 and 2 for treatments $\mathbf{N}, \mathbf{O}_{\mathbf{A}}$ and $\mathbf{F}_{\mathbf{A}}$. Left: Returns. Right: Prices. Fund $B$ returns are the same in three treatments. Fund $A$ returns in treatments $\mathbf{O}_{\mathbf{A}}$ and $\mathbf{F}_{\mathbf{A}}$ are two percentage points higher than returns in treatment $\mathbf{N}$. Prices are generated using the returns with initial values 60 and 50 for funds $A$ and $B$, respectively.

The left upper panel in Figure 16 shows the CDF of individual choices for fund $B$ in 5 different treatments. It aggregates the histograms shown in Fig. 3 of the paper. The remaining three panels of Fig. 16 show the CDF of individual choices for fund $B$ for the first block, the second block, and the last (third) block.

Figure 17 show the histogram of earnings in different treatments. They complement the CDF of earnings shown in the paper in Fig. 4. 

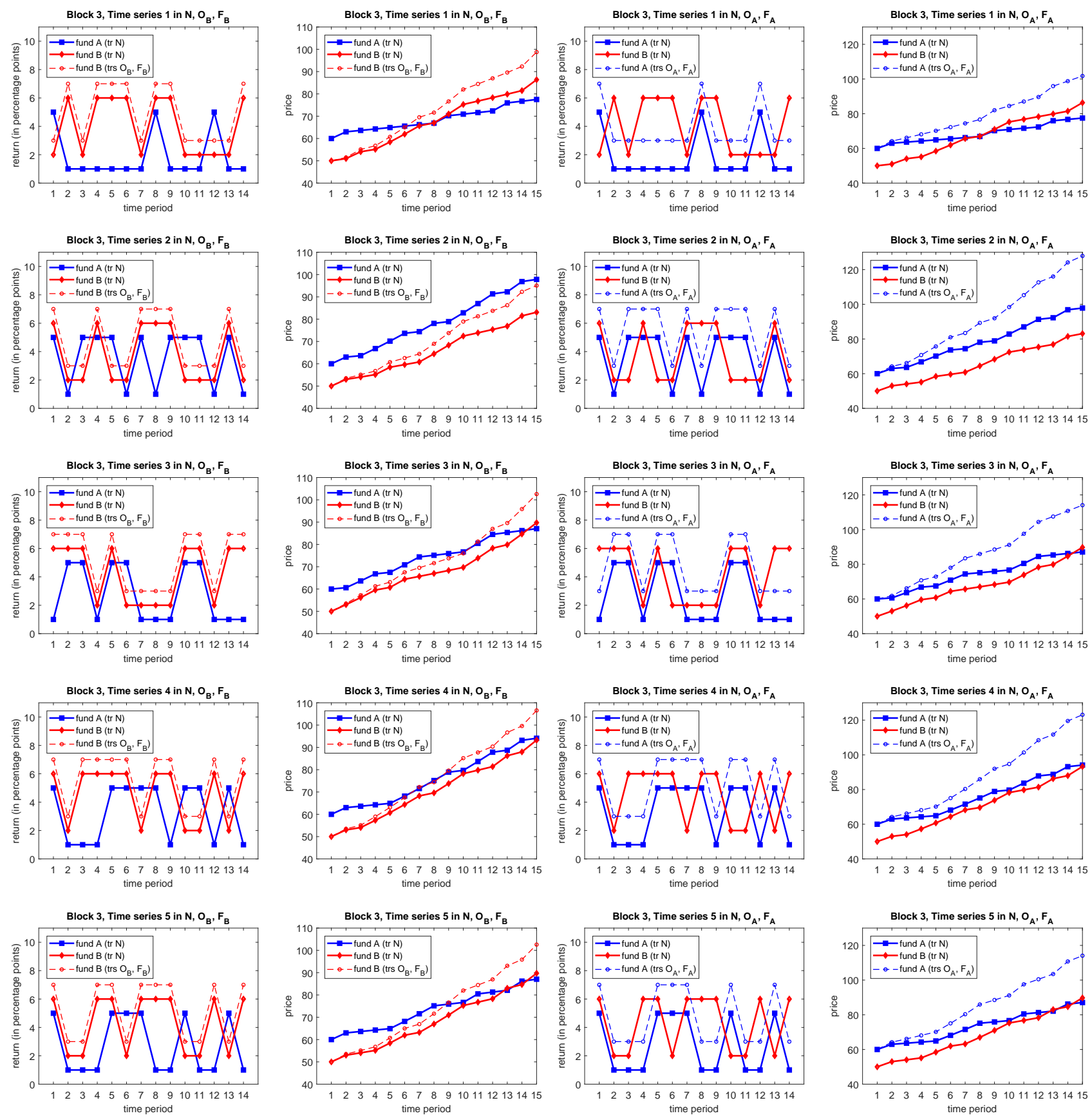

Figure 9: Generated time series in block 3 for all treatments. Time series 1 to 5 . 

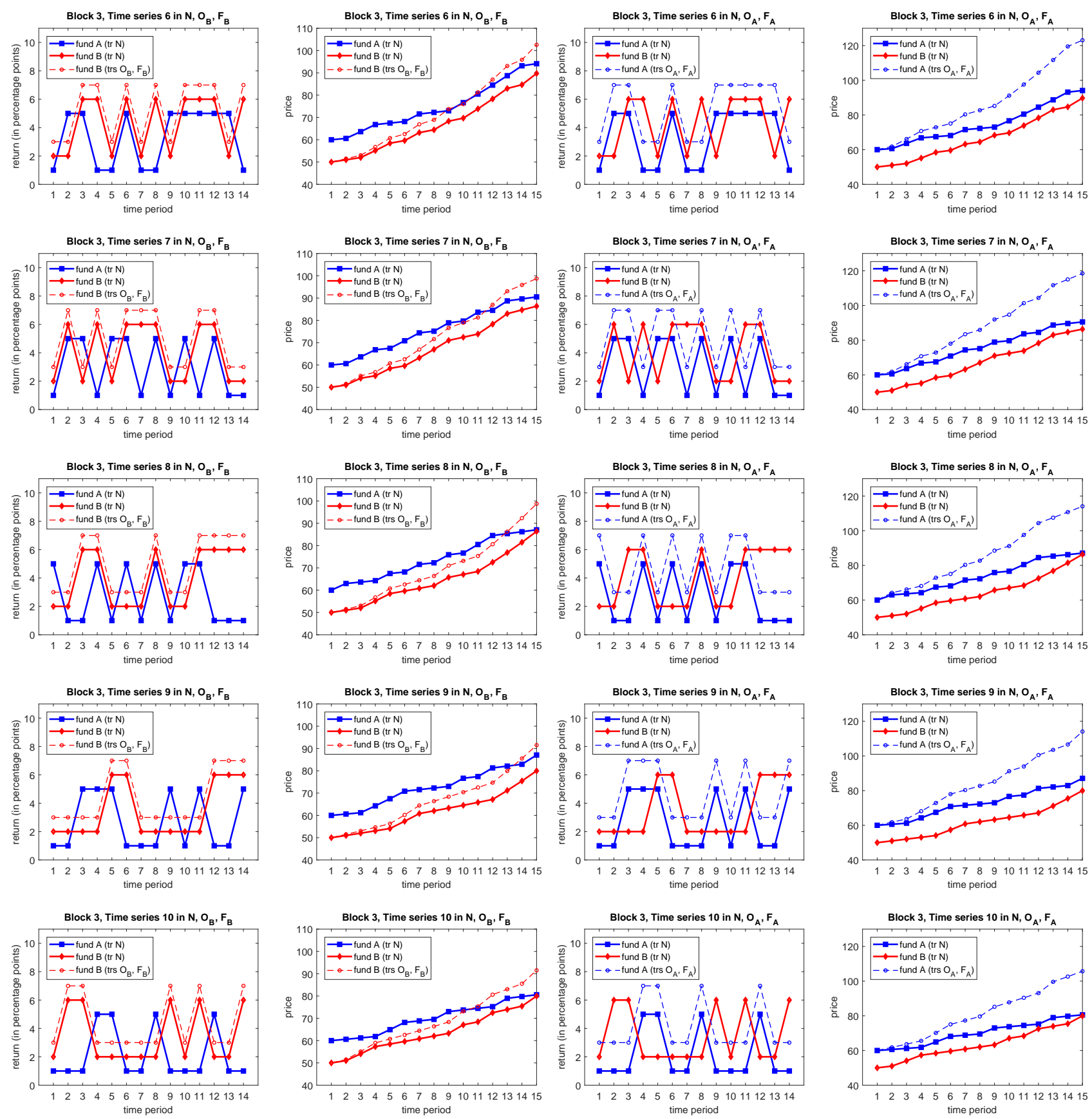

Figure 10: Generated time series in block 3 for all treatments. Time series 6 to 10 . 

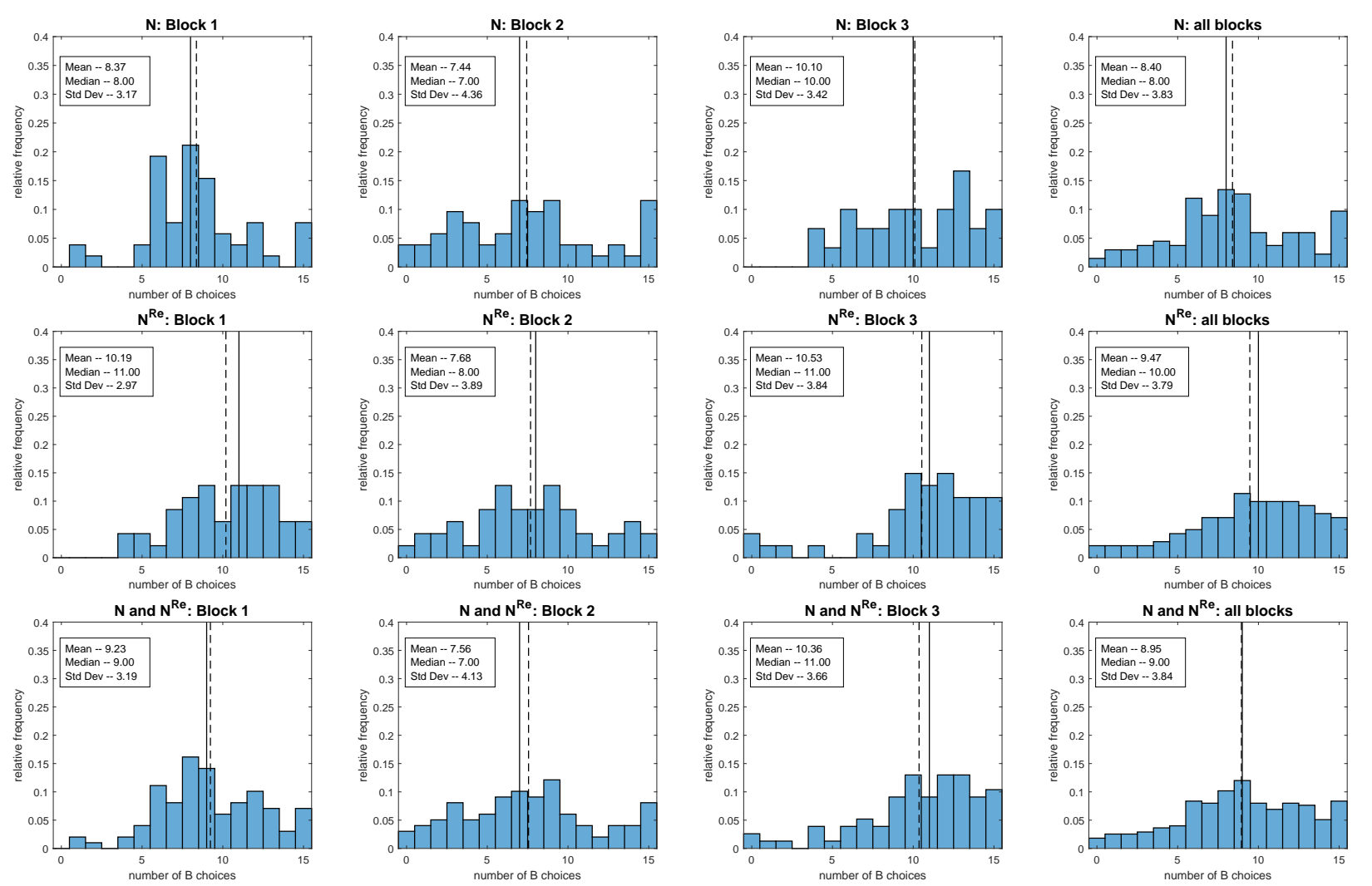

Figure 11: Histograms of investment in fund $B$ by blocks in treatments $\mathbf{N}$ and $\mathbf{N}^{\mathbf{R e}}$. The solid vertical line shows the mean and the dashed vertical line shows the median.
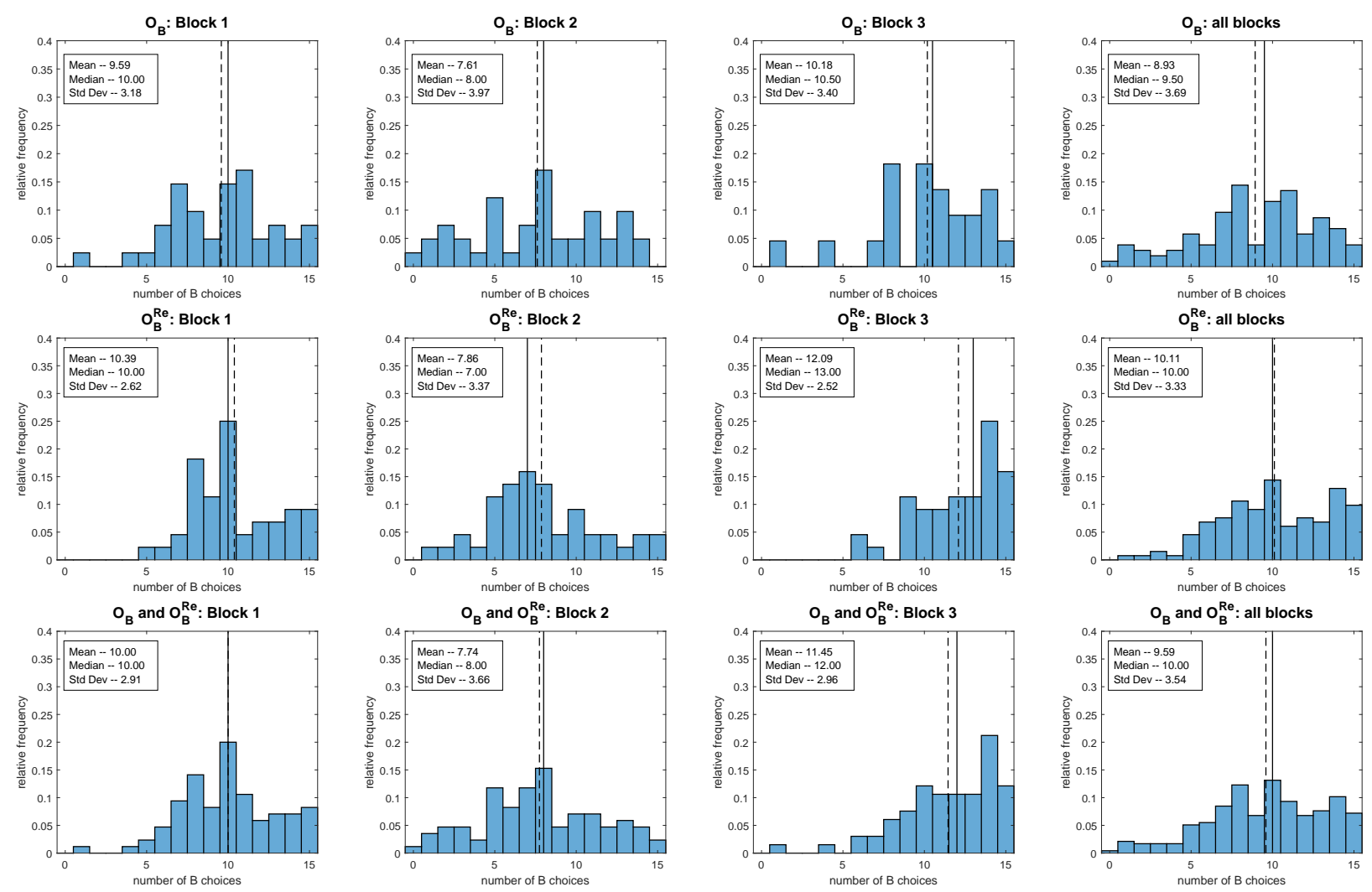

Figure 12: Histograms of investment in fund $B$ by blocks in treatments $\mathbf{O}_{\mathbf{B}}$ and $\mathbf{O}_{\mathbf{B}}^{\mathbf{R e}}$. The solid vertical line shows the mean and the dashed vertical line shows the median. 

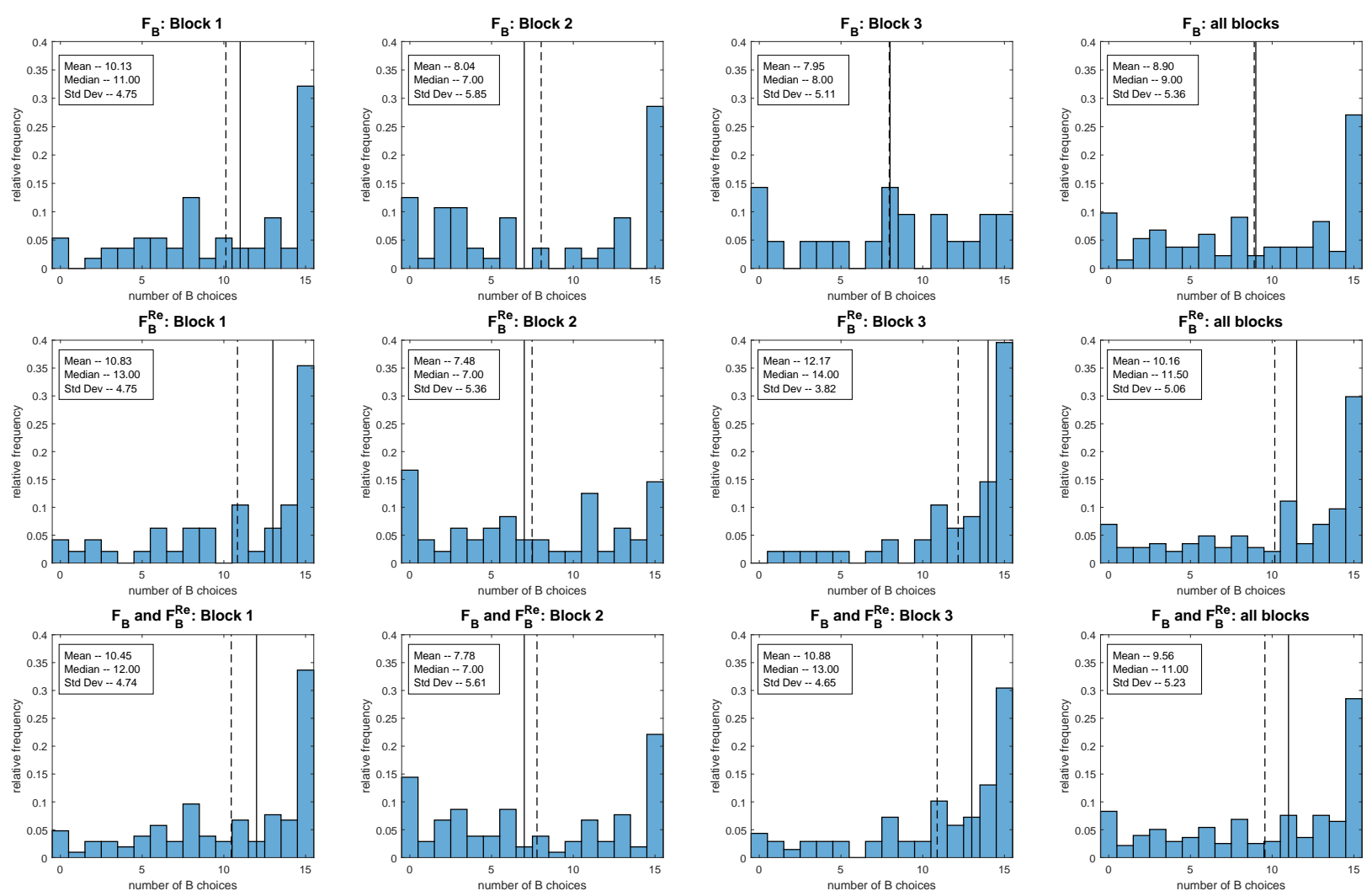

Figure 13: Histograms of investment in fund $B$ by blocks in treatments $\mathbf{F}_{\mathbf{B}}$ and $\mathbf{F}_{\mathbf{B}}^{\mathbf{R e}}$. The solid vertical line shows the mean and the dashed vertical line shows the median.
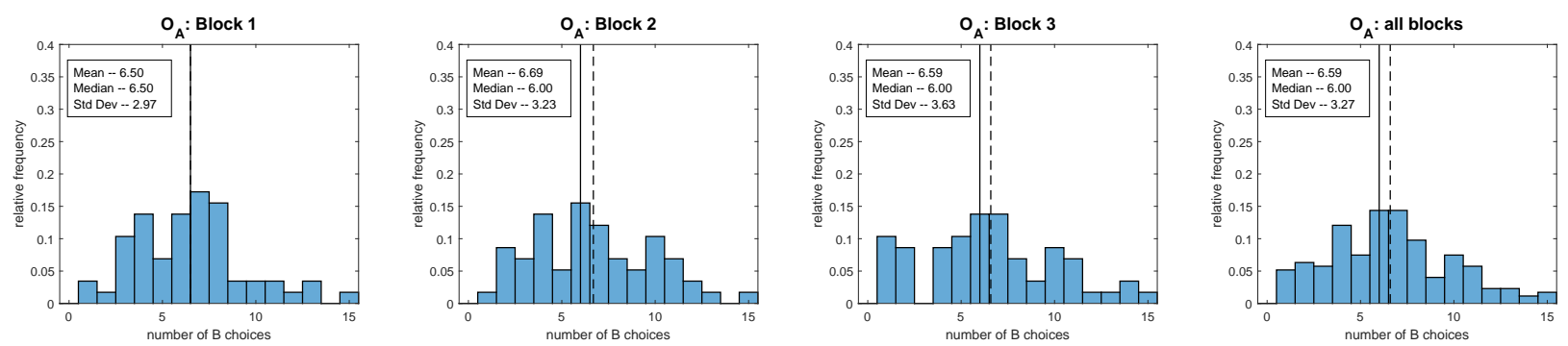

Figure 14: Histograms of investment in fund $B$ by blocks in treatment $\mathbf{O}_{\mathbf{A}}$. The solid vertical line shows the mean and the dashed vertical line shows the median.
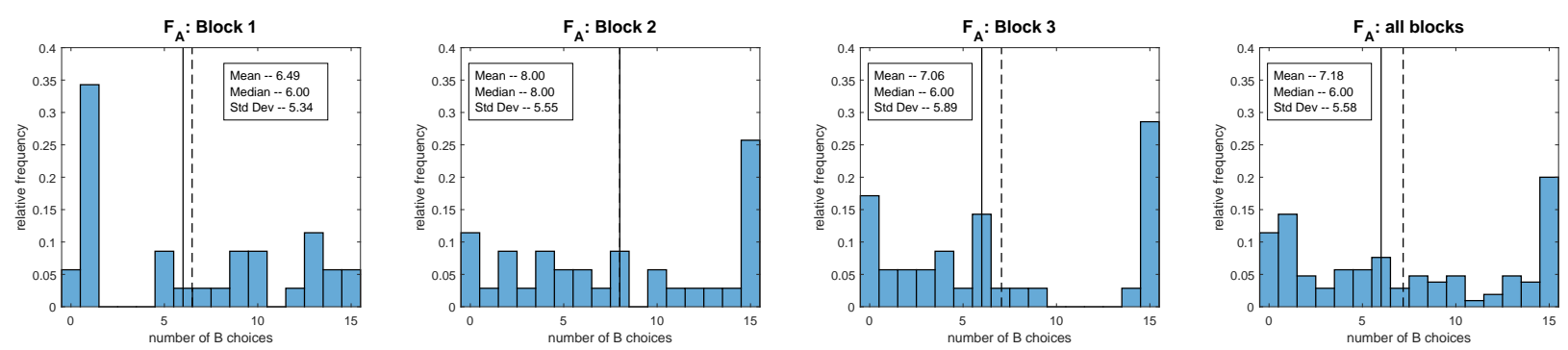

Figure 15: Histograms of investment in fund $B$ by blocks in treatment $\mathbf{F}_{\mathbf{A}}$. The solid vertical line shows the mean and the dashed vertical line shows the median. 

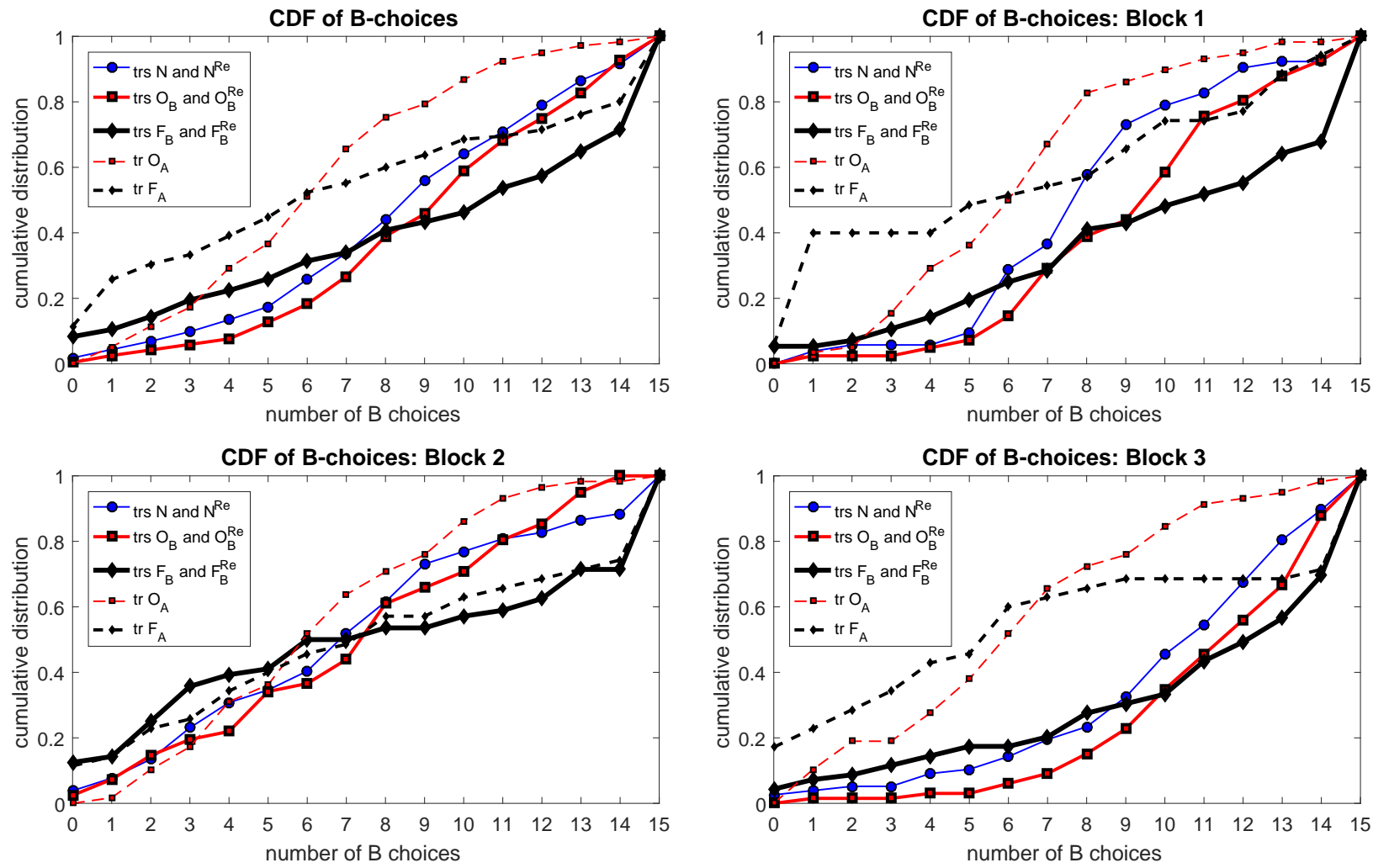

Figure 16: The CDF of individual choices of fund B. Top: Aggregated over all blocks. Middle: For block 1 only. Lower: For block 3 only. 

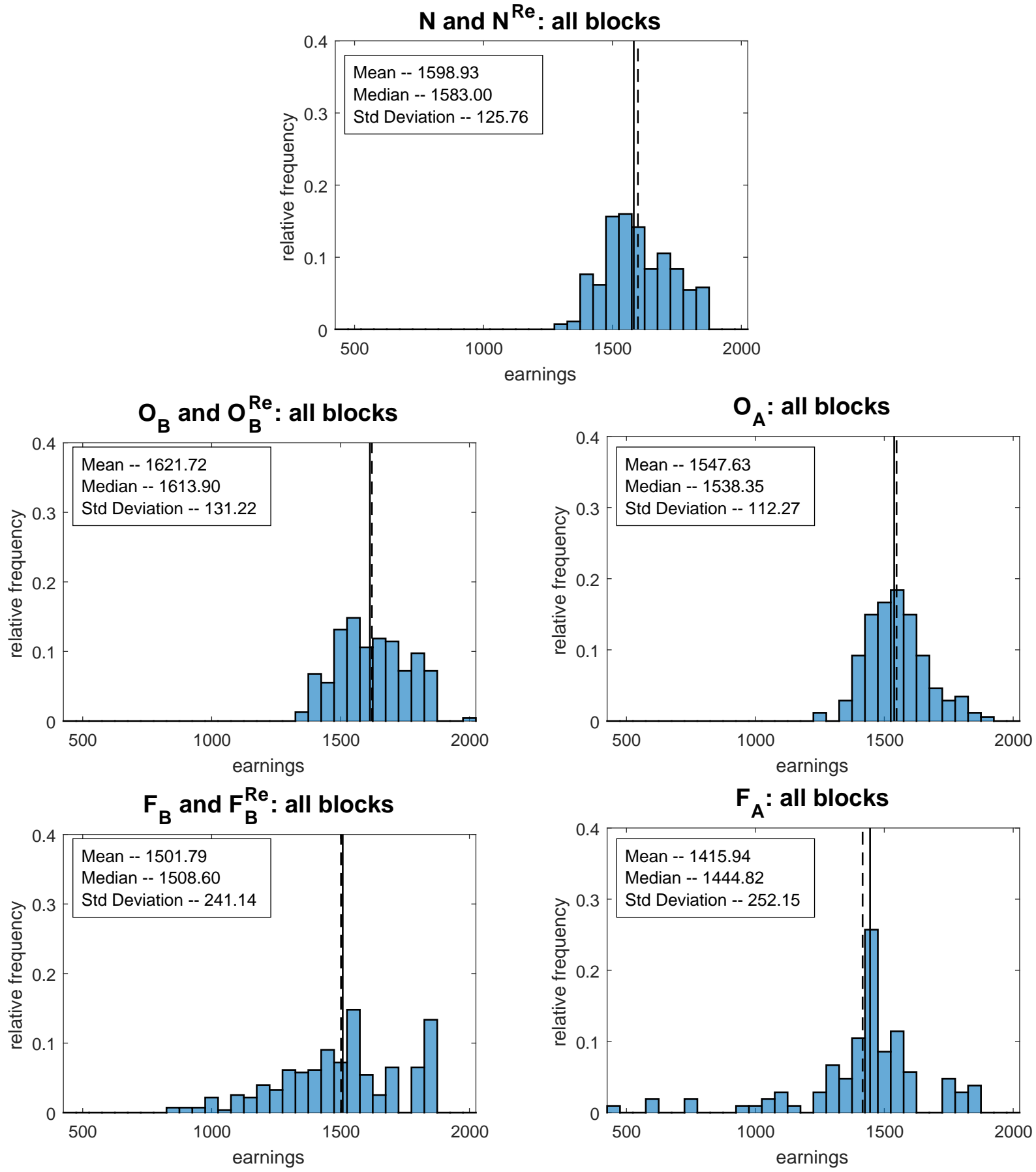

Figure 17: Histograms of earnings in different treatments. 


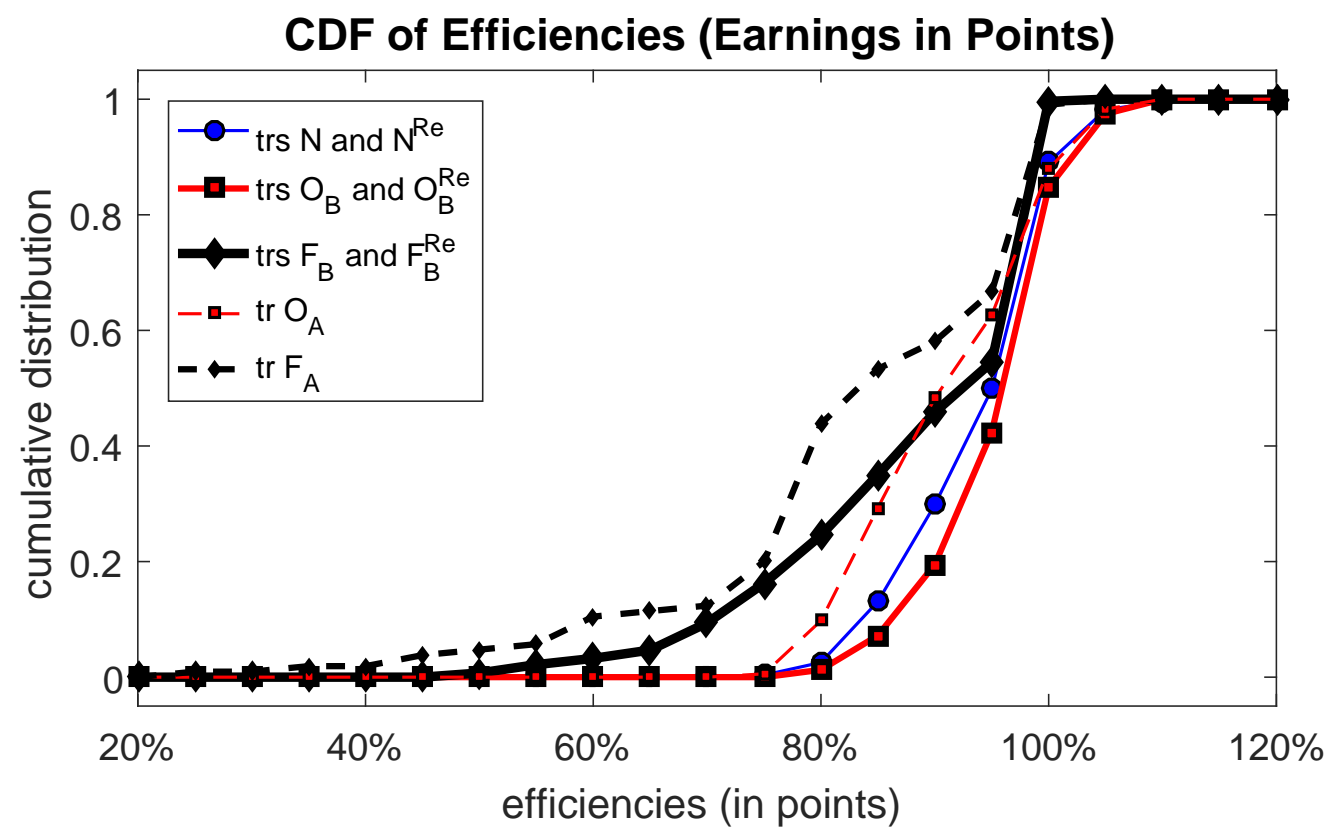

Figure 18: The CDF of efficiencies. 

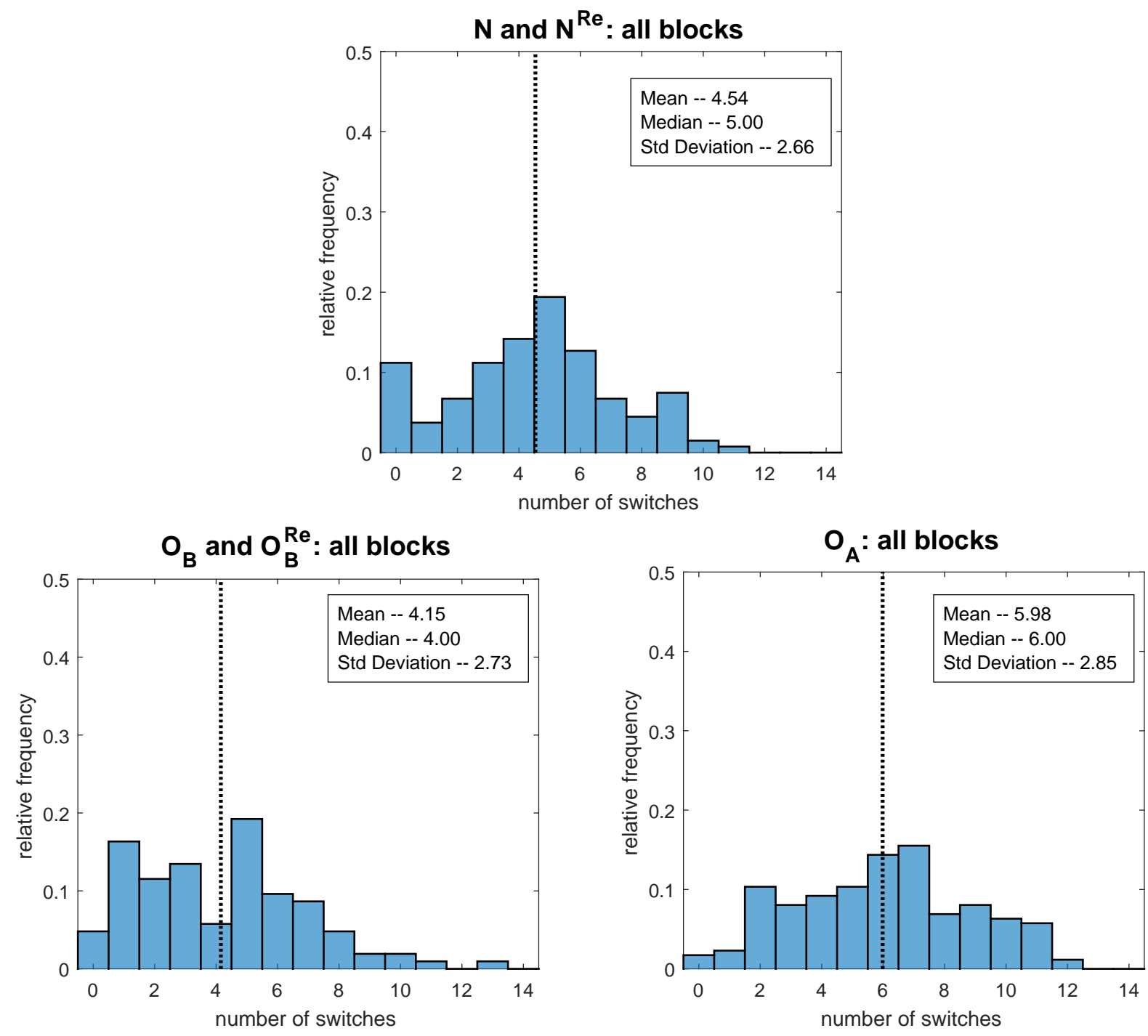

$F_{B}$ and $F_{B}^{R e}$ : all blocks
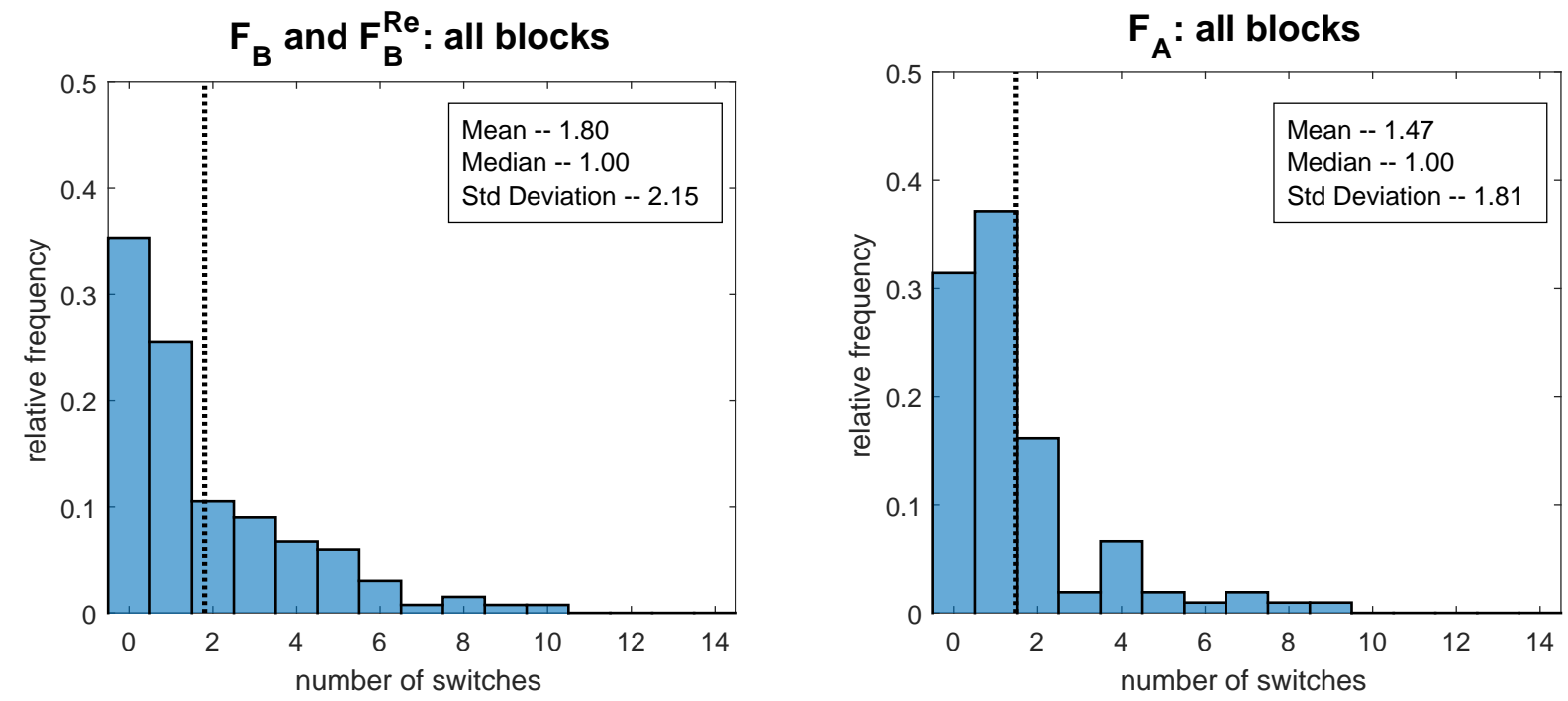

Figure 19: Histograms of switches in different treatments. 